\title{
The politics of good food : why food engineers and citizen-consumers are talking at cross-purposes
}

Citation for published version (APA):

Haen, D. F. (2015). The politics of good food : why food engineers and citizen-consumers are talking at cross-purposes. [Doctoral Thesis, Maastricht University]. Maastricht University. https://doi.org/10.26481/dis.20150313dh

Document status and date:

Published: 01/01/2015

DOI:

10.26481/dis.20150313dh

Document Version:

Publisher's PDF, also known as Version of record

\section{Please check the document version of this publication:}

- A submitted manuscript is the version of the article upon submission and before peer-review. There can be important differences between the submitted version and the official published version of record.

People interested in the research are advised to contact the author for the final version of the publication, or visit the DOI to the publisher's website.

- The final author version and the galley proof are versions of the publication after peer review.

- The final published version features the final layout of the paper including the volume, issue and page numbers.

Link to publication

\footnotetext{
General rights rights.

- You may freely distribute the URL identifying the publication in the public portal. please follow below link for the End User Agreement:

www.umlib.nl/taverne-license

Take down policy

If you believe that this document breaches copyright please contact us at:

repository@maastrichtuniversity.nl

providing details and we will investigate your claim.
}

Copyright and moral rights for the publications made accessible in the public portal are retained by the authors and/or other copyright owners and it is a condition of accessing publications that users recognise and abide by the legal requirements associated with these

- Users may download and print one copy of any publication from the public portal for the purpose of private study or research.

- You may not further distribute the material or use it for any profit-making activity or commercial gain

If the publication is distributed under the terms of Article $25 \mathrm{fa}$ of the Dutch Copyright Act, indicated by the "Taverne" license above, 


\section{THE POLITICS OF GOOD FOOD}

Why food engineers and citizen-consumers are

talking at cross-purposes

Dirk Haen 



\section{THE POLITICS OF GOOD FOOD}

Why food engineers and citizen-consumers are

talking at cross-purposes

\section{DISSERTATION}

to obtain the degree of Doctor at

Maastricht University,

on the authority of the Rector Magnificus, Prof. dr. L.L.G. Soete in accordance with the decision of the Board of Deans,

to be defended in public

on Friday the $13^{\text {th }}$ of March, 2015 at 10:00 hours

by

\section{Dirk Fons Haen}

Born on 15 August 1981

in Uden, The Netherlands 


\section{Supervisors}

Prof. dr. T.E. Swierstra

Prof. dr. J.P. Koenis

\section{Assessment Committee}

Prof. dr. ir. W.E. Bijker (chair)

Prof. dr. M.J.JA.A. Korthals (Wageningen University)

Prof. dr. ir. H. van Lente

Prof. dr. C.N. van der Weele (Wageningen University)

This work is part of the research programme Responsible Innovation, which is financed by the Netherlands Organisation for Scientific Research (NWO). The printing of this thesis has been financially supported by the Netherlands Graduate School of Science, Technology and Modern Culture (WTMC).

(C) Dirk Haen, 2015

Print: Ipskamp Drukkers

Cover design: Joost van Ommen 


\section{Acknowledgements}

Let me be brief about the process of writing this dissertation. Basically, I've been reading, listening, talking and writing. And I've gotten the opportunity, for once, to sit down and think. There are worse jobs.

This book is, in philosopher's terms, about conditions of possibility: those things without which other things would not be able to exist. The conditions of possibility of this book itself are the wonderful people who have given me the continuous support to do what I believed I had to do.

First of all, I am very thankful to my supervisors, Tsjalling Swierstra and Sjaak Koenis, for their wisdom, trust and the occasional but necessary impatience. It's been a privilege and a pleasure to think out loud with both of you. I would like to express my gratitude to the dear philosophers and former colleagues at the University of Twente - in particular Federica, Aimee and Lucie, who showed me how to have shameless fun and still make an intellectual appearance. I would also like to thank my fellow philosophers in Maastricht, who have given me a warm welcome as I moved over to the sunny South. You reminded me - just in time - of the many odd directions that philosophy can take us. Ties, I am most thankful to you for our engaging conversations while I held office at cafe De Poort. Let's keep the conversation going. Special thanks also to Rene Gabriëls and Huub Dijstelbloem, who provided sharp and timely commentaries on earlier versions of some of the chapters. Bart, Alexander and Natalia, I'd like to thank you for tolerating me as an office mate. Writing a thesis is a solitary business, but thanks to you I never felt lonely.

It was a delight to work with my fellow MVI project team members from Wageningen University. From Hedwig te Molder and Petra Sneijder I've learned much about the finesse of science communication and conversational analysis. Thanks for your cheerful company on this interdisciplinary journey. Michiel Kleerebezem and Harry Gruppen were a great help in finding my way in the world of food science and technology. You've given me just the right amount of street credibility a philosopher needs. 
I'd like to express my heartfelt gratitude to my colleagues at the Centre for Ethics and Politics of Emerging Technologies, and the wonderful teachers at the Research School for Science, Technology and Modern Culture (WTMC). Working with the marvellous people at De Nationale DenkTank is one of the best adventures I've embarked on. Huub, Charlie and Anna, you made me realize what good food really is about. Thanks guys. Also, a special thanks goes out to my friend Daan, whose animation film on my research helped me to tell the story in a way that is actually not boring.

Thank you so much, Fons en Marijke, for your unconditional support and full confidence. I am very lucky to be your son. Ankie en Guus, thank you for stepping in when the nights were sleepless and the days were rough. Lieve Puck, dank je dat je geboren bent. Nog elke dag herinner je me eraan dat vrijwel alles belangrijker is dan een proefschrift.

My deepest gratitude goes out to Susanne, my love, without whom my research would have been an impossible undertaking and this book would not exist. Thank you for not giving up on me, while I have given you so many reasons. 


\section{Table of contents}

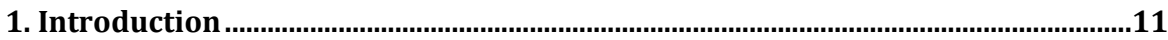

Trust and responsibility ................................................................................................. 14

Responsible innovation and technology assessment ..........................................................15

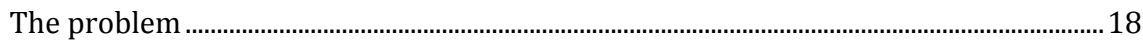

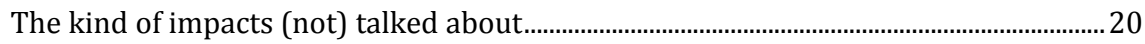

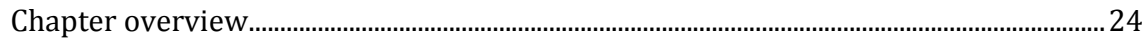

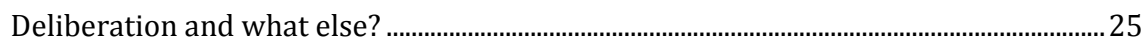

2. The paradox of E-numbers. Ethical, aesthetic and cultural concerns in the

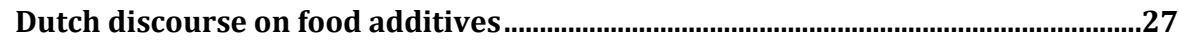

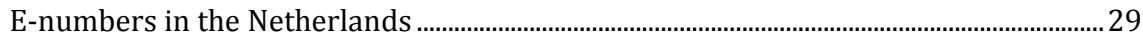

The mechanism of irrationalization.......................................................................................... 31

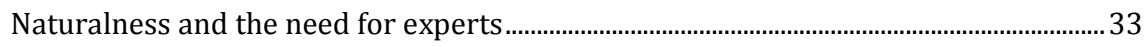

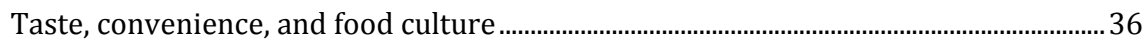

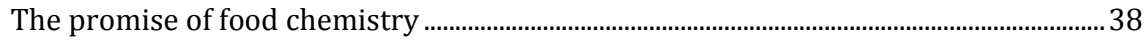

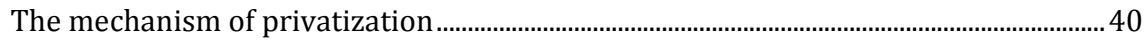

Re-imagining private impacts as public matters ……….......................................................... 42

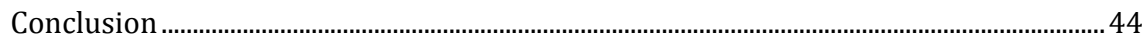

3. Quantifiability, publicity and causality. Three conditions of the public food

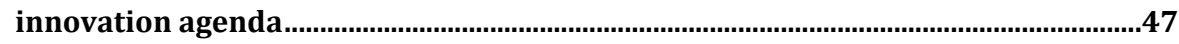

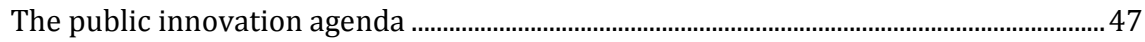

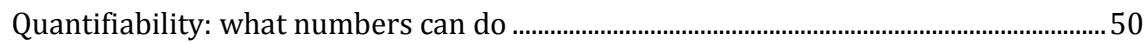

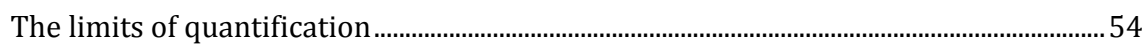

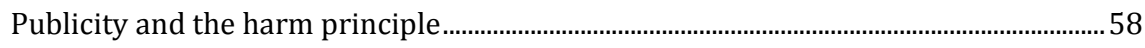

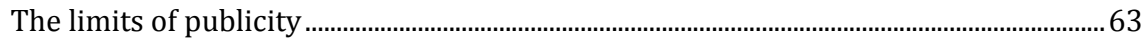

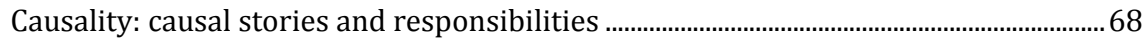

The problem with causal stories …………………............................................................. 72

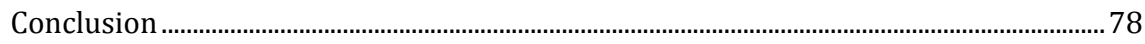

4. Growing concerns. The career of food sustainability as a hard issue..................83

Food sustainability ................................................................................................................ 85

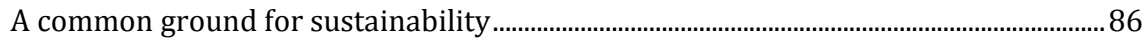


The quantification of sustainability. . .89

Causal stories about unsustainable food production . .92

Conclusion . .94

5. How to give concerns generally regarded as 'soft' a fair opportunity to gain

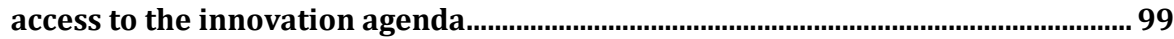

How societal actors can adapt their concerns to the agenda conditions .......................100

Translation 101

Combination 104

Entanglement. 107

Stronger entanglement 110

Recommendations for societal actors 114

How technology actors can accommodate soft concerns in a more charitable way 115

The principle of charity 117

Application of the principle of charity 119

Recommendations for technology actors. 122

Recommendations for facilitators. .124

Appendix: recommendations for facilitators (summary)

\section{A concept so dear to people. Naturalness and the use of techno-ethical}

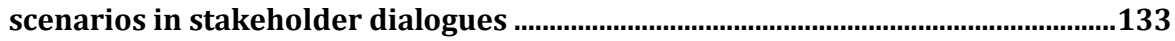

Three stakeholder dialogues ................................................................................................136

Facilitator 137

Scenario. 138

Stakeholders 143

Dialogue 143

Insight into interactional effects. 147

Recognition of shared problem .149

Exploring and negotiating the meaning of naturalness 151

Distributing responsibilities 154

Conclusion. 156

Appendix: scenarios 159

7. Conclusion. . .163

Findings. 164

The soft/hard distinction 170 
Responsible innovation 173

References 177

Summary. 192

Valorisation addendum.. 206

About the author. . .211 



\section{Introduction}

Until the 1970's, few home kitchens in the Netherlands were provided with a freezer. In 1980, half of the Dutch households possessed one (Buiter 2000). Manufacturers of ready-meals had to make considerable investments in getting consumers to buy frozen foods. In 1973, Lucas Reijnders and Rob Sijmons - chemists by training - published a volume on food quality and production in the Netherlands, in which they critically discuss several health and environmental issues. They were not very pleased with the march of the frozen meal:

Recently, the large-scale use of frozen foods for the preparation in hospitals and homes for the elderly is promoted, with governmental support. Particularly in various hospitals it turns out that frozen meals are not that appetising. As for taste, one could serve frozen food to those who stay short, but to those who stay for a long period of time (including staff) this is impertinent. Also, the apparently low nutritional value of frozen food makes large-scale use in hospitals rather debatable. Given the vulnerable position of the elderly, we consider the use of frozen meals in elderly homes, at large scale and for longer periods of time, irresponsible. Because of the relatively low nutritional value, and the terrible taste, we believe that for these care institutes a decentralized preparation of as much fresh food as possible is strongly preferred. (Reijnders \& Sijmons 1973)

In 2013, consumer organization Foodwatch Netherlands campaigned against major retailer Albert Heijn and accused the supermarket chain of misleading their consumers with the store brand puur\&eerlijk (pure and fair) - which comprises of a variety of organic, environmentalfriendly and fair trade food products. In response to the campaign, both parties met and sat around the table for a dialogue meeting. An excerpt from the minutes reads as follows:

Foodwatch (FW) asks Albert Heijn (AH) why there are so many unnecessary additives in the puur\&eerlijk products, such as sugar and flavour enhancers. According to $\mathrm{AH}$ what counts as 'unnecessary' is a difference of opinion. $\mathrm{AH}$ claims to use as few additives as possible, but points out that sugar, flavour enhancers and other additives are needed to make a product tasty and 
appropriate for a public as broad as possible. FW responds by saying that the term 'pure' suggests something quite different. AH wishes not to discuss the definition of 'pure' any further. AH says they want to make their products as tasty as possible. Consumers who prefer vegetables without added sugar are free to choose fresh vegetables instead. AH claims that their food packaging is completely transparent with regard to all of the ingredients. (Foodwatch 2013)

In 2014, the first shipments of Soylent have been sent to curious consumers all over the US. Soylent, an open-source meal replacement drink, claimed to contain nothing but the necessary nutrients for human subsistence, was developed by former software engineer Rob Rhinehart. Once he found the perfect formula, he managed to raise $\$ 3,500,000$ to set up a manufacturing company. One year earlier, Rhinehart reported on his personal experiment of a Soylent-only diet on his weblog:

Food is the fossil fuel of human energy. It is an enormous market full of waste, regulation, and biased allocation with serious geo-political implications. And we're deeply dependent on it. In some countries people are dying of obesity, others starvation. In my own life I resented the time, money, and effort the purchase, preparation, consumption, and clean-up of food was consuming. (...) I hypothesized that the body doesn't need food itself, merely the chemicals and elements it contains. So, I resolved to embark on an experiment. (...) I haven't eaten a bite of food in 30 days, and it's changed my life. (Rhinehart 2013)

Lizzie Widdicombe, writer at the New Yorker, reported on Rhinehart's enterprise. She tried the experiment herself: 'You begin to realize how much of your day revolves around food. Meals provide punctuation to our lives: we're constantly recovering from them, anticipating them, riding the emotional ups and downs of a good or a bad sandwich. With a bottle of Soylent on your desk, time stretches before you, featureless and a little sad.' (Widdicombe 2014).

The early doubts, recent dissent and future dreams portrayed in these three fragments make clear that the emergence of ever more technologically processed food begs for public and academic reflection on what good food is about; and what technological innovations can 
and should do to the food cultures they become part of. This book is about how food producers and consumers can talk about those things in a fruitful, meaningful way.

An often heard concern is that today, children don't know where the milk comes from. They would think it comes from the bottle, the milkman, the grocery store, or even the factory. The next concern may be that children are actually right about the factory. This concern reveals much about Western food culture: most of our food travels a long way from farm to fork, processed and distributed throughout chains of production that have become longer and more opaque than ever. In the light of this technological and distributional expansion of the way our food is made, a gap seems to exist between producers and consumers. That the milk concern is about children is an intuitive recognition that this gap is widening and future generations will be confronted with even more 'technological' food. This gap does not just represent a topographical distance, but is also experienced as a distance of knowledge, interests and meanings. The eater's urge to know 'where our food comes from' expresses exactly this gap: is his food sufficiently provided, safe and healthy, responsibly grown and traded, or in any other sense of good quality? Do farmers, engineers, industries, regulators and retailers take care of it? And how does he know? As our food is increasingly mediated by technologies and goes through more hands and machines before it reaches our plate, in modern Western societies food consumption has become a serious matter of trust and distrust.

This dissertation aims to understand and interpret a mutual lack of trust as one of the obstacles to a fruitful dialogue on food innovations between engineers, policymakers, consumers and other stakeholders. It critically analyses how concerns and impacts are framed in public discussions on food technology; it shows how these conceptual framings imply a specific, implicit attribution of responsibilities; and it explores alternative ways of speaking that make room for a broader range of legitimate concerns in the public dialogue on food (and) technology. The goal of this exploration is to hint at the possibility for technology actors and other stakeholders to engage in a relationship of mutually growing trust and responsibility. 
In this introductory chapter I will offer a provisional clarification of the concepts of trust and responsibility with regard to food innovation, give a broad outline of my conception of the problem with stakeholder dialogue in this context, introduce the way that impacts concerning food innovation are generally framed, and set out the main structure of this dissertation.

\section{Trust and responsibility}

As public controversies on the genetic modification (GM) of organisms have shown, public trust is a crucial ingredient for technological innovations in food to succeed and to become socially embedded. National policy reports on the public acceptance of GM and biotechnology all recognize the need to establish more trust. This need is most often presented as a reason to call for more transparency in decision-making processes and to provide objective, independent, consistent and unambiguous information (e.g. Nuffield Council on Bioethics 1999; Académie des Sciences 2002; Terlouw et al. 2002; Sheldon et al. 2009). The regulation and implementation of food product labelling is frequently considered as an opportunity to enlarge public trust or consumer acceptance.

Public trust can be understood as a cognitive judgment or attitude more or less informed, more or less indifferent - about the trustworthiness of experts, governmental bodies and other technology actors. It can express one's expectation of another's technical competence, like a patient trusts her doctor to carry out those procedures that any competent doctor should follow. Trust can also be the expectation that the other has the responsibility to demonstrate a special concern for another's interest, like a patient trusts her doctor to tell the truth. Whereas the first kind of trust follows from the abilities expected of the trusted, the second follows from a good willingness expected of the trusted (Barber 1983). Trust is inherently connected to expectations about responsibilities.

Moreover, as Szerszynski (1999) has pointed out, the expression of trust and distrust can also be interpreted as a performative speech act, not so much being an assertive report of a certain state of affairs, but rather a declaration about the mutual relationship between trustor and 
trustee: 'This kind of expression of trust would be an active trust (...) in the sense that the speaker would be actively trying to bind the 'entrusted' into a relationship of responsibility.' (1999: 248) Thus, an expression of trust as expectation can also be a specific act to encourage one to take seriously one's responsibilities. In this regard, the mere disclosure of more information about where our food comes from, how and why it is processed, and e.g. the risks attached to it, is not likely to rebuild public trust, as long as this relationship of responsibility - which is essentially a moral relationship - is not recognized and affirmed as such by those who govern the chains of food production. In relations of trust, the trustor expects of the trustee to act upon whatever values the trustor holds, and whatever interests he has. This is what Meijboom et al. (2006) call responsive trust: 'the trustor not only expects that the trustee respond in her acting on the object entrusted her, but also expects it of him' (2006: 431).

\section{Responsible innovation and technology assessment}

What, then, does responsibility mean in the context of technological innovation? In his discussion of responsibility in organisations, Bovens offers a rough but useful distinction between two meanings (although he recognizes there are several more to be specified): passive and active responsibility. Passive responsibility refers to accountability: someone has violated a norm, a causal relation between this violation and an undesirable outcome can be established, the act of violation is blameworthy, and the actor is held responsible (possibly liable) in the sense that he is asked to justify his action. By contrast, active responsibility refers to virtuous or excellent behaviour: someone has an adequate perception of events, one is attentive to the consequences of his actions, and one understands and takes seriously his role responsibilities - acting in accordance with what is expected from a good employer, father, doctor, administrator, citizen and so on (Bovens 1990).

For responsible innovation, responsibility in the active sense means that technology actors (such as engineers) are ready to take into account the desirable and undesirable, intended and unintended consequences of the innovation and consider what can be done to amplify or mitigate such impacts - for instance by engaging in dialogue 
with stakeholders. They are willing to listen and reflect, defend and revise. Responsible innovation in the passive sense means that technology actors take responsibility, to a certain extent, for the quality of the innovation - including some of the successes and failures that appear in the stage of societal embedding ('downstream'). They accept responsibility and account for it when things go wrong as much as they would if things go well; they hold themselves accountable for the fruits of their work and how it changes the world.

The two dimensions of responsibility are overlapping. For instance, technology developers can take an active responsibility in consulting stakeholders in the design phase and in the same time negotiate about what impacts they will and won't accept as their passive responsibility. They may decide to consult other stakeholders because they know that eventually they themselves will be held accountable if things go wrong.

This rough distinction clarifies that if we expect technological innovation to be responsible, we may ask for a range of different kinds of action. It implies that technology actors behind food innovation would have to understand and acknowledge the moral relationship they hold to those who are possibly affected by the impacts of innovation; which is a matter of attitude (active responsibility). It also means that (passive) responsibilities for those impacts should be clarified and allocated among key players in the process of innovation which is a matter of organization. If the quality of technological innovation in the widest sense is at stake, both dimensions of responsibility, and both kinds of action matter.

One way of organizing passive, and performing active responsibility in the process of innovation is technology assessment (TA). Innovations can have unintended, unexpected or undesirable impacts. As a systematic effort to anticipate and reflect on such impacts, TA emerged in the United States in the late 1970's, and in the Netherlands in the 1980's in order to inform decision-making, policies and strategies of actors involved in the process of technology development. By providing feedback on technologies embedded or emerging in society, TA aims to 'reduce the human cost of trial and error learning in society's handling of new technology' (Schot \& Rip 1996: 251). 
Current approaches of TA recognize that assessment should not be carried out exclusively by scientific experts and bureaucrats but needs to include the perspectives of other stakeholders. Basically two arguments can be given for this inclusion. First, stakeholders may perform as experts, too, as they have relevant experience in the field in which innovations can be expected to make a difference. Their perspectives can enrich, correct or affirm technical and scientific understandings of possible impacts. This argument stems from the tradition of political theories that emphasize the epistemic value of democratic deliberation (cf. Habermas 1996, Estlund 1997, Gutmann \& Thompson 2004) but is also raised by the 'second' and 'third waves' of science studies that question and rethink the boundary between experts and lay people (Wynne 1996, Collins \& Evans 2002). Second, democratic principles may entitle groups of citizens to participate in a process of decision or policy making if they are possibly affected by the consequences of technological innovation. As long as TA is part of this process, the outcome would be (more) democratically legitimate. This argument relies on the conception of technologies as the embodiment of a moral, social or political order (cf. Winner 1986, Akrich 1992) and the recognition that technological change requires public and collective judgment (Beck 1992, Latour 1999; 2005). Understanding TA primarily as a reflexive learning process, and only indirectly as a process of democratization (Bijker 1995 and Fischer 1999 are exceptions; cf. Genus 2006), advocates of stakeholder engagement propose to organise TA by means of setting up a dialogue between technology actors such as industrial, academic and governmental organizations, and other stakeholder groups such as consumers, users, patients, and residents.

To be sure, the (re)building of trust between technology actors and other stakeholders may not be an end in and of itself, but for responsible food innovation trust is important on (at least) two levels. First, a certain degree of trust among citizens and consumers is required for the societal embedding of technological innovations, that is, for the willingness to accept, tolerate, or consume the food that has been designed and processed by engineers. Where trust in either the product, the process, or the producer is lacking, innovation is likely to fail - even when such distrust may be unjustified. Second, technological innovations may result in trust or distrust 'downstream', but 
responsible innovation also requires trustful relationships in earlier stages ('upstream'). That is, without a minimal degree of trust among engineers, consumers, citizens, NGO's and industrial corporations as dialogue parties, fruitful conversations on the desirability and acceptability of food innovations are unlikely to occur.

\section{The problem}

The problem central to this book pertains to some of the obstacles to successful stakeholder dialogue about food technology and innovation, and how these obstacles can lead to the unsuccessful societal embedding of technology. The problem can be stated in basically three steps. As there is no guarantee whatsoever for successful dialogues, but at least certain conditions should be in place without which unsuccessful dialogue is guaranteed, I take these conditions as steppingstones for the formulation of the problem.

1. Out of many consumer concerns about the impacts of food technology and innovation, only few make it to the food innovation agenda. The others are marginalized and fail to be recognized as legitimate issues since they are easily - too easily - considered as subjective and irrelevant matters.

2. These marginalized concerns will not be included in a commonly shared allocation of responsibilities. They are 'orphans' in the sense that no responsibility for, or ownership of, these concerns will be attributed, enforced or claimed by any of the actors involved in the innovation process.

3. Where certain consumer concerns are structurally marginalized, innovations in food technology may run into acceptance problems as they meet resistance through controversy, suspicion, low demand or active boycotting. They may also run into acceptability problems since legitimacy is lacking: technological artefacts become part of the lives of citizens who are confronted with undesirable impacts without having had the opportunity to voice their concerns effectively. While innovations may be legitimate in the sphere of the market, they may turn out not be so in the public sphere. 
The problem analysis, as presented here and throughout this book, relies strongly on the concepts of soft and hard impacts of technology as developed by Tsjalling Swierstra (2002; Swierstra et al. 2009; Swierstra \& te Molder 2012). He refers to easily marginalized impacts as soft, 'not because they would be insignificant, but because that's how they are depicted by current institutions that don't know yet what to do with them' (Swierstra 2011). In the explanatory model that Swierstra proposes, soft and hard impacts are distinct according to three dimensions: whether impacts are considered soft depends on (1) the terms in which technology impacts are valued; (2) whether these impacts can be quantified; and (3) if a clear causal link can be made between the technology and its impact. I consider this a useful framework for the analysis of discussions about food technology and innovation.

Nevertheless, I have decided to speak primarily in terms of soft concerns rather than soft impacts, because I believe that the soft/hard distinction does not necessarily pertain to the consequences of technology but about how we think and speak about them. In fact, some of the problems that people raise in response to food technology are not about distinct consequences but rather point at how they value and experience food. In that case the term impact would be misguiding. Also, the concept of concern allows us to take a little distance from whatever the concern is about; regardless whether a particular concern turns out to be justified or not - it is real nevertheless. As a consequence, the conceptual shift from impacts to concerns makes it easier to think about 'softness' as something that prevents a private concern from becoming a public issue. After all, the public agenda is not populated by impacts but by issues.

Apart from that, my analysis should be understood as a constructive effort to further substantiate, conceptualize and operationalize this distinction in the field of food technology and innovation. That is, I put some more flesh to its bones and investigate how to make it useful. In this respect, the following chapters should make clear a few things. First of all, that it allows for a fresh perspective on why the public distrust of food additives has been so persistent. Second, what exactly makes the soft/hard distinction so appealing and productive; what reasons we may have to hold on to it - but also that there are 
theoretical and practical arguments for letting go of it. And third, that this framework can be used for the identification of particular strategies and recommendations for how to turn 'soft' food concerns into meaningful issues.

\section{The kind of impacts (not) talked about}

Concerns about health risks, food safety, food security and environmental impacts are typical food issues that have found a solid place on the public agenda. They are issues about which we may not agree, but at least it is implicitly agreed upon that they are legitimate topics of public discussion. Health risks and health benefits, economic costs and opportunities, sustainable development and loss of biodiversity, feeding or poisoning the world: this, in a nutshell, is what public debate is about when we talk about food. We somehow recognize that they are relevant when engineers, consumers, citizens, retailers, policymakers and producers discuss the impacts of food technology and innovation; their relevance is unquestioned (although for some issues this has not always been the case). Also, they are considered to be relatively manageable - eventually - by technology actors, as long as scientific experts in the natural sciences and the 'hardest' of the social sciences - economics - are consulted. Not only are these issues predominant in food debates, they also give structure to reports written about them, and eventually reach to the level of R\&D and policy agendas (Levidow \& Carr 1997; Wynne 2001; Rayner 2003). They are commonly considered as concerns about hard impacts.

Upon a closer look, however, a much broader range of food concerns are being publicly raised (often but not exclusively by consumercitizens) in response to technological food. They pertain to tradition, taste, naturalness, scientization, conviviality, authenticity, holism, slowness, pleasure or the plain fact that today's children don't know where the milk comes from. They are not only conveyed in different voices, but also in different repertoires. These concerns do not necessarily point at the potential harm inflicted by food innovations as is often the case with issues of health risk - but do raise questions about the broader meaning of food. They envision food as a part of our daily lives, the meal as an experience, taste as something that can be disputed about, and milk cartons as black boxes. 
Generally speaking, such concerns are not easily tackled. They do not fit well within a techno-scientific discourse, and their relevance seems to be somewhat dubious: they are easily dismissed as romantic, irrational, subjective or vague. In other words: as too 'soft' to become generally accepted as serious and legitimate topics of public dialogue about food (and) technology: they do not gain access to the innovation agenda as a collective program for action on the level of policy making, legislation or technology design.

To be sure, some of these 'softer' aspects of food are taken seriously in quite another sphere of action: food marketing. Here, romantic notions shared by a considerable segment of consumers, e.g. about nature, agriculture and authenticity, are the touch stone for effective food marketing strategies (Sagoff 2001, Datamonitor 2006). In this sphere, some of the softer aspects of food are considered legitimate: probably not because they make sense from a 'rational point of view' (as health risk issues would do) but because they sell. However, the strategic purposes of food marketing seem to leave little room for a truly critical dialogue on soft aspects of food - let alone on the technological innovations that they are attached to.

What the distinction between soft and hard impacts aims to clarify is that certain conceptual thresholds in public life prevent a specific set of concerns from gaining collective attention and becoming subject to public deliberation. In the following chapters, I will further specify the nature and effects of these thresholds, which, in the context of public dialogue on food technology and innovation, I will understand as conditions of the public food innovation agenda. To be sure, I do not claim that these conditons, taken together, would be sufficient - i.e. provide an exhaustive explanation for why some concerns do, and others do not gain access to the public agenda. I do claim, however, that these conditions are necessary: looking at the current public discourse of food and food technology, it seems hard to imagine that a particular issue would be subject to public deliberation, while the very same issue failed to meet any of these conditions. That is my claim; and the thrust of my argument is that we should try to imagine so nevertheless. 
A first threshold is the condition of quantifiability. A concern is deemed legitimate by policy and technology actors if its substance is appropriate for measurement and can be expressed in quantitative terms. It is largely based on the ideal of objective truth as produced and confirmed by scientific research. It prevents many ethical, aesthetic and cultural concerns from entering the realm of scientific investigation; it defines those issues as irrational, subjective or irrelevant from a scientific point of view - as long as they are not considered to be measurable. The easier an impact of technological innovation can be expressed by numbers, or by any other means be inquired by the empirical sciences, the likelier it is perceived as hard. Environmental impacts associated with the production of beef are hard in this sense; the concern that beef is not produced in a traditional way is - in itself - soft.

A second threshold is the condition of publicity. A concern is considered legitimate if it appeals to values commonly recognized by all of us; and if it proposes norms that, in principle, we can all agree on. This requirement is largely based on the liberal ideal of public reason, holding that in a pluralist society, arguments presented in the sphere of political decision-making should be comprehensible and acceptable for those who can reason. In essence, it seeks to restrict the public discussion of issues that appeal to debatable norms but relatively undisputed values. We may strongly disagree on whether genetically modified (GM) foods pose a threat to public health, dispute how to assess and evaluate the risks; but few of us will question that health issues are a legitimate topic of public debate at all. Especially concerns that suggest that (potential) harm is being inflicted are serious candidates for the public agenda. As the condition of publicity constitutes a liberal threshold between public and private affairs, it prevents certain ethical, aesthetic, and cultural concerns from attracting public attention and defines those issues as private, idiosyncratic or irrelevant. The more an impact of technological innovation appears as a case of harm or by any other criterion that lives up to the ideal of public reason, the likelier it is perceived as hard. Health risks associated with GM food are hard in this sense; that GM food would be unnatural is soft. 
To be sure, the term publicity may well apply to these two conditions (and the third discussed below) taken together, in the general sense that they prescribe what problems are appropriate or inappropriate for public discussion. From here on, for practical purposes, where I speak of the publicity condition I specifically refer to the politicalphilosophical concept that applies to values and norms: a criterion for the evaluative component of problem statements. Publicity in this specific sense is a requirement for the kind of goods (moral, natural or otherwise) that we seek to advance or protect, implicitly or explicitly, by raising concerns and issues. The requirement states that all reasonable people should be able to agree on the value of these goods and on the norms proposed (e.g. in terms of rules). This is the notion of publicity that Rawls has introduced with his conception of public reason (Rawls 1993).

A third threshold is the condition of causality. A successful concern articulates a problem as the clear consequence of either human action or technology. This makes sense from the point of view of those who are held responsible for the creating the problem and taking care of it; the underlying idea is that a relation between cause and consequence should be established before one can be held fairly accountable. Causal relations describe whether or not a certain problem really is an impact of technology proper, and not, for example, the consequence of whatever users decide to do with technology. Making this kind of distinction is typical for the instrumentalist conception of technology, which considers technological artefacts 'as tools that can reflect and be used in many different ways by diversities of human lifeworlds; (...) People shape their lives and cultures, then as individuals or groups incorporate and adapt technologies in whatever ways they choose' (Mitcham \& Waelbers 2009). The condition of causality thus demands that concerns already suggest who or what can be held responsible for the problem at hand. Thus, it poses a threshold for concerns that cannot offer such clarity and point at problems that may arise from fuzzy interactions between humans and technological artefacts. The more an impact of technological innovation can be directly ascribed to either technological design or human action, the likelier it is perceived as hard. That certain food additives would induce the risk of cancer is a hard impact; the indirect effects of preservatives used in ready-meals on our food culture are much softer. 
The three fragments at the beginning of this introduction each hint at 'soft' concerns ('soft' as they seem to fail some or all of the three conditions) that can be raised in response to technological innovations in food. Are processed foods an offense to good taste? Does the widespread use of food additives pose a threat to the ideal of purity? Will we lose anything valuable if we start to perceive eating as the efficient intake of fuel? Such questions are not easy to discuss in the context of responsible food innovation; but I believe they deserve a fair chance. In the following chapters I argue why they do, and how consumer-citizens, technology developers and other stakeholders in food innovation can engage in dialogue about such concerns in a meaningful way.

\section{Chapter overview}

In Chapter 2 I present my analysis of the current discourse of food technology and innovation, with a focus on the controversy of food additives in the Netherlands, and I identify the key discursive mechanisms that actors perform in public talk about mostly ethical, aesthetic and cultural concerns. In Chapter 3 I ground my analysis in a conceptual framework of soft and hard concerns and further explain the three conditions of the public food innovation agenda. I discuss the reasons why they are valuable but also the costs involved in respecting those conditions. In Chapter 4 I argue for a constructivist perspective on the distinction between soft and hard concerns by drawing lessons from the emergence of the issue of food sustainability. A short history of food sustainability in the light of the three agenda conditions teaches us that widely recognized food issues might not be as hard as they seem.

Chapter 5 concludes with concrete recommendations for technology developers and consumer-citizens who would like to give soft concerns a fair opportunity when they engage in dialogue on the societal impacts of food technology and innovation. These recommendations are inspired by more and less promising discursive strategies already performed by advocates of soft concerns; and by the principle of charity. This principle, originated in linguistics and anthropology, suggests what to do in case we want to understand someone who 
speaks a language radically different from our own. The chapter indicates what direction to take if actors are in search for pragmatic solutions. In Chapter 6 I explore another, more critical direction for those who seek to transform the parameters of the discourse of food technology and innovation all together. On the basis of recommendations for dialogue facilitators I set out what these imply for the design of techno-ethical scenarios and the organization of stakeholder meetings. As a proof of concept, I have organized and facilitated a series of dialogues on naturalness, food additives and probiotics in 2012 and 2013. The chapter concludes with a report of the key findings. Chapter $\mathbf{7}$ is the conclusion, in which I describe what my main analysis and recommendations imply for the ideal of responsible innovation.

\section{Deliberation and what else?}

Throughout this book I draw a critical-pragmatic perspective on responsible innovation in food technology, and more specifically on the quality of public dialogue on food and food technology in the Netherlands. The underlying question of how to deliberate (well) on food technology is relevant for rather practical purposes (i.e. learning) but also politically: responsiveness strengthens the democratic legitimacy of technological innovations, the consequences of which may, after all, structurally reshape the world.

But 'reasonable' and 'civilized' deliberation is not the only way of doing politics - and not always the most effective. In response to the unanimous enthusiasm for deliberative democracy in political theory, Walzer (1999) drafted a list of 'all the nondeliberative activities that democratic politics legitimately, and perhaps even necessarily, involves' - including items such as political education, organization, demonstration, lobbying, campaigning, voting and ruling. Walzer points out that a preoccupation with sterile deliberation bears the risk of turning away from the things that great numbers of ordinary people can do together.

In the Netherlands, a variety of alternative food networks and activities have emerged over the past ten years, such as Food Guerilla, Youth Food Movement, food design, Innovation Network, freeganism, Tijd voor Eten 
(Time to Eat), Damn Food Waste, biohacking, The Food Line-up, Food Film Festival, flexitarianism, freeganism and De Tostifabriek (The Croque-monsieur Factory). These initiatives demonstrate that the politics of food can well be practiced outside of the conversation room. The ideal of the polder model - a longstanding Dutch policy practice of consensus-based decision-making - now seems to make way for Do It Yourself. Is this an early sign that consumer-citizens are about to give up on institutionalized and industrial food technology, expecting little from dialogue? This may pose another challenge for technology developers who aspire to engage, or keep engaging, in public dialogue after all.

At any rate, those who make our food and those who eat it will maintain a fundamental interest in continuous conversation if they care to legitimize, criticize or re-invent the collective arrangements, formal and informal, that shape the broader food landscape in which we all reside. 


\section{The paradox of E-numbers. Ethical, aesthetic and cultural concerns in the Dutch discourse on food additives*}

In anticipation of technological food innovations, both food manufacturers and policy makers hope to learn from what turned out to be a delicate issue for European citizens: the cultivation of GM food crops. A remedy for public distrust is easily sought in the ideal of transparency; (improved) food labelling should (better) inform critical consumers and thus enable them to exercise their autonomy as wellinformed decision-makers. After all, those who have nothing to hide can be trusted.

Thus far, food manufacturers are hesitant about food labelling and seem to be well aware of the flipside of the coin: a prominent claim about either the presence or absence of GM ingredients could easily be interpreted by consumers as a warning, and provoke suspicion rather than trust. With regard to possible future labelling of nanotechnology in food products, Unilever's R\&D director Gaudefroy stated: 'We support labeling provisions where they provide meaningful specific information to consumers. We do not support logos that could be seen as risk warnings' (Food Standards Agency 2010: 15).

However, for an elaborate understanding of public acceptance of food technology, one does not have to draw on high-tech innovations such as GM. In fact, the slumbering but persistent distrust of food additives is perhaps a more interesting case in point. The use of food additives is an age-old technique; it has pervaded into almost any kitchen in Europe; and it is well regulated by European and national authorities. Though easily identified through a labelling system of 'E-numbers', as they are called by popular expression, even the technology of food additives cannot count on plain public trust. The stubborn manifestations of distrust, as well as the pervasiveness of the

\footnotetext{
* An earlier version of this chapter was published as an article in Journal of Agricultural and Environmental Ethics (2014) 27: 27-42
} 
technology itself, indicate that transparency and labelling do not necessarily result in habituation in the long run.

The regulation of labelling and numbering of additives (such as colourings, flavour enhancers, and preservatives) was introduced by the EEC in 1988 to help promote a free and fair market of safe food products within the European Community. It was conceived as a way to inform consumers about what exactly they buy and eat. What seems paradoxical of E-number labelling is that while the occurrence of an Enumber by definition means the additive has been scientifically tested and proved to be safe, some consumers associate E-numbers with chemicals that do not belong in our food. Criticism and controversy about E-numbers have been circulating in the Dutch public sphere over the last 30 years. If ' $E$ ' is for European safety approval, then why do some of the E-numbers still arouse so much suspicion?

In this chapter, I will analyse controversies on E-numbers in the Netherlands. By interpreting critical voices and responses as concerns that go beyond food safety issues, and focusing on the way in which certain arguments are marginalized as supposedly being irrational and irrelevant, I will make an attempt to disentangle the paradox of Enumbers. My claim is that without taking into account the wider range of ethical, aesthetic and cultural concerns, the persistence of controversy and distrust cannot be adequately understood nor addressed by people who would benefit from such understanding: food policy advisors, engineers, manufacturers and consumers. To give a twist to Gaudefroy's words: a meaningful discussion encompasses more than risk warnings.

But the desirability of a broader discussion about food production is nothing new. Brom (2000) has convincingly argued that in the broad variety of food concerns, each kind of issue requires a different response. He warns that food labelling is not always the best way to take consumer concerns seriously - especially where it is used as a means to avoid moral debate and political action. Wynne (2001) and Marris et al. (2001) have pointed out that a narrow focus on risk could be detrimental for the quality of public debate (see also Levidow \& Carr 1997). Thompson (2007) has discussed an extensive range of ethical perspectives on food biotechnology, in order to offer 'a fair and open 
hearing for all ethically motivated points of view.' With the concept of 'Ethical Room for Maneuver' Korthals (2008) offers a promising model for ethical deliberation in the food chain that hosts a diversity of dilemmatic and dynamic food concerns (see also Korthals 2004). More generally, Lassen and Jamison (2006) claim that 'cultural discourses' deserve more attention in the policy making process; while Verbeek (2006) and Van de Poel and Van Gorp (2006) highlight specific issues in engineering and design that require explicit ethical reflection. Some of these proposals have already been circulating for more than a decade. But the success of opening up the public debate requires a more in-depth understanding of what keeps engineers, policy makers, manufacturers and consumers from doing so. In support of the aforementioned proposals, I will identify two mechanisms inherent to the current public discourse on food additives that pose serious obstacles to a more meaningful discussion of food technology.

\section{E-numbers in the Netherlands}

One of the first signs of explicit consumer distrust of food additives in the Netherlands goes back to 1983, in the magazine Ouders van $\mathrm{Nu}$, where parents are warned against the potential adverse effects of artificial colours and preservatives on their children's behaviour. Pediatric allergist Benjamin Feingold discovered that certain food additives would induce hyperactivity or aggression in children (Feingold 1975). Although his findings were qualified as somewhat controversial among scientific experts, the magazine suggested that the so-called Feingold diet - a diet free from artificial colours and flavours - was at least worth a try. Feingold argued that the risks of synthetic colours and flavours outweigh their benefit, for 'they are used merely for cosmetic or aesthetic effects' (1975: 799). In 1987, a similar story featured in Libelle, a popular magazine for Dutch housewives, and one year later a Dutch hyperactive children support group was established. These voices challenged the assumption that additives are a necessary and unavoidable part of our consumption pattern.

The growing need of public awareness of E-numbers was responded to by several consumer guides that assist consumers in finding their way through the supermarket shelves. Some of these guides, such as Kamsteeg's $E$ = eetbaar? (2001), its seventh edition in press now, are 
rather technical and written in an impartial tone. Also, the Netherlands Nutrition Centre issued such a guide. The more recent Dutch translation of Gouget's Additifs alimentaires (2008), however, is highly critical and suspicious of E-numbers, considering only $22 \%$ of the listed additives to be completely innocent. Over 100.000 copies of the latter guide have been sold in the Netherlands. Some of these guides now feature as smart phone applications.

To be sure, food manufacturers recognize the controversial nature of Enumbers. In 2007 Unilever launched a marketing campaign, Eerlijk is heerlijk ('Fair is delicious'), and proudly claimed its pre-packed sausage to be free from unnecessary E-numbers. A year later, Unilever was brought to the Dutch Advertising Code Committee and charged by a former employee with the complaint that the campaign had wrongfully suggested that food additives are unfair or unsafe. The campaign was alleged to provoke unnecessary fear of E-numbers in the average consumer (Reclame Code Commissie 2008). Eventually, the Committee found the complaint unjustified - as the complainant allegedly did not represent the average consumer - but the explicit product claim about unnecessary E-numbers disappeared nevertheless. This case shows the food industry's ambivalence about Enumbers: should it give in to consumer fears or step up and explain that these fears are ill founded? A prominent Dutch food scientist stated this critical position quite aptly: "The fear of E-numbers is completely unjustified. (...) You shouldn't feed the consumer's fear, you should be proud of what industry can do for that consumer. (...) To fight a bad image is a matter of endurance. Constantly explaining how you work and why.' (Van Boekel 2008).

Expressions of distrust of E-numbered additives are still widespread. Consumer platforms such as the national TV show Radar and the Dutch Consumers Union critically discussed E-numbers. On several online discussion forums Gouget's guide was subject to controversy. An opinion piece in a Dutch national newspaper on ready meals and food additives reheated the controversy (Hertzberger 2010). The Consumers Platform conducted a survey and found that more than half of the respondents stated that if a food product has the label 'natural' on it, this is a good reason to purchase the product. And $80 \%$ agreed with the statement that natural products do not contain preservatives 
or added flavours (LNV Consumentenplatform 2004). A survey by the Dutch Consumers Union concludes that half of the consumers are 'occasionally or frequently worried about E-numbers' (Consumentenbond 2010).

\section{The mechanism of irrationalization}

How do food engineers understand this controversy? An exemplary document is Emerton and Choi's Essential Guide to Food Additives (2008), a standard reference book for the food industry. The very first line of the first chapter reads:

The role of food additives in food manufacture has been much maligned and misunderstood in recent years. Additives fell victim to bad press to the extent that, at the height of the anti-'E' numbers campaign in the 1980s, the word 'additive' became almost synonymous with 'adulteration.'

I will discuss this reference book as a typical example: at the risk of grossly generalizing, I do think a closer look at this book helps to identify how food technologists explain the bad reputation of Enumbers and what they see as a solution. In explaining the bad reputation of E-numbers, Emerton and Choi frame consumers who are critical about food additives as uninformed and easily susceptible to wrong ideas about modern food technology and chemistry. The authors emphasize that the use of chemical preservatives is but a continuation of the age-old practices of using salt, sulphite and spices to preserve perishable foods in the days before refrigeration and modern processing techniques' (2008:6). Thus, they implicitly respond to a consumer's preference for traditional foods from the old days: if consumers were reasonable, they would know it makes no sense to reject modern technological food and to long for traditional methods of preparation at the same time. In other words, consumers are inconsistent.

Second, the authors point out that there is nothing special or strange about food additives. They illustrate this with the innocence of a lemon - an often-invoked example in discussions of E-numbers of how natural E-numbers can be: 'How many people think of additives when they buy a lemon or a bottle of vinegar? Yet these too are authorised additives 
(as citric and acetic acid, respectively) and widely used in food manufacture for their preservation properties, as well as their acidic taste, precisely as they are used in everyday cooking' (2008:2). Such examples aim to refute possible objections against food chemistry and its products: consumers should realize that some of these E-numbers are not that strange and unfamiliar, and that some of them are perfectly natural, so to say. The explanatory model drawn upon here, again, is that either consumers do not know this, or that they are completely inconsistent - if not hypocritical - in their concerns.

But the authors take their analysis a little further. The problem is not just the bad reputation of E-numbers, but also the persistent character of the controversy. They give two explanations for it: food scares and lenient marketing departments. The emotional aspect of consumer concerns - fear - feeds to, and is fuelled by, mass media. As soon as a particular food additive has 'perceived adverse effects' and becomes suspect for consumers, the 'marketing men' respond to the media scare and take it off the shelf. That is quite unhelpful, the authors explain: every time this happens, a company reduces the range of possible ingredients to use, and 'the controversy left unresolved' (2008:16). Thus, Emerton and Choi take the on-going controversy of E-numbers as a result of consumer demands that are inconsistent, based on false perceptions of food chemistry, and invoked by emotional responses. The controversy will persist as long as the food industry yields to such demands.

How should the food industry operate within this field of unreason, food scares and false perceptions? According to Emerton and Choi, the solution lies in sound science, objective information on food additives, and consumer choice. This solution is grounded in the idea that despite the fears and false perceptions, there is one legitimate concern about food additives: their safety. Any food additive on the European market has been evaluated by the European Food Safety Authority (EFSA) according to strict safety regulations. It is claimed that if an additive is suspicious, it can easily be tested by sound science - and the controversy will be resolved. It is the authority of science that helps out here and can make the crucial distinction between safe and not safe.

Emerton and Choi's chapter contains virtually all the ingredients of the 
typical dominant approach of the controversy of E-numbers. The tone of this approach is undoubtedly one of complaint: consumers are emotional, inconsistent, and uninformed, and their concerns are based on false perceptions of modern food technology. Recurring as the default response to consumer concerns, it functions as a discursive mechanism of irrationalization of citizen-consumers. It subscribes to a deficit model according to which the public understanding of science is central to the interaction between science and public, and citizens are ignorant in that respect (cf. Wynne 1991; Jasanoff 2005).

But some of these consumer concerns are more reasonable than presupposed by food engineers. In order to clarify and disentangle the paradox of E-numbers, it is worthwhile to take a closer look and reinterpret such concerns, assuming that their arguments might not be that unreasonable after all. I suggest a more charitable interpretation of consumer concerns that leaves open the possibility that they express valid, comprehensible arguments.

\section{Naturalness and the need for experts}

Though health concerns are predominant in consumer discussions of food additives, they rarely come alone. Let me give an example how such discussions usually proceed. In 2010, several iPhone users responded to an online review of two iPhone applications that assist consumers in identifying E-numbers (iPhoneclub 2010). Interestingly, each of the posted comments on health effects of E-numbers is surrounded by remarks on the trustworthiness of the science behind Enumbers. In accordance with the dominant approach, citizens are confident that sound scientific research can give an answer to their first concern - are E-numbers harmful? - but they are sceptical about the independence of current research and official information - as they are supposedly informed by the economic interests of the food industry.

One of the discussants remarks: "There are many goats among the sheep. If you really want reliable advice you better see if the Health Council has said something about it. They base their claims upon uncontroversial sound science.' 
She tries to make up her mind in a highly scientific question of what to eat. At the same time, she is anything but confused. She does recognize the importance of scientific testing and consequently the importance of health safety, but she is concerned with what sources to trust. It is the health effects of additives that draw most attention of the discussants. While 'E' stands for 'Safe as approved by scientific research,' citizens also learn from consumer guides, dissenting scientific reports and alarming weblogs that at least some studies do not consider certain additives to be safe, or warn against allergic reactions. As the dominant approach has it, citizens are indeed concerned about this: are food additives really safe? Yet, it is the diversity of sources of information that gives rise to most concerns. Attached to this concern is the question: who is to tell what safe food is?

A typical response to the consumer's difficulty in identifying reliable sources on health effects is to stay away from food additives all together and to opt for what is perceived as familiar food. For example, one discussant suggests:

Only gives more stress, these applications. Just leave the diet products and margarine and take real products instead of those chemical fake substances. E.g. an egg and a slice of bread with good butter is healthier than you might think!

(Yla)

The advice to go for the real - that is, an egg, a slice of bread, butter - is presented here as a strategy for the consumer who recognizes the responsibility to know what to eat, who acknowledges the importance of health effects, but who simply does not want to get into the technical details surrounding strange and artificial foods. Another discussant agrees on this strategy, but goes beyond mere health concerns:

Easy solution: buy natural unprocessed products. It takes you some effort to prepare your meal, but a good amount of sugar, fat, salt and chemical substances will no longer enter your body. If that makes your body healthier, that's a good thing. If not, at least your food tastes much better anyway.

(Niels)

The preference for natural, unprocessed food here too is based on the 
idea that 'chemical substances' entering the body may affect one's health. But Niels is not sure about it. His solution is a strategic one as well: whether or not health is at stake, at least there is much to gain in terms of taste. From this discussion it appears that although health concerns are indeed leading in the discussants' comments, they are far from isolated from other concerns about E-numbers, such as the reliability of information on health effects, the strangeness of food additives, and the taste of products containing food additives.

In the examples presented above, negative health effects are indeed a predominant topic of discussion. However, these concerns give rise to a wider range of issues related to E-numbers, such as the reliability of scientific studies and publicly available information, the particular interests in and reasons for the presence of E-numbers in food, avoiding the science and technicalities surrounding the intake of processed food, and the supposed tastelessness of processed food of which E-numbers are a typical marker. Interestingly, the preference for natural food - whatever foods the discussants actually consider as such - is articulated here as a consumer strategy to deal with the individual's responsibility to choose safe foods, and with the problem of how to identify them. Consumers do not present 'natural' as inherently good but as the easy way out. As such, the call for naturalness is not necessarily a rejection of modern technology, or a flight to the past, but a pragmatic retreat to the familiar and recognizable.

Such concerns are procedural in the sense that consumers are concerned about how health effects of food additives are tested, reported and communicated to the public. They are concerns of a type that Wynne (2001) has identified in his discussion of public concerns surrounding GMOs: 'The central object of public concern is not GMOs per se but institutional behavior in relation to them.' With regard to food additives, citizens might not express such strong criticism and protest to engineers and policymakers as was the case with GM. Rather, their response is tied up with their roles as consumers who feel responsible themselves for what they eat. Yet, it is the background of uncertainty and strangeness surrounding E-numbers that gives full meaning to their concerns - and not just the health effects in themselves. There is nothing unreasonable about that: where food has 
become highly technological and the quest for good food is scientized (cf. te Molder \& Gutteling 2003), consumers may have good reasons to question the reliability of professionals, their dependence on expert information, or even to decide to turn away from experts all together. The dominant approach of E-numbers lacks the very recognition of such procedural concerns.

\section{Taste, convenience, and food culture}

Wynne (2001) has made clear that public responses to technological innovation are too often misinterpreted as irrational and subjective concerns; and that most of these concerns are to be understood as a political interrogation of knowledge practices. His analysis, however, is restricted to the legitimacy of procedural concerns: these concerns should be taken seriously because in the end they are about how science and society handles substantive issues such as health, safety and environmental effects. But this leaves open the question what happens (and should happen) to other substantive concerns. As Swierstra has pointed out, concerns about meanings, worldviews, identities, and conceptions of the good life are too often ignored by policymakers and technologists (Swierstra 2002; Swierstra et al. 2009). Especially concerns about impacts that are not easily quantified and are not perceived as cases of direct harm tend to be marginalized from the public debate (Swierstra \& te Molder 2012).

One of the fiercer Dutch debates on food additives and ready meals offers some examples of such concerns. In December 2010, molecular biologist and publicist Rosanne Hertzberger published an opinion piece in a Dutch quality newspaper, in which she criticizes TV chefs who conspicuously reject processed foods and who suggest that such inferior foods are for lazy people (Hertzberger 2010). As a response, she praises ready meals and food additives for giving her the opportunity to spend her time on things in life that are more important than cooking: processed food is convenient, not unhealthy and a fair alternative to fast food. The appeal to natural and whole foods is hypocritical, she argues, as in our daily lives we delegate so many other tasks to technology.

Hertzberger's article gave rise to a discussion on Foodlog, a prominent 
Dutch weblog on food in the broadest sense of the word. Janneke Vreugdenhil, cook and culinary writer, replies that we should ask ourselves a fundamental question: how do we relate to our food anyway? Is food to us what gasoline is to our cars? 'Food goes back to culture, to family ties, to traditions, to memories, to so many things that define us as human beings. Who regards the meal as a sum of useful nutrients, neglects the embeddedness of it in our civilization' (Vreugdenhil 2010). Here, Vreugdenhil pushes the discussion beyond the boundaries of what food chemistry can investigate, viz. beyond the physiological questions of nutritional benefit and potential health effects. She questions firstly, the reduction of food to its biological and chemical components and functions, and secondly, the explanation of the relationship between humans and food in terms of the most efficient way of transferring nutrients only. As the logic of these reductive approaches is inscribed in ready meals - of which food additives are a necessary component - we should be wary of ready meals, so the argument goes, if we appreciate other values that are expressed in our relation to food.

There is, for example, the social meal concern: ready meals would encourage people to eat in solitude, and as quickly as possible, while dining together is an important setting for families to tell, share, care, and give attention. As one discussant explains: 'At the dinner table one learns to take turns in talking, one learns to share, and parents encourage one child to speak up a little and ask the other to keep his voice down. And as a parent you show how much you love your child: Look, I made this for you, I take care of you' (Nadia). The food additive a symbol for the ready meal and its logic -would thus affect the daily practice of the shared family meal by enabling fast and isolated dinners.

The argument is also expressed in the appeal to cooking as meaningful practice. One discussant, for example, points out that one can have many reasons for preferring home made to ready meals: cooking can be an interesting and engaging activity, something to be enjoyed, and can also result in better-tasting food. These are the things she would miss if convenience foods took over the kitchen. Many discussants agree with her. To some, convenience may be one of the best things that ready meals can offer, but to others this appears to be a disputable 
value. If the effort of cooking is a worthwhile activity, convenience equals laziness and indifference.

But there are also concerns about the decay of taste and food culture. Children who are raised in a family that values the enjoyment of cooking and dining would learn how to appreciate and distinguish different flavours, and learn about various cooking methods. But children who are raised with the taste of cans and packages will not appreciate anything other than processed food. For a whole generation, the argument goes, the march of ready meals would result in a decay of taste. The concern here is that what we may call taste literacy and memory are likely to erode - and a sophisticated food culture with it. Many of the discussants are rather pessimistic about their food culture, and fear a decline of Dutch food culture because of the omnipresence of ready meals.

The point here is that food safety and health effects are rarely discussed. Most of the comments here evolve around food as a bearer of culture, a source of taste and enjoyment and as an ingredient of the good life. Concerns regarding the impact of food technology in these spheres can thus be characterized as cultural, aesthetic, and ethical. To recognize them as such, means to accept that scientifically established information could be informative, but not exhaustive in addressing those concerns. They require responses that take into account the normative dimension of what it means to produce good food.

\section{The promise of food chemistry}

Perhaps the complaint that consumers display irrational responses when it comes to food additives would best be countered by pointing out that citizens are playing a different game from the techno-scientific justification of the use of E-numbers in food products. In that game, ethical, cultural, and aesthetic standards are appealed to - a domain in which food technologists may no longer claim expertise, and are even reluctant to accept responsibility. Normative considerations of food technology's impact on practices of food enjoyment and food culture, then, are not part of the food engineer's concerns. But looking at the statements that food engineers make with regard to the justification of the use of food additives, we see that this is not the case. 
Food additives actually do subscribe to certain values and standards within the domains of the ethical, cultural and aesthetic: it is part of their nature. In fact, food engineers are far from reluctant to articulate the ethical, cultural, or aesthetic significance of E-numbers.

Preservatives, for example, are said to keep food from deteriorating over time and to increase the shelf life of the product. According to Emerton and Choi such additives 'meet the demands of modern lifestyles, including infrequent bulk shopping expeditions' (2008:6). De Jong, in his Dutch textbook on food processing, argues that 'modern man no longer wants to spend a lot of time in the kitchen and increasingly tends to leave food preparation to the food industry. The production of high tech foodstuffs is only possible by the use of additives' (2008:110). And in the textbook Food additives Branen and Haggerty proudly present convenience as one of the major benefits of preservatives: 'Convenience has been built into TV dinners and breakfast cereals as well as several microwave products' (2002:5).

Such accounts do not only express that additives contribute to, or enable the exercise of a particular conception of the good life, but also that these additives are intentionally designed to do so. Furthermore, they suggest that the convenient and fast life is simply not negotiable.

With respect to colourings, food engineers are willing to defend the aesthetic norms inscribed in food additives. In fact, they say, it is the consumer himself who demands those colourings. 'Colour is important in consumer perception of food,' Emerton and Choi explain, 'and often denotes a specific flavour.' (2008:8). The consumer's expectation that strawberries are red and butter is yellow is precisely what colourings are supposed to meet when they appear in strawberry flavoured yoghurt or in margarine. The consumer may express his desire by demanding or protesting, but in the end it is his behaviour (to buy or not to buy) that counts. And consumers do not always practice what they preach. Whether or not this makes sense from a strictly logical point of view is irrelevant: in this case, consumer expectation is considered a legitimate reason for adding colour.

We can, of course, provide more arguments in favour of food additives. 
But I highlight these two reasons - ethical and aesthetic reasons - since they explicitly claim to address consumer desires and expectations. In their account of the benefits of additives, food engineers, too make use of an ethical and aesthetic repertoire. E-numbers are here to enable a particular conception of the good life, and they fulfil a specific aesthetic ideal. If consumer concerns are to be judged as irrational or irrelevant simply because they appeal to non-technical considerations, then the promises of food chemistry are no less so.

\section{The mechanism of privatization}

Thus far, I have described how consumer concerns that do not relate directly to safety and health issues are usually dismissed as irrational and inconsistent responses to E-numbers. These concerns cannot be sufficiently addressed by sound scientific testing and providing clear information, since some of them question the institutional organization of such testing, and others object to the functions that additives are supposed to fulfil or at least the actual effects they have on how we relate to food. In the latter case, they challenge the values of convenience, efficiency and uniformity inscribed in certain food additives. However, even if such substantive concerns are recognized as ethical, cultural or aesthetic questions in their own right, the Dutch discourse on E-numbers shows another mechanism that systematically obstructs a meaningful dialogue: privatization. In this context, I take privatization as the exclusion of a particular concern from the discursive agenda for the reason that it should not deserve public attention. Grounds for that reason may be, for example, that the concern in case is considered to be informed by purely subjective and individual experience, and hence is not expected to find any common ground for meaningful (dis)agreements; or that the matter at issue is not of anyone else's business and needs to be protected from collective judgment and state regulation.

This demarcation of public and private matters is developed by the tradition of (neo-) liberalism and goes back to J.S. Mill, Constant and Humboldt. In the context of food technology, the supposed implication of this demarcation is that matters of taste, enjoyment of cooking, and the value of social meals, are unacceptable as public concerns and remain both protected and imprisoned in the private sphere. 
Eventually, the exclusion of ethical, aesthetic and cultural concerns from the public agenda finds its capstone in the logic of the free market: the principle of non-coercive, voluntary exchange of goods implies that no one is actually forced to buy or eat anything, especially if consumers have a large range of options to choose from.

This line of reasoning is strongly anchored as an intuition in the Dutch public discourse on food additives. Remarkably, at this point the dominant approach is not only taken by food engineers but also endorsed by consumers and citizens themselves. I will discuss an example to illustrate how issues of taste and the good life are privatized in a public discussion on food additives. In response to Hertzberger's opinion piece, a second discussion has taken place on the online discussion forum of the national newspaper NRC Handelsblad (De Jong 2010). It is quite similar to the Foodlog-debate: here, several versions of the argument against the reductive and alienating logic of food technology are put forward as well.

But one specific thread in the discussion is interesting in particular, because it concerns the sense of the debate itself, and in particular the terms in which it should proceed. Is the issue of ready meals, in the end, an ethical affair, and should we not decide for ourselves? Is it a matter of taste, about which one cannot and should not argue? Many object to the idea that taste and preference can be the subject of a meaningful debate. One discussant, Sander, comments: 'Mrs Hertzberger doesn't like cooking. Who cares, apart from $\mathrm{Mr}$ Hertzberger, perhaps.' Also, the alleged moralistic tendency of people who take a critical stance against processed food is strongly criticized by their opponents. While some explicitly dare to frame the discussion as a question of the good life, many dismiss such framing as moralistic, elitist, and paternalistic - stressing the importance that each should be free to cook and eat as he likes.

Remarkably, one discussant takes the analytical effort to clarify the problem with moralism. He argues that there is a significant difference between expressing one's personal taste and giving reasons for it on the one hand, and proposing that taste as a general rule, on the other:

As far as I know, there's no moral obligation to eat tastier or healthier food per 
se, apart from the fact that it makes human existence pleasurable / more convenient / more valuable. But to whom are we obliged to make our existence more pleasurable? To God? To the Good Life? To ourselves?

(P.)

This particular discussion thread, woven into discussions about taste, food culture, pleasure and alienation, reflects the obstacle that ethical, cultural and aesthetic concerns need to take in order to gain a legitimate standing in the discussion - an obstacle to be challenged even before such concerns can become serious positions in an argument. Again, the cultural, aesthetic and ethical concerns raised in this discussion are contested, not necessarily on the grounds that they would be false, wrong or inconsistent, but on the basis of the repertoire that they are part of. The repertoire of taste, enjoyment, and the good life is hardly considered appropriate for public discussions, since it seems to express a realm of private experiences and personal preferences which do not seem to have any public significance. The privatization of such concerns is often expressed in the reproach of moralism and paternalism: in the end, food is something to be consumed, and in matters of consumption there should be individual freedom of choice.

\section{Re-imagining private impacts as public matters}

Are some of these concerns surrounding E-numbers private matters indeed? In his essay Public Goods, Private Goods, Geuss discusses three historical cases in each of which the meaning of the public/private distinction is established. Although overlapping, these meanings differ from context to context: it may refer to a conception of intimacy and appropriate behaviour, to republican ideas of interests and responsibilities, or to what counts as cognitive access to beliefs and desires. His conclusion is that no single clear and substantial distinction between the public and the private can be drawn that would be generally meaningful. He argues that we should not start from a basic understanding of what is private/public and only later consider what it implies for collective action. 'Rather, first we must ask what this purported distinction is for, that is, why we want to make it at all' (2001:107). This does not mean that the line between public and private concerns does not exist, nor that it would be meaningless to 
respect and defend it, but that rethinking or redrawing that line can be part of any debate over concrete and contextualized matters. I suggest that we understand, perhaps not all, but at least some of the consumer concerns about food additives as an attempt to re-imagine what impacts of food technology count as public matters.

In this respect, there are good reasons to recognize concerns about the way we relate to our food as legitimate and public issues. These reasons have been offered in the field of political philosophy by critics of political liberalism, who advocate ethical deliberation on the good life in the public and political sphere. More interesting, however, are the arguments made in the field of philosophy of technology, since they pertain to the social and ethical impacts of technology in particular.

Albert Borgmann, for example, has argued that in modern society, the overall availability of technological devices reflects a pattern in how we perceive and interact with the world. The pattern is one of disengagement: many activities with intrinsic meaning and value have become redundant with technological devices to which their technical functions are now delegated. Borgmann presents the table dinner as an exemplary case of such an activity: 'Once food has become freely available, it is only consistent that the gathering of the meal is shattered and disintegrates into snacks, TV dinners, bites that are grabbed to be eaten; and eating itself is scattered around television shows, late and early meetings, activities, overtime work, and other business.' (1984:204). Borgmann's point is not that we are somehow forced to do so by food technology. But it would be naive to claim that our food habits remain unaffected by it. Invisible and self-evident, pervasive and consistent, the pattern of technological delegation has become the default position or background against which we make choices. 'Living in an advanced industrial country, one is always and already implicated in technology and so profoundly and extensively that one's involvement normally remains implicit.' (1984:104-5 italics are mine).

Also, Bruno Latour has criticized the instrumentalist assumption that technological artefacts are neutral instruments that in themselves do not prescribe or effectuate particular actions. Rather, he argues, artefacts are inscribed with a certain program of action: they embody a 
particular view of how they are supposed to be used, what context is appropriate, and what kinds of actions are to be promoted. In this sense, artefacts have the ability to mediate our actions in the sense that what we do is co-shaped by both artefacts and by ourselves. This is conceivable only if we recognize that things, like human beings, can be actors with a certain agenda (Latour 1999; see also Winner 1986; Akrich 1992).

Bringing together Borgmann's and Latour's conceptions of technology, Verbeek (2005) has argued that although artefacts can and often do have a decisive role in how we lead our lives, their influence is not necessarily coercive or strictly determined. That is, they rather invite or discourage certain ways of acting - and this includes those practices that we consider to be part of the good life. To be sure, Verbeek revises Borgmann's gloomy claim that artefacts would only draw us away from meaningful practices; they might as well enable us to engage with the world around us in new ways that are different, but just as meaningful (2005: 186-191).

In pointing at the mediating character of technology, and by making explicit the ways in which human action is implicated by artefacts, these authors have made clear that technologies can invite, hinder, enable, transform, guide, seduce, delay, restrict, or assist our actions. To qualify technologies as matters of public or even political concern, as these authors have done, means to question the pervasiveness and desirability of their impacts. From this perspective, the ethical, cultural, and aesthetic concerns surrounding food additives cannot be dismissed for the reason that the consumption of processed food is simply a matter of individual and free choice, because that is exactly the claim that is contested in the first place. Even though such concerns do not draw a direct causal relation between the use of food additives and the way we eat, they point out cases where food additives mediate the practices of preparing, identifying, memorizing, enjoying and sharing food that they value so much.

\section{Conclusion}

The paradoxical about E-numbers is that they suffer from a bad reputation while they explicitly indicate - by definition - that the use of 
the food additives they refer to has been scientifically tested and proved to be safe. I have argued that this paradox, as commonly perceived by food engineers, disappears once we notice those consumer concerns that go beyond the question of safety and health impacts. These concerns draw critical attention to the highly scientized and technological character of food (procedural concerns), and to the impact of the use of food additives on current food practices and the development of food culture (substantive concerns). The usual call for sound science and the dispersion of objective information on Enumbers does not address any of these types of concerns. The recurrent appeal to consumer autonomy fails to recognize the mediating character of food additives, or at least paralyzes any meaningful public dialogue about it. The two discursive mechanisms I have identified, irrationalization and privatization, are serious obstacles for addressing these concerns. Rather than merely showing that a much broader set of concerns circulate among citizens and consumers, and that they should be taken seriously because they are numerous, my point is that they may not be as unreasonable as they seem, and they may even turn out to be not that private.

As Meijboom et al. (2006) point out, trust cannot be forced, but trustworthiness - a precondition for trust - can be enhanced. For the food sector this means acting reliably, but also explicating the norms and values they act upon. After all, trust is a matter of normative expectations. Also, trustworthiness means to be responsive to public concerns and engage in a critical discussion about those norms and values (Meijboom et al. 2006; see also Brom 2000). For the public discussion of food additives, this means that food engineers should explicitly acknowledge that the use of certain food additives have ethical, cultural and aesthetic implications; and that they are at least willing to reflect on, and publicly discuss, their responsibilities with regard to those implications and impacts. Citizen-consumers, on their part, may need to develop more effective ways of articulating their concerns and better not avoid moral and even political repertoires in doing so.

Thus far, I have left many questions open. For example, is the consumer's sceptic attitude towards scientific testing and the dependence on experts based on reasonable doubt? Are there good 
reasons to question the motives of the food industry? Are food additives really that successful in making our lives more convenient? If consumers say they are concerned about food additives, why do they still buy processed food? How pervasive is the march of processed food? How to attribute responsibilities if no clear causal relations can be established? And is it true that there's no arguing about taste? I am not so sure. But those are exactly the kind of questions that may feed into a meaningful, public dialogue in which consumers and citizens, technology developers and - why not - marketers engage in the open. 


\section{Quantifiability, publicity and causality. Three conditions of the public food innovation agenda}

In the last chapter I have shown that in discussions of food technology, certain discursive mechanisms (irrationalization and privatization) marginalize citizen and consumer concerns that are commonly labelled as ethical, cultural and aesthetic. If these mechanisms indeed restrict or block the opportunity of a rich and fruitful dialogue on food technology and innovation, it seems worthwhile to identify the tacit assumptions underlying such mechanisms and to make them more explicit. That is, what is presumed to be reasonable or fair about giving priority to certain concerns at the cost of disallowing other concerns? What arguments could be given for denying certain concerns access from the public innovation agenda?

This chapter is an inventory and analysis of such arguments, in accordance with Swierstra's framework of what constitutes the distinction between soft and hard impacts (Swierstra 2011; Swierstra \& te Molder 2012). As a further elaboration of that framework, it also offers a critical evaluation of these arguments: both merits and pitfalls will be discussed. Although there may be good reasons to prevent certain ethical, cultural and aesthetic concerns from entering the public innovation agenda, it should also become clear that the validity of these reasons is limited, and that there is a price to pay.

\section{The public innovation agenda}

An analysis and evaluation of what kind of concerns may or may not enter the public innovation agenda of food technology should start with an explication of this very notion. What do I mean with the public innovation agenda?

Cobb and Elder (1971) offer a useful entrance to the concept by distinguishing two kinds of agendas. The so-called institutional agenda' denotes 'a set of concrete items scheduled for active and serious consideration by a particular institutional decision-making body', whereas the term 'systemic agenda' refers to 'a general set of 
political controversies that will be viewed as falling within the range of legitimate concerns meriting the attention of the polity.' (1971: 905) The difference between the two kinds is that the latter is more abstract and broad in scope and domain and is closer to what we may call a public agenda, where the first expresses the attention of a particular formal institution, such as court or parliament. The larger the discrepancy between both kinds of agendas, Cobb and Elder claim, the likelier serious conflicts (e.g. a lack of trust, or legitimacy crisis) will arise in the political system.

The distinction of Cobb and Elder is useful in explaining the dynamics of issue formation within the formal political system and the polity at large. Yet, technological innovation does not present itself in the form of law or policy but rather as a product or process, doing its work somewhere in the long chain of food production, processing, distribution, retailing, and consumption. In a technological society it does not just matter what policymakers and legislators consider worth of attention; what matters also is the attention of food scientists, engineers, consultants, marketers and other key players in the process of food technological innovation. In this context, relevant discrepancies are to be detected not only between the broader public agenda and the formal policy agenda, but also with regard to academic and industrial research agendas.

Assuming that attention - either public or institutional - is a scare resource, an agenda can be considered the temporary outcome of a competitive and strategic process; it suggests a particular attribution of priority and hierarchy of concerns that seek attention (Hilgartner \& Bosk 1988). Yet, taking the term literally, an agenda is not only an outcome but also a beginning, as it states 'what ought to be done'. The notion thus implies commitment by an individual or group of individuals with regard to potential actions and, with it, a sense of responsibility of at least taking the issues at hand into consideration by investing time and resources in gathering information or weighing options. Being both temporary outcome and possible starting point, agendas have the peculiar nature of being a selective mediator between 'what ought to be spoken about' and 'what ought to be done'. That is, not every issue that enters the agenda will be acted upon. It may be the case that further attention results in the deliberate conclusion that no 
action is necessary or desirable.

Cobb and Elder's model serves to highlight the potential gaps between systemic and institutional agendas. This model, however, tends to take the systemic agenda as a given, and institutional players as receiving, responding and potentially adopting parties. But how does the systemic agenda itself come about? What this model leaves out of sight is the potential discrepancy between the various concerns articulated in the public sphere (informal public debate), and the set of issues recognized as 'meriting the attention of the polity' (public agenda). Also, it does not account for the active involvement of institutional players such as policymakers, retailers and marketers, academic and industrial researchers, in framing and setting that public agenda. In other words, what is recognized as 'the public agenda' is itself the product of a competitive process; and discrepancies may appear between informal public debate and the public agenda as it is commonly recognized. If we are interested in the fate of citizen and consumer concerns, this particular agenda needs to have a central place in our analysis. After all, the public agenda is the very touchstone with which discrepancies with institutional agendas are measured.

What I take to be the public innovation agenda is that part of the public agenda that seeks to inform multiple institutional agendas, and which itself is shaped in and through public debate. The public innovation agenda is a set of issues (regarding technological innovation) commonly recognized by public and institutional actors to deserve attention and deliberation. Traces of such agenda can be found in policy reports, consumer platforms, news media coverage, corporate mission statements, advertising, public debates, newsletters and so on. The agenda implies that stakeholders acknowledge themselves as such, commit themselves to give attention to and are willing to openly discuss the issue. Decisions and actions are potential results from this attention, but by no means a given. Commitment here means that publics and actors accept responsibility for discussing the issue, but not necessarily for resolving it.

What this understanding of the public innovation agenda suggests, then, is to consider it essentially as a discourse agenda. The assumptions prescribing what types of concerns qualify as legitimate 
topics of technological innovation can be taken together as conditions for meaningful discussion. Each of these conditions is grounded in a broader view of science, politics and technology respectively. In this chapter, these conditions as well as the underlying worldviews will be further discussed. It is a further specification of the previous chapter, where I have identified two discursive mechanisms that occur whenever certain concerns are marginalized in and through public discussion.

\section{Quantifiability: what numbers can do}

The first condition that concerns have to fulfil in order to become a legitimate issue on the public innovation agenda is that their substance is appropriate for measurement and thus can be expressed in quantitative terms: it counts if it is counted. The underlying assumption is that at least we should be able to agree on the facts before we can actually discuss the problem and possible courses of action. Counting and measurement can help in making such agreement possible. This can be explained by roughly four understandings of what numbers can do.

The first and perhaps most common understanding of quantification is that numbers represent or mirror reality in such a way that it establishes a stable image of the world with exactness and accuracy. An exemplary statement of this view can be found in Carnap's Introduction to the philosophy of science (1966) 'Science begins with direct observations of single facts. Nothing else is observable. Certainly a regularity is not directly observable. It is only when many observations are compared with one another that regularities are discovered. These regularities are expressed by statements called 'laws'.' Elaborating on the concept of temperature, Carnap explains why quantification is more useful than qualitative or everyday language: 'Subjective methods of establishing the relations 'equally warm' and 'less warm' are of little use in an empirical search for general laws. What is needed is an objective method of determining temperature - a method more precise than our sensations of heat, and one about which different persons will usually agree.' In other words, quantification would be a way of getting rid of subjective interpretation and vagueness. Rooted in the positivist line of thought set out by Auguste Comte, who considered science an 
important source of societal harmony, progress and unity, the strong preference for quantification and measurement is one of the key features the predominant techno-scientific discourse.

Carnap's explanation also highlights a second function of quantification and measurement: that of control. Representations of the world have a practical significance; emerging patterns and regularities can help humans in anticipating or manipulating their natural, social and technical environment. This is the positivist promise of science: quantification and measurement are useful in establishing the knowledge of regularities, patterns and laws. If one wants to formulate laws of nature in order to predict and manipulate events, phenomena should be described and investigated by systematic observation, exact measurement, quantification, ordering or classification. The rationale of this idea of modern, experimental science is that findings should be reproducible regardless the individual who performs the observation or experiment - as long as a specific set of clearly defined parameters are in place. Establishing law, in this sense, is one of the fundaments of good science, and quantification provides the means to do so.

The ideal of establishing laws cannot be understood without accounting for the need for prediction and control. As Porter (1995) has pointed out, the ideal of quantitative objectivity, such as found in the widespread use of statistical analysis, does not find its sole origin in the natural sciences, but for the most part in the bureaucratic administration of societal and state affairs, and in the applied social sciences. Quantification is a tool for administration and policymaking: what is counted and measured can be recognized as an affair of government control, and whatever needs to be governed must be measurable. Quantification promises control, then, through scientific explanations of both natural phenomena (e.g. 'evidence-based medicine') and social phenomena (e.g. 'evidence-based policymaking').

A third way of understanding quantification is that numbers settle disputes between conflicting views of the world, taking the role of the impartial arbiter. The act of counting suggests a reliable practice with unequivocal results that can easily be repeated by anyone who would contest those results: 'You do the math.' It appeals to an impartial way of settling disputes about knowledge claims, as counting would not be 
influenced by contingency, political bias and private interests. Quantification promises the kind of objectivity associated with impersonal and mechanic judgment: it de-personalizes human judgment.

Quantification as an arbiter is particularly productive in political accountability. In the 1950 's, cost-benefit analysis, as a particular quantitative technology, became acknowledged in the United States as offering a rigorous and trustworthy basis for public policy making. Porter emphasizes that this decision model did not emerge from business practices or highly personal decision making: it is first of all 'a public language, and in many ways a political one, developed to deal with public contention rather than to direct the solitary mind.' (1995:251). As such it exemplifies a kind of rationality suitable for public justification; public investments can be accounted for in advance, and evaluated after, by non-subjective, or rather intersubjective means.

Rose (1991) has made a similar point: calculation is particularly functional in a democratic society with a plurality of interest groups and a rich public sphere, since numbers reflect some sort of disinterestness amidst conflict and contestation. In fact, Rose argues, numbers provide with a powerful resource of political decisions exactly because they 'simultaneously promise a 'de-politicization' of politics, redrawing the boundaries between politics and objectivity by purporting to act as automatic technical mechanisms for making judgments, prioritizing problems, and allocating scarce resources' (1991:674). Quantification, in sum, is a technology that makes possible such public accountability and closure. The possibility of quantification has become widely accepted as a necessary condition for public issues.

Finally, a fourth function of quantification is that it offers a standardized language that renders a diversity of phenomena compatible, and to some extent, equal. The core strength of cost-benefit analysis, for example, is that it accounts for a variety of values and interests by standardizing them in such way (often in terms of monetary value) that they are mutually comparable, and that overall utility, well being, or happiness can be calculated for each policy option. Thus, options can be compared, efficacy can be projected, and 
efficiency can be measured.

A forerunner of the cost-benefit analysis can be found in Bentham's hedonistic calculus, which he developed as a practical tool for evaluating the moral goodness of legislation. His approach of ethics was not so innovative in its emphasis on the fundamental principle of utility, which offers a moral standard for actions according to the extent that they promote overall happiness. Bentham's major contribution was first and foremost that he proposed to quantify and measure utility with systematic exactness and scientific rigor, for which he found inspiration in Newton (Mitchell 1918). The main qualities that feed into this calculus, pleasure and pain, need to be expressed in quantitative terms. The most abstract value of happiness is thus operationalized into numerical values: 'Pleasures and pains are the instruments [the legislator] has to work with: it behoves him therefore to understand their force, which is again, in other words, their value.' (Bentham 1789: IV, I). The use of the term force is not accidental: it complies with the positivist and empiricist vocabulary of science, as are the categories of intensity, duration, certainty, proximity and extent according to which pleasure and pain are measured. The calculus results in a balance of numbers and, as a formula, offers a guideline for governmental actions as moral options.

One of the most appealing features of Bentham's approach is that it transforms values into numbers; and that it turns normative judgment into an investigation of facts. As with cost-benefit analysis, Bentham's hedonistic calculus provides with a unifying method, balancing a broad diversity of interests and experiences and rendering them compatible under a single metric: the language of quantification.

In a similar fashion, quantification is a sine qua non for classical risk analysis. Risk is a calculable set of problems as numbers would easily feed into the classical formula of risk = probability $x$ effect. It offers the prospect of an objective language for articulating the nature of hazards, the probability of their occurrence, the distribution of exposure, and so on. The risk vocabulary has permeated the governance of environmental and technological impacts in particular, but also extends to the discussion of public health issues, the construction of 'at risk populations', and the setting of national security levels. Although 
the field of risk governance has evolved in a more reflexive and inclusive research and policy practice, the classical definition of risk is still powerful in current practices of risk assessment (Hermans et al. 2012). Social and cultural studies of risk offer various explanations for and interpretations of the emergence of the predominant risk discourse (see Lupton 1999 for an overview), the discussion of which would go beyond the purpose of this chapter; but at least it is safe to say that risk as a category or denominator of social problems has grown well into the self-understanding of modern societies as advanced, globalized, technological and industrial. As Douglas points out, 'the idea of risk could have been custom-made. Its universalizing terminology, its abstractness, its power of condensation, its scientificity, its connection with objective analysis, make it perfect.' (Douglas 1992: 15).

\section{The limits of quantification}

Although quantification and measurement are powerful tools to represent, order and understand the world, they also have their limits. The idea of counting, for example, bears the promise of exactitude, accuracy and neutrality, while in concrete situations one sometimes need to make categorical judgments about what counts as something, making sense out of ambiguous and vague observations. Things are never just things: they need to be classified in order to count. Where the things don't speak for themselves, such decisions are informed by contextual interests, shaped by presumptions of relevance, and may provoke controversy when the stakes are high.

A typical example is the production of unemployment rates: these are intricately bound to specific notions of who should be counted as the unemployed at all. Such notions are subject to historical change, variations between nations, and social contestation. The criteria used for who counts as unemployed depends on a given interpretation one maintains of unemployment as a social issue. Such interpretation is not just a methodological consideration but also a political one: what groups are relevant enough to take into account? (cf. Shiskin \& Stein 1975; Norwood 1988; Stone 2002). Another example is counting the number of chromosomes in human cells. Discussing the history of cytology, Martin and Lynch (2009) explain that 'chromosomes do not 
have nicely defined boundaries and cytologists must decide what counts as a chromosome, and whether it belongs to 'this cell' or to another.' (2009: 250) The tedious work of visualization, interpretation, identification and the building of consensus on each of these steps is easily forgotten once the resulting number is there. Martin and Lynch point out that even the counting of marbles can be a matter of dispute, as soon as children try to establish the result of a game.

Even the simplest operation of counting is an act of interpretation. Therefore, the positivist assumption that the use of numbers would automatically lead to normative or epistemic agreement is questionable: in highly polarized matters, the presentation of numbers and statistics is rather the continuation of politics with other means. Sarewitz (2004) speaks in this sense of an excess of objectivity, pointing out that objectivity itself is not the problem, but rather the multiplicity of legitimate ways of how to select, interpret and deliver the facts. This also means that where the stakes are low and no overt conflicts arise, numbers may conceal normative judgments, but do not substitute them.

This is not a reason for rejecting quantification as a tool for making sense of the world all together. Numbers and measurement can still offer productive tools for rendering a problem visible and manageable, and may provide us with the means of holding each other (politically) accountable. The point, however, is that the promises of accuracy and agreement cannot be taken as sufficient reason for giving priority to quantifiable knowledge. Quantification is a mode of translation, in the sense that numbers are the product of framing, classifying and ordering the world in a particular way, for particular purposes.

Two things follow from the idea that quantification and measurement are acts of translation. First, that anything could be counted and measured, as soon as people decide to do so. This becomes clear once we realize that quantified concepts have histories: the concept of biodiversity, for example, was coined only twenty five years ago and emerged from research in the fields of species extinction, forestation and tropical biology. Although the exact way of calculating biodiversity is still disputed among biologists, the concept proved an effective way of articulating the phenomenon as a problem of loss, and as a political 
and economic challenge (Hannigan 1995). Obesity, originally a sign of wealth and prosperity, but long recognized as a disease, was quantified in the $19^{\text {th }}$ century with the introduction of the body-mass index, rendering the concept objective enough for the World Health Organisation to frame it nowadays as a growing and global public health problem. Many of such quantified concepts (e.g. animal welfare, crime, toxicity, literacy, quality of life, unemployment, sustainable development) have histories that describe for what reasons, and under what conditions qualitative phenomena were made quantifiable. In this respect, it does not make much sense to block qualitative concerns from the public agenda all together for the reason that they would not be quantified. Rather, they may as well invite us to invest and develop the means to render them calculable and measurable. To take up that invitation means to recognize the difference between quantified and quantifiable concepts.

Surely, anything could be counted and measured, but is it always productive to do so? This brings us to a second consideration that follows from the idea that quantification is a mode of translation. What it means to be extraordinarily corpulent in modern western society, or what it means to enjoy the richness of our natural surroundings, or simply the enjoyment of good food, may get lost in translation to numbers - and yet, these experiences matter to how we relate to obesity and biodiversity loss as public and political problems.

As Mundry (2009) has shown, the quantification of meals is a case in point: for more than a century, the United States Department of Agriculture has consistently framed the question of what is good food as a quantitative assessment: the quality of a meal is to be counted by calories, nutrients, vitamins, dollars, serving sizes, and food groups. The effect of that discourse, Mundry argues, is that the key understanding of good food has focused on health, rather than culture, tradition, taste and experience of the meal as a social practice. In this sense, quantification is a translation in which various experiences and meanings are standardized, reduced, set aside, or forgotten.

Where the importance of taste is at stake, numbers fall short on settling, accounting, judging, and managing. But other ways of reasoning may do the job as well. Mundry describes three alternative 
discourses that draw their resources respectively from history, geography and personal experience.

Historical discourses, to be found in cookbooks and food magazines, refer to culinary traditions, family histories, and memories in order to make authoritative knowledge claims about food quality. Geographic discourses - in particular on wine and cheese - rely on soil, region and season as indicators of good food, since these constitute 'an environmental fidelity to its place of origin'. Rather than trying to compare and standardize, they appreciate difference and locality. A third kind of discourse draws on taste as a personal experience. Restaurant reviews and gastronomy websites offer space to such discourses, assuming good food to be inextricable from conversation, education and advice about good taste. Here, idiosyncratic rather than standardized language is considered a sign of expertise (cf. Teil \& Hennion 2004). Mundry points out that these alternative discourses are able to articulate what cannot be expressed in the language of science, while making possible meaningful (dis)agreement nevertheless (see also Gronow 2004).

What remain blind spots to the quantitative discourse of food, then, can be articulated and evaluated by means of alternative discourses, enacted as a supplement to the quantified outlook. Does this imply (as Mundry suggests) that loose talk, common sense, idiosyncrasy and dialect should qualify for the public agenda? Not necessarily. Just as the quantitative sciences can make sense of the world by systematic and rigorous inquiry, so do the humanities and some of the social sciences. With the art of interpretation rather than calculation, they make sense of the meanings and values, purposes and interests, experiences and expectations that run through the problems of the human world. They have their methods, their checks and balances, their analytical tools and their uncertainties.

Grounded in the tradition of hermeneutics (see e.g. Gadamer 1960), a rich body of social research has been offering valuable insights into social and cultural issues. Biotechnology, juvenile delinquency, migration, euthanasia, traffic congestion, emancipation, animal protection, collective memory, waste management, digital piracy, cultural heritage, domestic violence, literacy, public surveillance and 
elderly care are but a few examples where effective public policy would be inconceivable if not informed by a critical understanding of the multiple meanings and morals we attach to these phenomena. This is where numbers don't speak for themselves.

I am fully aware that my argument touches upon a fierce and complex debate on what is (good) science - a discussion that deserves much more space than I can afford here (see Bernstein 1982, Rickman 1990, Dooremalen et al. 2007). Nevertheless, the basic point is that scientific communities have, next to quantification, many more resources to draw on to account for public problems, and that these resources may be fruitful supplements to quantification in offering guidance on how to deal with those problems.

\section{Publicity and the harm principle}

A second condition that a concern need to fulfil is publicity: that it appeals to values commonly recognized and shared by all of us; and consequently, that it (implicitly) proposes norms that, in principle, we all can agree on - no matter how different our experiences and perspectives of the world may be.

As I mentioned in the introductory chapter, the condition of publicity is also appropriate for describing all of the agenda conditions taken together, since each of them specifies what makes a concern into a relevant and appropriate issue fit for public consideration. Quantifiable concerns, for example, have the potential to make problems fit for public discussion and meet the condition of publicity in this general sense. Here, however, I discuss the publicity condition as a criterion for the evaluative, normative component of problem statements - simply because I don't have a better word for it. Swierstra and te Molder (2012) use the term valuation; that is indeed the relevant dimension but it does not yet constitute a criterion. Publicity in the specific sense here is a requirement for the kind of goods (moral, natural or otherwise) that we seek to advance or protect, implicitly or explicitly, by raising concerns and issues.

The condition of publicity is, roughly speaking, the legacy of liberalism as a political philosophy. It perceives the set of such values as quite 
minimal and tied to the protection of the sovereign and autonomous individual - in both his bodily integrity and his capacity to flourish. Liberalism is essentially restrictive, as it specifies what sort of values and norms may inform and justify our coercion over others. As Walzer (2007) has put it, key to liberalism is the art of separation: between private and public matters, or between civil society and political community. This type of demarcation is exactly at work where concerns seek access to and legitimate status on the public innovation agenda.

Although the liberal paradigm includes many strands and conflicting views, one of its cornerstones remains the harm principle formulated by J.S. Mill: 'That the only purpose for which power can be rightfully exercised over any member of a civilized community, against his will, is to prevent harm to others.' (1859). From a liberal perspective, the significance of this formula does not lie merely in the protection of individuals vis-à-vis the state per se, but becomes apparent in rejecting any other purposes and considerations a community might have in interfering with individuals. That is, neither particular conceptions of what the good life entails, nor any belief of how one should give meaning and substance to one's freedom, can justify acts of coercion on behalf of that community. The plurality of beliefs of what makes life worth living is thus warranted by the liberal threshold. This minimalist approach is also reflected in Rawls' insistence on the priority of the right over the good in evaluating the basic structure of society (Rawls 1993). This supposes a hierarchy of what is, and what is not absolutely necessary and inalienable for individuals to live as free and equal citizens.

Leaving the intricate arguments among liberals and their critics aside, we see that the harm principle and its minimalist approach towards the good life has gained a strong foothold in the innovation discourse of food and food technology. Regardless of how this principle and approach is interpreted, safety and security, as 'basic' values, enjoy a non-controversial and perfectly legitimate standing in public debate as well as in policy reports and techno-scientific accounts of food innovation. In a similar fashion, although probably to a lesser degree, concerns for sustainability, biodiversity and animal welfare have become serious issues on the public food innovation agenda - in the 
sense that they have been interpreted as direct or indirect instances of harm potentially inflicted upon those we consider to be morally relevant. Key to understanding the non-controversial nature of these issues - as legitimate public issues - is exactly the commonly shared conception of what is in the public interest and what concerns remain to be private.

The liberal enterprise of delimiting state power has, at least in modern liberal democratic societies, its foundation in a certain ideal of public reason. Rawls' conception of public reason prescribes that 'each of us must have, and be ready to explain, a criterion of what principles and guidelines we think other citizens (who are also free and equal) may reasonably be expected to endorse along with us.' (Rawls 1993). Where political responsibilities and rights are at stake, the public use of reason means to assume certain beliefs and values to be shared with those who are addressed, and that this assumption is reflected in the kind of concerns and arguments one raises. Concerns that would be informed by purely subjective and individual experience, then, have no place in the public use of reason in the sense that they cannot justify general laws, public policies or any sort of political-institutional design.

This liberal conception of public reason, or at least a rough version of it, is strongly embedded in modern democratic societies. Concerns that articulate cases of harm, or infringements of rights and liberties, easily capture public attention as they fit well into a restrictive conception of what the state can and should do. As far as concerns appealing to particular conceptions of the good life, or particular religious and metaphysical worldviews receive public attention as well, they are immediately recognized as exceptional, essentially private, and politically uncomfortable issues - as if they were matters of personal taste.

What does this common sense understanding of public reason make possible? In what sense are liberal restrictions productive? What is so powerful about the harm principle? Two kinds of stories can be told.

The first is the moral story. Liberal restrictions protect individuals from excessive, arbitrary and intrusive state power. It requires the state to respect individual liberties and rights by observing the 
public/private distinction and aims protects the plurality of substantive ideas of how one should live one's life. Essentially, the liberal stance advocates an organization of public and political life that recognizes all individuals as free beings with equal moral standing. The guiding principle of that organization is the public use of reason. It prescribes that individuals are subject to fair power structures that are shaped and justified by values and norms they can reasonably agree with. That is the standard moral account.

The second story is a pragmatic account. It highlights three major aspects of what liberalism can do for us. Firstly, liberalism relieves us of what Rawls has coined 'the burdens of judgment'. Suppose a free and pluralist society includes radically different and sometimes conflicting world views, but suppose also that all of us were reasonable human beings: why then couldn't we agree on the one, true view? Rawls gives several reasons for this. For example, even where we agree on the kind of moral considerations we have, we may disagree about their weight and their priority. Also we could agree on the moral and political concepts relevant to political judgment, but then we still would have different interpretations of these concepts. More generally, our moral and political judgments are always somehow shaped by our personal experiences of life, which in turn are never identical. 'Our individual and associative points of view, intellectual affinities, and affective attachments, are too diverse, especially in a free society, to enable [religious and philosophical doctrines] to serve as the basis of lasting and reasoned political agreement.' (1993: 58). These words suggest that trying to reach agreement on such fundamental matters would be a waste of time and resources. Such attempt would lead to moral deadlock and political paralysis: it would be senseless from the start. The liberal conception of public reason is a practical way of avoiding endless and useless debate.

Secondly, the restrictive nature of liberalism heavily relies on what Berlin (1958) has called the concept of negative liberty. This means that it emphasizes on what should not be done to the individual, rather than what needs to be done: whatever the individual chooses to do with his freedom, we need to make sure that he has as little constraints as possible. A similar negative approach is reflected in Mill's harm principle. To put it in classical utilitarian terms, in state affairs the 
reduction or avoidance of pain has priority to the promotion of happiness or pleasure. It was Popper who emphasized that pleasure and pain are not symmetrical: the promotion of happiness is 'much less urgent than the rendering of help to those who suffer, and the attempt to prevent suffering.' (1945, I 5 n. 6). As Swierstra and Rip explain, 'the underlying idea is that suffering is (...) also a somehow more objective or uncontested criterion than happiness.' (Swierstra \& Rip 2007). Although applying the concept of harm in concrete situations can be subject to fierce debate, the negative approach would make public and political debate much easier compared to the effort of reaching agreement on a positive goals. Negative goals are supposedly easier to define and less controversial. For example, citizens need to share some beliefs on what makes life worth living in order to agree on active state support of the fine arts. But the agreement that acts of murder should be prohibited only requires the belief that life is worth living.

Thirdly, the public/private distinction is shorthand for previously established conclusions on what deserves the attention of the state, what should be subject to political debate, what is vital to the common interest, what is a matter of collective responsibility, and so on; and what remains to be free from it. Like any conceptual distinction or demarcation, it can be considered as the solidified result of a long history of controversy, conflict, doubt, and trial and error. Although the exact meaning of the private/public distinction may be somewhat ambiguous and subject to different interpretations, in most practical and everyday cases it serves as a moral and political guideline, commonly recognized as something to rely on. The contrast between public and private is a highly effective and efficient commentary on what is my business, what is your business, and what is ours.

If moral pluralism and disagreement is the problem, the liberal conception of politics offers a solution that is both morally justifiable and pragmatically appealing. It seeks universally acceptable principles and procedures that justify what the state can and should do; and that guide public contestation and deliberation with regard to collectively binding decisions. Publicity, in this sense, serves as a marker for objectivity, neutrality, or fairness as organizing principles for coping with fundamental disagreement on what is the good life. 


\section{The limits of publicity}

The political liberal tradition has met, and tried to accommodate, powerful criticisms from communitarian, feminist, multiculturalist and neo-Marxist points of view. But even where liberalism is taken for granted, and accepted in its most basic and sketchy ideas, as an intellectual and ideological source it is not able to cover the full spectrum of considerations why matters of food safety, security, health, and sustainability would deserve priority over other values in public debate. Nor does it pretend to do so. The problem is not liberalism as such, but the narrow way it is interpreted and applied by many policy makers, technology developers and consumers.

What most liberal theories share is that they distinguish a sphere of discussion from a sphere of legitimate power. Mill's statement of the harm principle, for example, offers a solution where state power and the 'tyranny of the majority' jeopardize the individual's freedom of thought and expression, and the liberty of 'framing the plan of our life to suit our own character'. Should we think that our fellow citizen would be wrong somehow, acting against his own interests, or holding mistaken views, Mill argues, 'these are good reasons for remonstrating with him, or reasoning with him, or persuading him, or entreating him, but not for compelling him, or visiting him with any evil, in case he do otherwise.' Here, the crucial distinction appears between state coercion and civil debate. Mill rejects the use of force in the name of what we consider truth, taste, piety, or the good life; but he also points out that these matters should be up for public discussion. In fact, Mill argues that we even have a moral duty to engage in such discussion (IV, 4-5). His defence of the freedom of thought and discussion, then, does not only reject state interference but also highlights the importance of discussing what is true, good, right, tasteful and so on. For Mill, a fallibilist, the quality of our beliefs partly depends on the quality of public discourse, and the liberty of discussion warrants that quality. Hence, the central and coercive powers of the state must leave a sphere for free, vivid public discussion (Mill 1859).

Liberal democratic theorists like Rawls and Habermas have taken up Mills plea for defending that sphere. To be sure, the demarcation here is not between the private and the public; but between the sphere of formal political and legal institutions that govern through the state, and 
the sphere of informal discussions that do not directly result in collectively binding decisions enforced by the state. The ideal of public reason only applies to deliberations that lead to state coercion, and explicitly serves to legitimize such coercion. Although Habermas and Rawls strongly differ in their conception of the scope and substance of the public use of reason, at least both leave room for rich and vivid public debate on matters that do not necessarily live up to the requirement of public reason: matters of taste, religion, the good life, ethics. Both insist that the ideal of public reason starts where collectively binding decisions are made, and ends where such decisions play no role.

Whether the condition of publicity should apply to citizen concerns, therefore, depends on the sphere in which these concerns are raised. Rawls draws the line where fundamental principles prescribe the structure of legislation, administration, and jurisdiction. He suggests that 'the limits imposed by public reason do not apply to all political questions but only to those involving what we may call 'constitutional essentials' and questions of basic justice.' (1993). The ideal of public reason may put restrictions on the content and form of concerns to be addressed, but is itself restricted in its application.

A similar line is drawn by Habermas, who distinguishes the formal sphere of constitutional and political power (centralized around parliaments, governments, and courts) from the informal and 'weaker' sphere of public discussion. Whereas the first is a sphere of activities that aim at collectively binding decision-making, the latter is concerned with public opinion- and will-formation. Habermas emphasizes that the informal public sphere is and should be the sphere in which (not only questions of the right, but also) questions of the good are openly discussed, however controversial and contested they may be. Why? Because 'if we do not even present our different ethical views for discussion, then we cannot sound out the possibilities for reaching consensus through discourse.' (1996: 309). In other words, Habermas argues, what grounds do we have to assume the impossibility of agreement on questions of the good life, other than the experience of public deliberation itself? If Rawls' claim of the 'burdens of judgment' is correct, we are to find out by means of public discussion, testing it over and over again, case-by-case. This is what Habermas (1995) means by 
claiming public reason to be 'open-ended': that it may be endless doesn't make it meaningless.

Certainly, there are many objections to raise against the idea of artificially separating the informal sphere of public discourse from a more formal one. But they do not touch upon the central point here: the condition that citizen and consumer concerns face in public discussions - that they appeal to values commonly recognized and shared by all of us - cannot be justified even by a liberal political philosophy.

The priority of the right - or at least some principle of neutrality with regard to contested conceptions of the good life - may be valuable and useful in those situations where collectively binding and legally enforced decisions are made; but when generally called for in public discussions, it unnecessarily frustrates the quality of public discourse, in its richness and depth. Such call reflects a narrow focus on the political aspect of public discourse, and a narrow interpretation of the political as the making of laws, regulations and policies. I would call this anticipatory liberalism. The anticipation of formal political and legal procedures, lurking in the background as a form of conversational (self-)censorship, offers a poor repertoire for discussing concerns.

The flipside of such anticipation is the retreat to the private sphere: what cannot inform and justify the powers of the state would by the same token be left to private considerations. Concerns of the good life and matters of taste are thus labelled as themes that are not qualified for political regulation, and implicitly denied access to the public sphere all together. As Habermas points out, the tacit but odd assumption in this (anticipatory-liberal) line of reasoning is that fundamental liberties and rights would be under attack as soon as any of these concerns become public issues: 'Making something that so far has been considered a private matter a topic for public discussion does not yet imply any infringement of individual rights. (...) To talk about something is not necessarily the same as meddling in another's affairs.' (1996: 313)

What is overlooked, then, in this dichotomy of state affairs versus private affairs, is the potential of the public sphere as a set of argumentative practices that go in between. We lose sight of the broad 
spectrum of deliberative tools that the public sphere has at its disposal, apart from political demands and legal claims: to doubt and ask, to instruct and advise, to teach and learn, to support and appreciate, to provoke and experiment, to show and tell, to imagine and suggest, to identify and remember, to protest and negotiate. In its extremity, we would forget how to hold each other and ourselves accountable for our ideas, our words, and our actions. We would forget how to disagree and how to change our minds. Deliberative democratic theorists have pointed out the political and intellectual importance of this public sphere for well-functioning democratic societies (Dewey 1927; Habermas 1996; Gutmann \& Thompson 1996; Dryzek 2000).

Indeed one could maintain, as a liberal, that public debate allows for a more diverse set of concerns but that Mill's harm principle still applies as soon as state intervention comes to view. The prevention of harm as a negative goal would still count on a broader moral agreement. Yet, a few considerations make this position quite problematic. It is simply not true that the harm principle reflects a purely negative good and does not draw upon any positive, substantial notion of what makes life worth living. Once we start invoking the concept of harm in moral, legal and political controversies, it turns out to be hard to draw the line.

For a number of questions we then need to fall back on broader and less unambiguous notions of what is most significant to us. What do we take for harm? Death and injury? For sure. Loss of (potential) profits, property damage, theft, corruption and abuse of power? Probably. Plagiarism, fraud and deception? Damage of reputation, misrecognition, offensive talk, discrimination, hate speech? Perhaps. Indirect harm? Potential (but not currently existing) harm? Harm to future (but not currently existing) generations? Harm to non-humans, such as animals, or humans-to-be? Harm inflicted upon 'our way of life'? Corruption of the youth? Structural violence? Propagation of an unhealthy life style? It depends. Not only on what we want to prevent, but also on what we seek to promote (Skorupski 2006; see also Taylor 1979).

That the concept of harm is not as clear-cut in certain contexts does not mean it is of no use to the articulation of real-life problems. It does mean, however, that the concept requires interpretation of a wide 
range of facts and values - only some of which we seem to agree on. Public and political debate (like the judiciary) is a way to settle the question whether certain issues indeed qualify as cases of harm. Who invokes the principle of harm as a criterion for legitimate topics on the public innovation agenda only implies that such debate has been settled already.

In more general terms, such an appeal to the harm principle implies that a settlement has been achieved about the line between private and public affairs. As I have argued in Chapter 2, however, this line can be subject to continuous debate - in the sense that specific concerns may actually have the function of drawing public attention to what is wrongfully considered as a private concern. Domestic violence against women, for example, was long considered a private affair. Eventually, it was recognized as a public issue, but not before a feminist minority was able to publicly articulate their concern as a systemic injustice that requires the attention of the polity. It shows that the division of private versus public concerns is subject to change - and sometimes for the better. The distinction is historical and man-made, not 'natural'.

So a concern can pose itself as a candidate for public attention; and refuting its candidacy for the reason that it would be a private matter $a$ priori does not make any sense. It suggests that there would be no room for new and changing moral and political insight. Nor would it be fair according to democratic standards, as Fraser (1990) points out: 'democratic publicity requires positive guarantees of opportunities for minorities to convince others that what in the past was not public in the sense of being a matter of common concern should now become so.' (1990:71). A democratic society requires that in the end, through contestation, citizens rather than naturally given distinctions decide what topics and problems count as common concerns.

In a pluralist democratic society, the condition of publicity is valuable but tends to do its job too well in the public discourse of food technology and innovation. Concerns about impacts on the decay of taste and the degeneration of our food culture, for example, are too easily dismissed as private matters and too often labelled as subjective, moralistic or paternalistic. In light of the liberal tradition, it is hardly surprising that such concerns are associated with religious affairs: they 
are to be tolerated, but expected to stay away from the sphere of state power. Anticipatory liberalism, as an incomplete but popular interpretation of the ideal of public reason, forestalls any public discussion on good food, good taste and how these can contribute to a life worth living.

\section{Causality: causal stories and responsibilities}

A third condition for a concern to gain access to the public innovation agenda is that it articulates the problematic situation as a consequence, and in particular as a consequence of which either human behaviour, or the technology clearly is the cause. This is the condition of causality.

To see why this point is perhaps not as trivial as it seems, consider the distinction commonly drawn between causal responsibility and moral responsibility. The first perspective focuses on empirical investigation of causes and consequences as part of a causal chain; the second, normative perspective focuses on the investigation of who is guilty, liable or can be held accountable for the course of events. As an agenda literally implies a set of issues that need to be taken care of, the underlying idea is that such issues should say something about who is expected to take care of them, or should have taken care of them. Before such moral (or otherwise normative) responsibility is to be asserted, it seems only fair to start with empirical investigation: why would one accept responsibility if a causal chain of events is not established in the first place? The basic idea, thus, is that causal explanation should be prior to the attribution of moral responsibility.

But what counts as a good causal explanation? There are three answers to that.

The first answer is that a causal explanation must restrict itself to relevant factors, in the sense that they rule out trivial and obvious affairs. That is, causal explanation is a vital part of problem solving, presuming that removing, adding, or altering causes can change a problematic situation. However, in theory, the sequence as well as the scope of causes leading to an event (say, an accident) can be endless. For example, if I happen to fall from slippery stairs while being absentminded, what has caused my falling? The fact that the stairs were 
slippery, caused by the fact that someone had just cleaned them? Is it the fact that I was absent-minded, caused by the fact that I had an important deadline to meet, which in turn was caused by the impatience of my employer? Or perhaps the fact that there was no warning sign? Or was it gravity that made me fall? From a set of innumerable phenomena, then, roughly speaking, we can select decisive or contributory causes, isolate them from necessary or sufficient conditions, and from irrelevant circumstances.

As Meyer (2000) has convincingly argued, the attribution of causes is a situation of articulating relevance. 'For all practical purposes, we are content with much less than a listing of all the conditions, regularities, probabilities, and laws of nature that account for the event in question. A satisfactory explanation, in fact, is not one that lists all this. A satisfactory explanation is concise and concentrates on one or just a few causes.' (2000:12). What counts as relevant depends on the specific situation in which causal explanations are asked and given. In this sense, causal attribution can be understood as a social and discursive phenomenon. Only in the light of specific human interests, in a specific context, can factors be relevant and causal explanations satisfactory.

So what counts as relevant? According to Searle (1969, as quoted in Meyer 2000), one aspect of good explanations is that it highlights the unexpected or extraordinary part in courses of events. In the previous example, it makes sense to point out that I was absent-minded, but not that the law of gravity did its work, since the latter is, in normal circumstances, quite obvious and taken for granted. But if it were common knowledge that I have always been absent-minded, and that I never fell before, we might consider my dreaminess as part of the normal circumstances and look for another cause in order to offer a satisfactory explanation. Relevance is thus defined by what we take for an extraordinary event against the background of what we perceive in a particular situation as normal and trivial.

So successful articulation of a problem requires the attribution of a cause. The stronger the link between cause and consequence, the better the chances for concerns to gain access to the public agenda. This strength appears where the surprising or extraordinary factor is clearly highlighted from the normal course of events. 
A second answer is that causal explanations highlight relevant factors, in the sense that they point at those factors we can change. That is, relevance becomes even stronger where human agency is clearly part of the causal explanation. Here, insights from political sociology are instructive. Stone (1989) has pointed out that drawing clear causal connections is a process of transformation: causal stories render difficulties into real, that is, commonly recognized, problems. In discussing the kind of causal stories needed for more or less political attention, Stone points out that where actors try to present their difficulties as candidates for public attention, they usually shift the problematic situation from the realm of nature, fate and accident to the realm of human agency, purpose and control.

Stone distinguishes two axes along which such shift occurs: the extent to which the problematic consequence was intended by some actor, and the extent to which the events resulting in the consequence are directly linked to human, deliberate actions (see figure 3.1).

\begin{tabular}{|c|c|c|}
\hline & Consequences & \\
\hline Actions & Intended & Unintended \\
\hline Unguided & $\begin{array}{l}\text { MECHANICAL CAUSE } \\
\text { intervening agent } \\
\text { machines } \\
\text { trained animals } \\
\text { brainwashed people }\end{array}$ & $\begin{array}{l}\text { ACCIDENTAL CAUSE } \\
\text { nature } \\
\text { weather } \\
\text { earthquakes } \\
\text { machines that run amok }\end{array}$ \\
\hline Purposeful & $\begin{array}{l}\text { INTENTIONAL CAUSE } \\
\text { assault } \\
\text { oppression } \\
\text { conspiracies that work } \\
\text { programs that work }\end{array}$ & $\begin{array}{l}\text { INADVERTENT CAUSE } \\
\text { intervening conditions } \\
\text { unforeseen side effects } \\
\text { neglect } \\
\text { carelessness } \\
\text { omission }\end{array}$ \\
\hline
\end{tabular}

Fig. 3.1: table taken from Stone (1989): A typology of causal explanations

In Stone's typology, intentional causes refer to human actions that are taken, willingly and knowingly, for bringing about the consequences that actually occurred. Inadvertent causes are those human actions that, 
although purposeful and perhaps well intended, were taken in neglect or ignorance of the full consequences: with hindsight, not all of the conditions of the action were taken into account. These are causes with unintended or unforeseen consequences. The upper two boxes refer to unguided actions. In fact, accidental causes are no actions at all, but mere events. They are causes that no human could possibly control, and happen without any purpose. Mechanical causes are those causes with consequences that were intended and foreseen, but the occurrence of which are not directly controlled. As Stone admits, these categories are rough distinctions with gradual boundaries, but they help to make clear along what dimensions issue advocates tend to shift.

Most importantly, these categories say something about blame. Usually we don't really blame anyone for earthquakes to happen (accidental cause). It is only a bit easier to blame traffic planners for putting traffic bumps in very inconvenient places (mechanical cause); and it is perhaps equally appropriate to blame motorists who forgot to fasten their safety belts (inadvertent cause). But blame will strike hard when someone hit me in the face, knowingly and willingly (intentional cause).

The better narratives are able to identify and highlight human intentions as the direct cause of problems, the stronger their case will be for mobilizing legal or political action. Conversely, where stories frame problematic situations as unfortunate accidents, and attribute causes to random, unpredictable and inevitable events, they implicitly reject political or legal interventions since no responsibility can be taken for the causes.

Stone has demonstrated that many disputes involve proponents who frame problematic situations as consequences that can be or could have been prevented versus opponents who try to emphasize the inevitable and unchangeable.

But this scheme also reveals a third answer to the question of what makes a good causal explanation. It shows that two extreme and opposite types of causal stories dictate the tension: the realm of intentional and direct action versus the realm of the unintended and uncontrolled. What both types of stories have in common, is that 
causes as well as responsibilities are clear and unambiguous. Nature and technology outside us cause the problem; or humans among us. The other two categories lack that kind of clarity. Mechanical and inadvertent causes are fuzzy: they are part of stories in which humans are only partly the cause, and only partly responsible, since their actions are interfered, mediated, and transformed by other agents and circumstances that are somehow out of sight or out of control. The binary opposition of outside us versus among us helps us in clearing up the fuzzy causes and require that we disentangle them.

This means that concerns that seek access to the public agenda are expected to identify and isolate human agency as a clear and distinct cause. Conversely, stories in which machines or other technological artefacts are assumed to constitute the problem, are likely to fail in gaining access to the agenda, since such causal stories are either politically irrelevant - human agency is lacking - or ambiguous and blurry - i.e. not living up to the requirement of clarity.

These three requirements of causal explanations prevent us from investing public attention and resources on trivial affairs: matters that we can't do much about anyway. Also, they tend to ignore causes that are too fuzzy to even disentangle. Taken together, they specify the more general belief that causal responsibility precedes moral responsibility.

\section{The problem with causal stories}

The general belief that causal responsibility is prior to moral responsibility implicitly relies on the idea that descriptions go before normative judgments, or that we should get the facts straight before we can assign moral responsibilities. A study by Gusfield of the discourse of drinking and driving (1981), however, shows that sometimes this is not the case in fact, and more importantly, that the idea is quite problematic in itself.

The selection of data, for example, for a 1977 US safety council report on road accidents already implied who was morally responsible and what kind of actions needed to be taken if traffic accidents were to be diminished. The driver's actions prior to the accident, as well as the 
driver's sex, age and drugs or alcohol use were indicated as relevant facts; the type of road and vehicle were mentioned, as well as the time and place. Gusfield remarks that so many other factors remained invisible from this account: there was no mention of the age and weight of the vehicle, the presence of safety belts and protruding objects in and on the car, the specific road design, the distance from the accident to emergency facilities, and where the driver was coming from, and his destination. They were simply not reported in the first place.

The collection of such facts, Gusfield contends, has led American policymakers and public opinion to focus on irresponsible driver performance as the major cause of car accidents: 'Holding the motorist politically responsible seemed 'normal' and 'natural'. It met prevailing concepts of fault traditional in American law. It was congruent with the desires of the automobile industry to avoid safety as a major consideration in the design of cars'. (1981: 45) Until the late 1960's, the careless or incompetent driver was the primary object of attention and gave rise to certain legal and policy measures, aiming at the irresponsible driver. Only later would the attention shift to 'unsafe cars' and 'unsafe roads' - an indication that car manufacturers and the government got a (larger) share in the social distribution of responsibilities.

Two lessons can be learnt from Gusfield's study. First of all, facts can be instructive and guiding in attributing moral responsibilities, but the act of reporting and selecting them in presenting a causal story may already suggest - intended or not - some attribution of moral responsibility in the first place. In the example of road accidents reporting, car manufacturers, traffic planners, or even bartenders were supposed to be morally irrelevant in the first place, so why look at their roles? Normative presuppositions, then, precede mere description.

A second lesson can be drawn, with respect to the idea that trivial and obvious elements -the 'normal state of affairs' - cannot be part of a satisfactory causal story. In the example discussed by Gusfield, the design and performance of automobiles as technological artefacts were not taken into consideration, just as the broader traffic and emergency infrastructures remained unquestioned. In this image, they constitute the trivial background against which the problem of accidents occurs. 
Where technological artefacts are entrenched in daily routines of human behaviour, or assume invisibility as they become part of infrastructure, they are easily considered trivial as long as they 'work'; as long as they do what they are supposed to do.

There is something specific about our view of technology that makes it easy to consider it part of the normal state of affairs - and thus leave it out of the causal story: this will be discussed in the next paragraph. But at least the invisibility and trivialness of technology points at the difficulty of directing one's attention to it and suggesting that technology may in fact be part of the problem, rather than the background of it. Also, it means that perhaps there is no particular $a$ priori reason for rejecting technologies as relevant causes, other than the fact that we then would have to start with the tedious and complex task of opening up and questioning the larger context of agency. The general principle that the trivial and obvious things cannot be relevant causes of a problem, then, still stands; but it doesn't say what we should consider part of the ordinary state of affairs. Another way of stating this: what doesn't surprise us could still be the cause of a problem.

Two other beliefs that could justify the condition of causality need to be addressed: the idea that technologies are mere instruments, not agents; and the idea that human actions must be clearly distinguished from the material conditions and circumstances that may influence them.

I have argued that concerns have a better chance at getting access to the public innovation agenda if they express intended and purposeful behaviour as the direct cause of problems. This makes sense, considering that human agency is something that can be subject to responsibility attribution and also something that we can change. The implication of this idea, however, is that technologies easily get out of sight as candidates for direct causes of problems that require our collective attention. It suggests that technological objects are merely neutral instruments that, in themselves, do not exert any influence on the social world which these problems are part of. They only do so in the hands of free agents who decide what to do with them. Yet, this suggestion has been forcefully contested by STS scholars and philosophers of technology (Akrich 1992; Latour 1994; Achterhuis 
1995; Verbeek 2005) who emphasize that many technological artefacts invite or inhibit certain roles, decisions and actions in humans who work with them. They 'mediate' in the sense that they offer specific options, competences, goals or expressions that would not be available to humans without them. Some of these are unintended, unforeseen, or out of direct control. Surely, technologies 'work' if they do what they are supposed to do, but they also 'work' beyond their distinct functionalities: they interrupt - for better or worse - in how humans interact with each other and the world around them.

In drawing on Latour's mediation theory, Verbeek (2005) offers a simple example of 'what things do'. Over the past decades, the microwave has proven able to change human eating habits, including the social relations within family life. 'The microwave facilitates a particular kind of meal, the frozen, ready-made kind that can be 'prepared' in a short period of time and for a single person. It promotes such meals amongst its users, thus fostering a change in eating habits in which fewer are taken in company and more are eaten solo.' (2005: 6) The crux of this example is that technologies (the microwave as an artefact, but also those technologies that enable the production of ready meals) actually have the capacity to intervene and influence the domain of human agency. They are more than instruments, since they are able to suggest, modify, or compromise our goals and plans.

Yet, if one would perceive the ever-growing practice of eating in solitude, as quick as possible, as a serious problem that deserves public attention, it would still seem preposterous to blame the microwave for it. First of all, because intuition tells us that inanimate objects cannot be subject to reactive attitudes (such as blame or praise) at all (Strawson 1963); but more importantly, because such complaint would deny consumers or citizens the freedom to decide and act according to their own interests and goals. After all, the typical couch potato is not forced to use or even purchase a microwave - at most he is only invited or seduced to do so (cf. Borgmann 1984). For this reason, it also doesn't make sense to blame the engineers who developed the microwave, or the chemist who gave birth to the frozen meal.

Here the belief that human actions must be clearly distinguished from the material conditions and circumstances that may influence those 
actions becomes relevant. This idea touches upon the philosophical problem of free will and determinism - which goes back at least to Aristotle's discussion of human agency in the Ethica Nicomachea. Verbeek's mediation theory takes a firm position in between the view that genuine human actions are completely free from any forces, and the idea that actions are completely determined by forces external to the human actor (one could add: even forces internal to the human actor). Invoking Foucault's conception of freedom, Verbeek argues that power and freedom are not opposites: only by critically engaging with the forces that shape one's subjectivity, one can be free. Freedom is an activity in the midst of powers, not an end state in which external forces are absent (Verbeek 2011:73).

This makes sense if we compare the role of mediating technologies with the influence of our friends, colleagues, family members, and neighbours. We can grant their influence on our perception of goals without necessarily denying our own freedom of action. The example of the microwave shows that technologies may invite or inhibit certain eating habits: it doesn't force us to eat in solitude, as it isn't a direct physical cause sufficient in and of itself, but neither does it remain completely inactive and neutral. In this case, mediation theory suggests, it's an association of humans and technological artefacts that acts and brings about changes in the pattern of family life. In Stone's typology of causes, such associations fit well into the domains of mechanical and inadvertent causes (depending on whether you would consider the technology as respectively 'intervening agent' or 'intervening condition') - indeed, the fuzzy ones.

Does this all mean that responsibility cannot be attributed at all, where a collective of things and humans appear the principle actor? Isn't this exactly the reason why we should keep away from this fuzzy image of mediated agency? Not necessarily. At this point it makes sense to distinguish between different meanings of responsibility. Van de Poel et al. (2012) argue that we can attribute responsibility for very different reasons - and blame is only one of them (see figure 3.2). For example, someone is (held) responsible not because he knowingly and willingly caused a wrong in the past (blame) or because this wrong needs to be compensated (liability); but because he is expected to maintain or prevent a certain state of affairs in the future (obligation) 
or because he conceives of himself as someone who should promote a particular kind of behaviour suitable to the circumstances (virtue).

\begin{tabular}{|l|l|l|}
\hline Sense of responsibility & Function of attributing responsibility & Perspective \\
\hline Blameworthiness & Retribution & \multirow{2}{*}{$\begin{array}{l}\text { Backward- } \\
\text { looking }\end{array}$} \\
\hline Accountability & Maintaining moral community & \\
\hline Liability & Justice to victims & Forward- \\
\hline Obligation & Efficacy & \\
\hline Virtue & Due care to others
\end{tabular}

Figure 3.2: Table taken from Van de Poel et al. (2012)

Van de Poel et al. argue that the conceptual distinction of the five senses and functions of responsibility is especially helpful where 'the problem of many hands' occur, i.e. where collectives (such as organizations or society as a whole) bring about a problematic situation that is not necessarily causally reducible to the actions of each individual in that collective. The fuzzy situation of many hands is only morally problematic where the attribution of responsibility cannot fulfil the intended function.

If we consider an association of technological artefacts and human actors to cause a many hands problem, and grant that some of these hands are not human at all, we may not be able to assign blame and organize retribution at all. Also, accountability for past mistakes may turn out to be quite problematic. To account for past mistakes and injustices is neither impossible nor undesirable (on the contrary), but the point is that the difficulties that come with backward-looking responsibilities are not necessarily the ones that prevent us from discussing forward-looking responsibilities.

Where the public innovation agenda concerns the collective attention to new and emerging technologies, a forward-looking approach of responsibility is likely to be more productive. Improvement of 
technology-society interactions requires a deeper understanding of the kind of mediations that occur, but not necessarily the detailed and exhaustive causal explanations required for questions of blame and justice. Also, the question who has what capacities to cure the problem becomes more relevant than the sole question who or what caused it (Miller 2001).

Consider, for example, the growing concern for the obesity epidemic: one of the key issues in public debate is about who or what is responsible (cf. Lawrence 2004). One could point one's finger at the convenience foods industry for making unhealthy food products and marketing them aggressively. Food manufacturers, in turn, suggest that food products are not unhealthy; consumption patterns are. And others see a more structural problem, pointing at the material and social surroundings that pose a continuous seduction to those who tend to overeat: in our society, food is everywhere and always available. From a forward-looking perspective on responsibility, the food industry may be held responsible, not because their products would have caused the problem in the first place but because they could be in the position to change the tide.

This would still mean that we entangle the fuzziness case-by-case - not in order to blame, or to do justice to hypothetic or real victims - but in order to suggest better technological design, to gain better insight of the mediations involved, and to discuss what we can and should expect of all stakeholders involved with food innovation - including consumers - and the technologies that surround them. The alternative is to ignore this fuzziness and to leave responsibilities untouched; or simply presume that the 'end user' will be fully responsible in all cases. The consequence of such ignorance is that we loose sight of an important aspect of modern technological society - mediation - and that we fail to do justice to a reality in which consumers and citizens, producers and engineers are immersed.

\section{Conclusion}

To sum up, the three conditions of the public innovation agenda have important functions to fulfil and can be grounded on a fairly consistent set of ideas. Quantification and measurement are acts of 
transformation that helps representing a problem and making it manageable. It is a depersonalized way of holding each other accountable and settling disagreements. Anticipatory liberalism helps sorting out what kind of concerns would be legitimate candidates for policy and legislation: it instructs us to propose only those rules of societal coordination that can reasonably be agreed upon by any of our fellow citizens. And if concerns about the societal impacts of technology cannot provide clear causal explanations for the problem they try to articulate, then indeed it is hard to see who or what is responsible for it and why we should care.

Holding accountable, settling disagreement, proposing rules of societal coordination and attributing responsibility; such functions are typical of what matters when things become public issues. The three conditions of publicity (in the general sense of the word) can be regarded as filters, or sluices if you will, that apply whenever concerns are raised. Their 'work' is the purification of what is worthy and meaningful of being 'public'. These conditions, taken together, surely do not provide an exhaustive explanation for why some concerns do, and others do not gain access to the public agenda. But they are necessary conditions: in the public discourse of food and food technology, it seems impossible that a particular issue would be subject to public deliberation, while the very same issue failed to meet any of these conditions.

However, I also hoped to show that all of these conditions have their limits. In keeping these conditions in place, there's a price to pay. Vital aspects of our relation to food - those that pertain to how citizens would like to enjoy the preparation and eating of food - remain below the public radar.

We overlook the qualities that are not (yet) captured in numbers, such as good taste, the value of history and tradition, the pace at which we cook and dine, and company at the dinner table. The experience of our food culture cannot be fully captured in numbers, but parts of it can be collective none the less. On the other hand, it may prove useful to render certain food practices into numbers in order to make problems visible (e.g. the average number of hours that American citizens spend on dinner or the percentage of Dutch households that have more than 
three family dinners per week in comparison to twenty years ago). Yet, measurements do not say much if not preceded and accompanied by considerations about the meaning and significance of such practices. This still invites for an open confrontation and evaluation of interpretations. Narrowing down the public food innovation agenda to measurements and numbers is not going to help opening up that discussion.

Furthermore, we miss the opportunity to publicly discuss qualities of food that are considered by many as elementary to the experience of food, such as taste, authenticity and naturalness, with those who take part in reshaping that experience. As such concerns are easily delegated to the realm of the private sphere, we miss out on public considerations that may result in fruitful alternatives to the anticipation of legislation and policymaking. Anticipatory liberalism prevents us to reconsider the boundary between private concerns and legal and political issues by short-circuiting the sphere of public deliberation. It denies us the possibility of finding out that, perhaps, there can be dispute in matters of taste; and of exploring conceptions of the good life about which we can, in fact, meaningfully disagree.

Also, we fail to do justice to the reality of living in close connection with technologies that have been shaping our food habits for years and many to come. As long as we tend to believe that either technology outside us or humans among us are causally responsible for any problem, and clear causal explanations need to be given first, it seems impossible to publicly attribute and manage responsibilities for how food is produced and consumed. Responsibility is mistaken for blame, and fuzzy human-technology interactions are instantly delegated to the responsibility of the citizen-consumer who will have to find a way in negotiating the seductions and inhibitions of food technology. A blind gap keeps us from publicly exploring and investigating how to organize responsibilities for mediated impacts of food technology, and which of these seductions and inhibitions are actually acceptable or even desirable.

The three conditions taken together make up for what Swierstra (2011) has coined the soft/hard impact distinction. It is a persistent and rigid distinction that runs through the very foundations of the 
discourse of food technology and innovation. It is a conceptual distinction in the sense that its substance is made of beliefs. These beliefs can be identified, described, analysed and evaluated; in terms of consistency but also in terms of what work they do for us. If they no longer do a good job, and the distinction has become a dichotomy too rigid for us, we have good reasons to start thinking and talking differently 


\section{Growing concerns. The career of food sustainability as a hard issue}

In the previous chapter I have argued that three conditions are predominant thresholds in the construction of the public food innovation agenda: concerns that seek public consideration and attention need to be quantifiable, should appeal to publicly recognized values, and must offer a clear causal story in which technology has a distinctive role. Also, I have argued that while there may be fair reasons for holding on to these agenda conditions, the validity of these conditions is somewhat restricted and based on a too narrow view of science, politics and technology. Also, it comes at a price. The price is that certain food concerns remain below the public radar while they are potentially important issues that touch upon vital aspects of our relation to food. This may explain the rather troublesome and fragile relation of trust that consumers and citizens experience with regard to food technology and innovation.

Taken together, these conditions constitute an implicit distinction between hard and soft concerns. We have good reasons to give up the soft/hard distinction - at least for how it currently gives shape to public discussions on food technology and innovation: apart from theoretical objections against the positivist, quasi-liberalist and instrumentalist worldviews underlying this distinction, it simply obstructs a meaningful and fruitful dialogue on good food and good food technology. As such, it poses a serious obstacle to relations of trust between citizen-consumers and food technology developers.

The soft/hard distinction is a theoretical construct: it serves to make the implicit hierarchy of concerns more visible and subject to critical discussion. While actors themselves may not use the terms 'soft/hard' to justify this hierarchy, it does touch upon more conventional oppositions that many actors appeal to in discussions on food (and) technology: public/private; objective/subjective; clear/vague; strong/weak; real/imaginary; and rational/emotional. 
I suggest that we conceive of 'hard' and 'soft' as rudimentary classifications that implicitly follow from the degree to which a concern is considered to meet any or all of these three conditions.

Concerns are not hard in and of themselves, but implicitly labelled as such as they tend to meet most of the three conditions to a large extent. Take concerns about food safety as an example. The effect of technological innovations on food safety is commonly considered a hard concern, in the sense that safety standards are highly quantified (e.g. acceptable daily intake) and that they concern the integrity and health of the human body (health) as an uncontested moral value. Although causal stories about negative health effects do not only feature technological artefacts (e.g. fast food causes obesity) but also individual eating behaviour (one should consume moderately and with variation), food laws and regulations suggest that food products as such may have serious negative health effects that can and ought to be avoided. This makes the causal story relatively clear-cut, while there still is some room for debate about specific responsibilities.

Taken together, this line of reasoning - and nothing else - is what makes food safety a hard issue.

Concerns about e.g. naturalness, on the other hand, typically score low on the three parameters. To claim that naturalness is a soft concern, therefore, means nothing more than implying that it is not quantified and probably not quantifiable; that no publicly recognized values are at stake; and that there is no clear causal story to be told in terms of the effects of food technology. Thus, 'soft' and 'hard' can best be understood as constructions, shorthand descriptions, rather than intrinsic and essential properties of these concerns. To be sure, this constructivist perspective on concerns does not make an issue any less real or serious. Also, it does not follow that all concerns are equally relevant. It only specifies what we mean when we consider concerns as 'hard' or 'soft'.

If we are looking for a way to give concerns generally regarded as 'soft' a fair opportunity to gain access to the food innovation agenda, this is an important thing to remember. 


\section{Food sustainability}

The constructed nature of hard/soft becomes even clearer when we take a closer look at a relatively new issue on the food innovation agenda: the concern for sustainable food. This concern (or rather: set of concerns) is rather ambivalent when it comes to its hardness. The following discussion will serve as an illustration of the idea that 'soft' and 'hard' are labels that rely on a multi-dimensional, gradual judgment, and also can be seen as both the result and the starting point of a public search for numbers, common values, and causal stories. Far from presenting an empirically exhaustive case, it broadly highlights what kind of challenges food sustainability as a growing concern had (and still has) to face in order to gain its full recognition as a serious food issue.

In the Netherlands, concerns about the environmental effects of economic and technological systems have been around in public, policy and research agendas for at least fifty years. Carson's Silent Spring (1962), on the detrimental effects of pesticides on the environment, proved to be an important document to scientists and environmentalist groups concerned with industrial and agricultural pollution issues, but much more influential was the 1972 report Limits to Growth which projected that global natural resources would not be able to keep up with the growth of population and economic production (Cramer 1989). With the report Our Common Future (Brundtland 1987), the concept of sustainable development was successfully launched as a prominent, well-recognized global need.

Only in the last five to ten years, sustainability of the food supply chain has become a legitimate, almost self-evident issue on the agendas of a broad variety of NGOs, national and international governing institutions, academic and industrial researchers, engineers and corporations (Van Otterloo 2012). Not only as a serious (set of) problem(s) to be investigated, but also as a drive for assigning and accepting social responsibilities (see e.g. FNLI 2008, FNLI 2010, TIFN 2009, LNV 2009, Topsector Agro\&Food 2011, CBL 2011, Nationale DenkTank 2012, Alliantie Verduurzaming Voedsel 2014). 


\section{A common ground for sustainability}

One of the conditions for the public food innovation agenda is that a concern appeals to values commonly recognized and shared by all citizens and consequently, that it (implicitly) proposes norms that, in principle, all of them can agree on - no matter how different their experiences and perspectives of the world may be. In short, it requires a minimum of common ground. The harm principle (as discussed in Chapter 3) specifies the most common understanding of this minimum. It suggests that the prevention of 'harm' inflicted upon others is a good, if not the only, reason for state intervention. What it also seems to prescribe (but not according to a more critical understanding of the principle, of course) is where to draw the line between private and public affairs.

Back in the 1960's, environmental concerns failed to meet that condition, at least in the sense that there was no evident broad consensus that these concerns would indeed be matters of public concern. In Cramer's historical description of the environmental movement in the Netherlands, she points out that until the end of the 1960 's, environmental matters of concerns were hardly recognized as a public affair, at least not in the parliament: 'political parties paid little attention to the environmental issue. In none of the political election programs it was a central point of concern, apart from that of the Pacifist Socialist Party (PSP). ... Bram van der Lek, then PSP representative in the parliament, remembers that his interpellation on the death of owls due to the use of pesticides caused great hilarity and was not taken seriously at all.' (Cramer 1989: 20). In most Western countries, it was not before the 1970's that the environmental movement, and its focus on food production and consumption, was actually able to draw widespread, public attention to their cause (Van Otterloo 2012).

In retrospect, one of the most obvious reasons why sustainability of the food supply chain now does appear on the public innovation agenda would be that most, if not all stakeholders 'discovered' that certain effects of current modes of food production and consumption are cases of harm that ought to be prevented. But to what extent does this conclusion really reflect a widespread agreement on the nature of this harm? Does the mere fact of harm provide sufficient common ground? 
(See, for example, Lin 2006 for an extensive discussion of the concept of harm in environmental law). It is far from clear for what reasons multiple stakeholders are concerned with sustainable food production in the first place; what values and interests they do share regardless their differing worldviews. Not long after the Brundtland Committee introduced its now widely quoted definition of sustainable development, critics have pointed at the vague and non-committal character of the concept. According to Richardson (1997), 'sustainable development is a political fudge: a convenient form of words,(...) which is sufficiently vague to allow conflicting parties, factions and interests to adhere to it without losing credibility.'

Even where roughly three kinds of sustainability can be identified, i.e. social, economic and ecological (Goodland 1995), still many different values, norms and ideals can be invoked for the justification of sustainability as an issue, and a conceptual distinction of three kinds does not take away the conflicts and tensions inherent to the concept. That is, some consider sustainability from a biocentric point of view, arguing that sustainable development is needed for the qualitative well-being of human and non-human life on Earth, and the intrinsic value of our natural environment, even if this means that the North will have to lower current standards of consumption. Others regard natural resources in a strictly instrumental way and take the sustainability approach for a way of thinking how industrialized societies can increase their level of production without running out of fuel in the long run. For some, sustainability is eventually an issue of food security, whereas others conceive it as essentially a matter of global justice. Sustainable food production can imply the call for more efficiency and long-term cost reduction in the current food supply chain, but it might as well indicate the need for a minimal set of decent circumstances in which humans and animals can function sufficiently.

So even though food sustainability appears to many stakeholders to be a hard issue, it does host a diversity of normative orientations that do not necessarily go hand in hand. To see why this is relevant, consider the very efficient way that chickens are usually grown in modern supply chains: more efficient ways of production decrease standards of animal welfare; but raising these standards can, in turn, be disadvantageous with regard to land and water use. Yet, each option 
can be argued for in the name of sustainability. In fact, this was exactly the point of dispute when in 2012 animal rights group Wakker Dier accused a large frozen food manufacturer of misleading consumers. The manufacturer claimed to produce his frozen chicken sustainably but did not take into account standards of animal welfare, according to Wakker Dier. In turn, the manufacturer objected that Wakker Dier seems to ignore the importance of environmental protection (Retailnews 2012).

Such trade-offs may be inevitable, but are not necessarily unsolvable. For example, a slight overall decrease of meat consumption in favour of alternative sources of protein can eventually promote a more efficient use of natural resources, an improvement of animal welfare, and under certain circumstances even prove beneficial to human health. To this end, environmental group Natuur \& Milieu launched its 2011 campaign to encourage Dutch citizens to become a 'flexitarian'. Also, technological solutions can be found to tackle this trade-off. For example, engineers now promise to take up this challenge by developing in-vitro meat. In the summer of 2013, a Dutch team of scientists publicly presented the world's first lab-grown burger. In The Guardian, an ethics professor praised this effort: 'Artificial meat stops cruelty to animals, is better for the environment, could be safer and more efficient, and even healthier. We have a moral obligation to support this kind of research. It gets the ethical two thumbs up.' (2013)

So the point here is not that sustainability would be infeasible, insufficient or internally inconsistent as a concept. It's simply that its presence on the innovation agenda suggests some sort of substantial moral or political agreement among stakeholders, where actually there is little common ground (see also Becker et al. 1999; Sachs 1999; Redclift 2005).

And yet, the issue of food sustainability seems to have found a legitimate place on the food innovation agenda. The reported variety of conflicting values and interests may indeed be formative of the 'political fudge' of sustainability, but this does not mean that the legitimacy of the issue has no normative, common ground to rest upon at all. Only, it is very thin: what many if not all stakeholders are concerned about is food security in the long run, or more generally, the 
long term security of natural resources. It may not be the only concern, and it may not be ultimate concern, but it is a concern shared nonetheless - and recognized as a clear matter of public concern (see e.g. Godfray et al. 2010). Sustainability can thus be framed as deeply entangled with global food security: the availability and access to food for all. Only in this sense - as a collective act of depleting natural resources - unsustainable food production and consumption can be identified as a case of potential harm. Evidently, securing the access to and availability of raw materials is also in the direct interest of food processing industries and other technology actors. If not for the greater good, at least their economic prospect is what keeps them committed.

This is why the Brundtland report proved so important for the status of food sustainability as a public issue: it suggested that economic development and environmental protection are not necessarily conflicting goals. It may be true that the issue of sustainability hosts a variety of incommensurable values and ideals, and that this amounts to conflicting ideas of what remains to be done; but without this minimal common ground (however misinterpreted, however multiinterpretable) it is hard to imagine how sustainability could have enjoyed the public legitimacy that it currently does.

\section{The quantification of sustainability}

Another condition that concerns have to fulfil in order to become a legitimate issue on the public innovation agenda is that their substance is appropriate for measurement and thus can be expressed in quantitative terms: it counts if it is counted. The underlying assumption is that at least we should be able to agree on the facts before we can actually discuss the problem and possible courses of action. Counting and measurement can help in making such agreement possible.

But as much as the meanings and practical implications of food sustainability are diverse, so are the indicators, methods and metrics that can be used for identifying, monitoring and managing the causes and effects of unsustainable food production. One typical way of assessing the environmental impacts of food products, as they go through the chain from farm to fork, is Life Cycle Assessment (LCA). By 
the end of the 1960's, Coca Cola was the first company to develop and use such a model, for the manufacture and use of packaging, by quantifying and measuring material, energy and environmental impacts. As Hunt and Franklin (1996) recall, the manager who initiated this enterprise 'knew the process of definition and analysis would be very complex, and that incorporating the results in strategic analysis would be difficult.' After twenty years of fine-tuning, a broader public of academic, commercial and policy organizations came to see LCA as a recognized and well-established tool for measuring the sustainability of industrial products and processes. It was the visible problem of garbage waste and growing environmental awareness in 1988 that exploded the development and use of LCA's in the US (Hunt \& Franklin 1996).

In other words, some industrial engineers and scientists have had good reasons for initiating quantification and measurement - economic or otherwise - and did not need to see problems only where they are already quantified. This indicates that measurement and quantification do not necessarily precede but rather go along with the entrance of sustainability as an issue on the food innovation agenda.

Measurement and quantification, as processes of knowledge production, were far from conclusive and all-encompassing at the time when sustainability made its entrance to the food innovation agenda. The Brundtland report in 1979 articulated concerns of unsustainable food production through very global calculations, but only recently a broad range of larger corporations have made assessments at the specific level of food categories and food products, as is the case in e.g. The Sustainability Consortium - a global partnership of corporations, universities and NGOs. At the level of companies and other organizations, the Global Reporting Initiative publishes sustainability performance according to specific standards. In 1999, 11 reports were published; for 2011, that number is 3050 (GRI 2012).

These are clear examples where measurement and quantification did not occur before sustainability concerns were recognized as legitimate issues; in fact, the growing recognition of problems can be a driving force behind further measurement and quantification. Regardless whether these accounting exercises are useful and meaningful with 
regard to the various ideals behind food sustainability, at least they work in the confidence that (un)sustainability is quantifiable after all. So the point here is that, for sustainability, technology actors apparently did not need to sit and wait for all of the numbers before they were willing to take environmental concerns seriously.

This confidence in the quantifiability of sustainable development was strengthened by the 1972 report to the Club of Rome. This report had a significant impact on the growing recognition of environmental effects of (food) production and consumption meriting public attention. One of the main reasons for its credibility was the fact that its projections were based on computer modelling: several aspects of the future, such as world population, industrialization, pollution, food production and resource depletion were now quantified and shown to be interrelated.

As Parenti (2012) recalls, 'It was a message that many people in the industrialized world already seemed to feel intuitively. (...) For many people, the world was moving too fast and in the wrong direction, and The Limits to Growth seemed to prove that point scientifically.' Even where their models were soon to be disputed, and their numbers contested, at least the Club of Rome made a strong point in showing that their concerns were quantifiable, measurable, and an appropriate object of study for a team of scientists at Massachusetts Institute of Technology.

If food sustainability is now perceived as a hard issue, these instances make clear that this 'hardness' is far from an inherent, stable property but rather the result of more or less successful attempts - made over the past decades - to formalize and quantify the causes and consequences of a set of related concerns. Pioneers in this on-going process must have had the confidence that quantification was a meaningful way of understanding the problems they faced, and would yield to reliable, credible and relevant knowledge. By developing methods, metrics and indicators, they have made food sustainability quantifiable. In the same time, current attempts of accounting (such as the Sustainability Consortium) make clear that many relevant aspects of food production still are to be quantified. For this reason, it is far from clear whether sustainability really is a hard issue, and why more qualitative concerns would not merit public attention in the first place. 


\section{Causal stories about unsustainable food production}

A third condition for a concern to gain access to the public innovation agenda is that it articulates the problematic situation as a consequence; and in particular as a consequence of which either human behaviour, or the technology clearly is the cause. The basic idea is that causal explanation should be prior to the attribution of moral responsibility.

Sustainability as a food issue is not in itself a problem: unsustainable food production and consumption is. The problem can be framed in different ways, as there are many values and interests behind the issue that do not necessarily coincide. But suppose, however, that environmental impacts are roughly the kind of problematic impacts that most stakeholders are concerned with. Suppose these impacts can be considered, more or less, as cases of harm. Even then, there is no clear-cut and evident cause to be identified as the relevant factor: virtually any aspect of the food system and its environments can be identified in one way or another as a factor that contributes to unsustainability. Indeed, one could argue that sustainability is an attribute of the global food system itself (cf. Clayton \& Radcliffe 1996; Food Ethics Council 2013).

It is therefore no surprise that those who are concerned with turning our food system more sustainable have suggested a broad range of potential solutions, including innovative business models, more efficient food processing, industrial waste reduction, cleaner technologies, nudging consumers, recycling of materials and nutrients, decrease of food miles, organic agriculture, genetic modification, democratizing the food system, and so on. The Brundtland report already acknowledged the complexity that, in a broader sense, is involved in the causes and solutions to be identified for sustainable development: 'Environment and development are not separate challenges; they are inexorably linked. Development cannot subsist upon a deteriorating environmental resource base; the environment cannot be protected when growth leaves out of account the costs of environmental destruction. These problems cannot be treated separately by fragmented institutions and policies. They are linked in a complex system of cause and effect.' (1987: 1/40) 
From the report it becomes clear that technologies only do play their parts, both as causes and as solutions, within this larger sociotechnological and environmental system. Where many different (partial) causes and solutions are suggested among stakeholders, also expectations and assumed responsibilities are differing. Most actors including technology actors - are well aware that food supply is organized through long and complex chains, which in turn are part of a larger global food system. That is, they do recognize that food sustainability is a many-hands problem: a problematic situation that is brought about by a collective, while not necessarily causally reducible to the actions of each individual in that collective.

Yet, this has not prevented concerns for food sustainability from becoming a legitimate issue on the food innovation agenda. Despite the recognition of these complexities, humans were (causally) responsible for the detrimental effects of current production systems - however globally this was framed. The authors of Limits to Growth, for example, frame technology as rather neutral instruments: 'We would deplore an unreasoned rejection of the benefit of technology as strongly as we argue here against an unreasoned acceptance of them.' (Meadows et al. 1972: 154) Although unintended consequences of the use of technologies are considered part of the problem, it is human agency that is to solve it:

Man possesses, for a small moment in his history, the most powerful combination of knowledge, tools, and resources the world has ever known. He has all that is physically necessary to create a totally new form of human society--one that would be built to last for generations. The two missing ingredients are a realistic, long-term goal that can guide mankind to the equilibrium society and the human will to achieve that goal (1972: 183-4).

Also, as I have argued in Chapter 3, causal explanations become stronger where an extraordinary factor is clearly highlighted from the normal course of events. This is what makes an explanation relevant: not only that it implies that something can be done about the problematic consequences, but also that it indicates that something was not normal (indeed - unnatural). In the following causal story line, the authors of Our Common Future offer an explanation that meets both 
criteria:

Over the course of this century, the relationship between the human world and the planet that sustains it has undergone a profound change. When the century began, neither human numbers nor technology had the power to radically alter planetary systems. As the century closes, not only do vastly increased human numbers and their activities have that power, but major, unintended changes are occurring in the atmosphere, in soils, in waters, among plants and animals, and in the relationships among all of these (Brundtland 1987).

In other words, Limits to Growth and Our Common Future, both very influential reports in the growing awareness and recognition of unsustainable food production and consumption, have articulated these concerns as public problems of which human agency is both cause and solution. As far as technologies are presented as causes or solutions, the instrumentalist view of technology seems to be predominant: technologies are framed as neutral tools that in themselves would not shape society in any significant way, but rather are to be used by humans, for better or worse.

In this respect, food sustainability as a concern has met the condition of causality in a rudimentary way: humans, not technologies (nor nature for that matter) are the cause of unsustainable food production. On the other hand, the multiplicity of possible solutions (ranging from technological, business and economic to behavioural, political and cultural solutions) suggests that there is little agreement on the distribution of specific responsibilities for tackling the issue of food sustainability. This suggests that food sustainability is to some extent 'hard', but not in the sense that concrete, separate causes (and corresponding moral responsibilities) have been identified. That would be impossible, given the fact that unsustainable food production is a many-hands problem. When it comes to the clarity of causes and responsibilities for food sustainability, its 'hardness' is at best a matter of degree.

\section{Conclusion}

From the discussion above, it should become clear that the issue of 
food sustainability refers to a rather ambiguous set of concerns that seem to have gained just enough legitimacy over the past decades. With regard to the three agenda conditions, it has probably met the requirement of publicity (the publicly recognized value of global food security) best, while still a lot of quantification, measurement, and further causal story building remains to be done.

The case of food sustainability offers no exception to the claim that the three conditions - quantifiability, publicity, and causality - have to be met before concerns can become legitimate issues on the public food innovation agenda. As an issue, food sustainability fits well enough within positivist, liberal and instrumentalist worldviews in order to be subject to collective attention. If food sustainability was ever (or originated from) a soft concern, its advocates have now built a rather strong case by successfully adapting their concerns to the dominant discourse of food innovation and technology. Part of that success can be attributed to the strong entanglement of sustainability and global food security - even where the numbers, the values, and the causes later turned out to be not that clear and unequivocal as they seemed.

The issue of sustainability also shows, however, that the work that these three conditions imply is not finished as soon as the issue has been granted access to the public innovation agenda. On the contrary: the issue of food sustainability also justifies further quantification and measurements. It offers sufficient reason for further exploring the variety of values, norms and interests at stake, by identifying unavoidable trade-offs, potential conflicts, and overlapping interests among stakeholder groups. And it legitimizes the further exploration of types of solutions, and the discussion of expectations and responsibilities. The perfect public issue is not one that is already resolved in the first place; but one that has enough potential to grow, develop, and transform through collective inquiry.

From this point of view, the establishment of an issue is a temporary stage - problem institution - of a larger process of collective problem solving. The career of food sustainability makes clear that it seems unrealistic, if not unproductive to expect that all of this work should have been done before concerns are actually worthy of public attention and recognition. Where societal and technology actors who marginalize 
'softer' concerns implicitly rely on the soft/hard dichotomy, this temporal dimension is exactly what they tend to overlook.

Two conclusions can be drawn from this section. First, where concerns are generally considered as soft, the most promising and effective way of trying to get these concerns publicly recognized as a potentially relevant issue is to seek for normative, common ground by suggesting an entanglement of values (viz. sustainability and food security) - even when the numbers and neat, causal stories are largely absent or underdeveloped. That is what the concern of food sustainability hints at, having found its fairly established place in the dominant discourse of food technology and innovation. The case of food sustainability thus indicates how a set of rather 'soft' concerns can be raised within the range of the current three conditions for the public food innovation agenda: sustainability concerns are increasingly 'adapted', as it were, to the present agenda conditions. In the next chapter, the strategy of adaptation will be further discussed.

The second conclusion to be drawn is more fundamental. From the case of food sustainability it becomes clear that even issues considered by stakeholders to be fairly 'hard' are work-in-progress. It is misleading to consider a certain set of concerns - however implicitly - as 'hard' and others as 'soft' when it is suggested that (the lack of) hardness is an inherent and invariable feature of concerns. Rather, such implicit judgment is the product of human estimations, negotiations, judgments and efforts that can only be considered as reasonable with hindsight. So what does this mean?

Surely this constructivist account of the legitimacy of food issues does not necessarily indicate that reality - apart from human thought and action - has no role to play in the construction of public problems, and that just any concern is a viable candidate for gaining access to the food innovation agenda, as long we decide so. But it does point out that naked reality, in itself, does not offer a satisfactory explanation and justification for the fact that food sustainability has been able to rise as a legitimate, publicly recognized issue over the past decades. For this, one has to acknowledge the human efforts to allow it to grow.

More importantly, it means that societal and technology actors have a 
certain responsibility for what concerns do, and what concerns do not enter the food innovation agenda, because it is not the mere hardness of a concern that attracts our collective attention but, more precisely, the extent and degree to which it would meet the three agenda conditions. That, in turn, is a matter of human judgment.

So what must be done? This conclusion points at roughly two possible directions to take.

If we conclude that the three agenda conditions in themselves are reasonable but that they are often applied too rigidly and too early in the process of problem institution, then it follows that the solution lies in practical suggestions on how to 'put these conditions to work' in a more fruitful and meaningful way.

There is another direction to take - one that in principle does not conflict with the first option. If we conclude that the three agenda conditions are, in themselves, too restrictive, a more inclusive way of discussing emerging concerns need to be developed. That is, dialogues need to be organized and structured such that they invite stakeholders to consider 'softer' concerns on their own terms. Facilitators then pick up the task of showing how and why concerns that (1) are expressed in mostly qualitative terms, (2) appeal to contested values and meanings, and (3) point at technologically mediated impacts, are still worth exploring and discussing - even if it is unlikely that these concerns eventually (1) can be quantified, (2) present a clear case of harm, or (3) identify technologies as clear-cut causes. Facilitators then need to address the stakeholders with a compelling image that invites them to take responsibility for deliberating collectively on the meaning and validity of 'soft' concerns.

These two directions are further explained and specified in the next chapter. What they both hint at, is that the soft/hard distinction as such should be opened up, as it were, in order to enable a more reflective and critical discussion among stakeholders about the specific responsibilities that follow from emerging consumer concerns. With new food technologies emerging, a serious reconsideration of established roles and responsibilities may be needed. The soft/hard distinction now proves to be an obstacle to this end. 


\section{How to give concerns generally regarded as 'soft' a fair opportunity to gain access to the innovation agenda}

If concerns generally considered as 'soft' are to be given a fair opportunity to gain access to the food innovation agenda, broadly two directions can be taken. In the present chapter, both directions will be further specified. Whereas the first is more pragmatic and suitable for short-term improvements of public dialogue, the second is more critical of these conditions in themselves and proposes a more radical change of the discourse of food innovation and technology in the long run. Supposing that the current three agenda conditions are in themselves reasonable and as such need no revision, the first direction proposes those who raise 'soft' concerns, and those who are addressed with these concerns, to adopt, respectively, a strategy of adaptation and a principle of charity. The second direction, on the other hand, is motivated by the conclusion that the three agenda conditions are problematic in themselves. It proposes that facilitators have a special role in challenging the largely positivist, quasi-liberalist and instrumentalist views of what constitutes a legitimate public issue (see figure 5.1).

\begin{tabular}{|c|c|c|}
\hline Direction & Typically suitable for & Type of solution \\
\hline \multirow{2}{*}{$\begin{array}{l}1 \\
\text { Pragmatic solutions, } \\
\text { short term }\end{array}$} & Societal actors & Adaptation strategies \\
\hline & Technology actors & Principle of charity \\
\hline $\begin{array}{l}2 \\
\text { Critical solution, } \\
\text { long term }\end{array}$ & $\begin{array}{l}\text { Facilitators / } \\
\text { meta-level actors }\end{array}$ & Transformation \\
\hline
\end{tabular}

Figure 5.1: Two directions for solutions

These two directions are not simply different in terms of how pragmatic or radical their proposals are; they are also divided according to the kind of actors involved in the societal evaluation of 
technologies.

Here, I will roughly follow Schot and Rip's (1996) distinction of three kinds of actors: (1) 'Technology (en)actors' actively invest in, and effectuate, technological innovation. Examples are firms, certain government agencies, industrial R\&D departments and technology programs. (2) 'Societal actors' try to respond to or anticipate technological developments. These can be government agencies, nongovernmental organizations, or loosely defined groups of consumers, users, clients or citizens. (3) Meta-level actors, or 'facilitators', regulate or modulate the interaction between technology actors and societal actors. Governments and semi-public institutions typically take up this role, but specific technology assessment institutions, formal advisory boards and other civil society organizations that set the stage for public dialogue can also count as such.

The premise of this chapter is that facilitators, by their role and capacity, have a special responsibility in setting the stage for a more inclusive stakeholder dialogue and challenging the three dominant agenda conditions (direction 2 - How facilitators can do this, will be further discussed in Chapter 6). In principle, technology actors and societal actors could also question these agenda conditions, but are in the present chapter (for practical purposes) primarily addressed as those who raise and those who respond to 'soft' concerns in a particular way.

\section{How societal actors can adapt their concerns to the agenda conditions}

Let's start with societal actors. If they are not in the immediate position to change the current conditions for what concerns may get access to the innovation agenda, they will have to strategically adapt to the three conditions. From the point of view of those who are concerned (citizens, NGOs, consumers), three modes of articulation can already be identified in current public debate: translation, combination and entanglement. Each of them is a way of 'smuggling', as it were, soft impacts into the innovation agenda. I speak here of 'modes of articulation' rather than 'strategies" since the latter term suggest that actors intentionally pick and choose their methods for meeting their 
objectives. That may be so, but not necessarily. The concern here is to what extent these modes of articulation are indeed worth turning into deliberate strategies.

The present section thus offers an assessment of each of the three modes of articulation in terms of their usefulness. Successful agenda setting, however, involves many more factors than I could possibly discuss within the limits of this chapter. Furthermore, assessing which of these modes of articulation have proven to be effective thus far on the basis of a discursive analysis, might give the impression that the world is constituted by words only. This is the kind of impression that I would like to avoid. The successes and failures of agenda setting cannot simply be attributed to manners of speech alone. Many other factors play a role; e.g. how many (kinds of) concerns are competing for collective attention; how many resources are available for giving that attention (i.e. size of the agenda); the involvement of powerful issue sponsors; economic trends and cycles; timing and windows of opportunity; perceived novelty of issues; saturation of audiences; balance of political and economic interests; and so on (see Kingdon 1984; Dutton 1986; Hilgartner \& Bosk 1988).

Yet, the premise of this thesis is that for the expectations we have and the responsibilities we assume, it does matter what we think and how we speak. The focus of this analysis, therefore, is the extent to which these articulations align with the public discourse of food technology and innovation as described in Chapters 2 and 3. 'To align well' here can perhaps best be understood as the propensity to survive: to what extent are concerns able to adapt to the environment in which they are raised and probed, while preserving the integrity of the message they aim to express? The better they do, the more fruitful or promising they appear.

\section{Translation}

Translation is a mode of articulation where concerns that prima facie score low on the three conditions of the innovation agenda are wrapped up and presented in terms of hard impacts. The idea behind it is that ethical, cultural or religious concerns can be interpreted as 'nothing but' impacts of safety, health, risk, sustainability and so on. 
These concerns are expressed in numbers, explained in the language of 'hard science' and framed in terms of harm.

This mode of articulation has consistently been used by the Natuurwetpartij, a Dutch branch of the transnational organization Natural Law Party. From its foundation in 1992, it has been a marginal voice in the political landscape of the Netherlands until its abrogation in 2007. Their sister organization, Natuurwetmoeders (Natural Law Mothers) presented itself as an organization that aims for harmony between society and Natural Law. In 2000, they published a manifesto in which they tie their cosmological outlook to their position on GM: 'In the cosmos, everything is well-adjusted. There's a close connection in and between everything that lives. Genetic manipulation and cloning will confuse things with unforeseeable consequences, because the results will not live up to the quality of life as it is meant to be. Genetic manipulation (...) is a human error in the natural play of plants, animals, and humans in coherence with the universe.' (Natuurwetmoeders 2000).

In justifying their position before the Commissie-Terlouw, who organized a nation-wide public dialogue on biotechnology and GM food in the Netherlands, the Natural Law Party made extensive use of the repertoire of science. They referred to public statements by several professors of biology and physics who criticize the current paradigm of genetic engineering. This paradigm is alleged to take a reductionist approach of genes and overlook the complex multi-level interaction between genes and their environment; classic mechanistic conceptions of causality would not be applicable to life on micro scale. Thus, the Natural Law Party opted for a methodological and epistemological line of attack, rather than drawing on the ethical, cosmological or spiritual repertoire for which they were known. This approach is consistent with their political programs. Their 1994 program is full of graphs and exact numbers, e.g. depicting how moral progress can be induced by transcendental meditation techniques. Their 1998 program quotes a variety of critical scientists in order to support their claim that 'genetic manipulation, the simplistic juggling with fragments of DNA, goes against the reality of life and is at odds with our scientific understanding.' (Natuurwetpartij 1998: 258). 
This translation of ethical concerns into the language of hard science is not a prudent strategy because the Natural Law Party's concerns are informed by a comprehensive worldview for which there seems little room in the current paradigm of scientific research; the standard scientific understanding of nature is not theirs. That in itself may not be a problem, but it does not help if one wants to make an essentially moral point.

The introduction to their 1998 program reads as follows:

The violation of natural laws is the cause of all problems (...) The smallest deviation of naturalness leads to conflict and resistance. Unnatural behaviour is unavoidable whenever humans are alienated from their nature, or, in different words, whenever their intelligence, their consciousness is underdeveloped. (...) The intelligence of nature is incomprehensible to human understanding. The Greeks called the creation 'kosmos', a neatly ordered entirety, an ornament. We call it 'universe': everything is united by it, and it is full of beauty.

In this view, nature is not something to be controlled or engineered, but something essentially unknown and to be respected. Nature is good in and of itself, and a source of goodness and beauty. Laws of nature are not simply regularities to be described, but norms that humans are able to violate - and not without serious moral consequences.

Now this worldview (comprising ontological, moral, political and aesthetic beliefs) offers a key for how the NLP's concern about GM is to be interpreted. But in isolation from this view, their criticism of 'genetic reductionism' does no longer point at violation and alienation, and could be taken as the objection that there are more effective ways of manipulating nature. Also, it questions the dominant paradigm of cell biology but no longer challenges the materialist and mechanistic paradigm of science on a more fundamental level. It easily sets aside the moral and aesthetic qualities that nature would provide: they simply disappear once it takes shape in the language of science.

So this is what happened to the NLP's concerns: they were 'duly noted' in the 2002 biotechnology report but did not make it to any of the main 
findings, nor were they referred to in the policy recommendations. The Commissie-Terlouw concluded in their main findings that only few organizations, such as the NLP, 'clearly express their doubt about the safety of GM foods that are already allowed to the market,' and immediately emphasized that 'the committee has not found any scientifically established indications from the medical literature that would support this concern about the consumption of GM foods.' (Terlouw et al. 2002).

Khushf (2006) has shown that the scientific outlook on such morally contested issues leads to 'a truncated, shallow public discourse that never addresses what we are really talking about.' (2006:59). From his critical analysis of arguments about embryo research in the US, he concludes that:

Everyone accepts that some of the world can be understood by the conceptual tools and the forms of rationality integral to science (however we choose to understand 'science'), and everyone would value attempts to extend scientific knowledge. The point of contention concerns whether all of reality is amenable to such description, and whether there are alternative modes of practice with epistemic warrant; for example, sources arising from the creative arts or moral reflection, or from revelation or religious experience.

If the latter issue is not addressed, truncation (or black boxing) is exactly the kind of problem with translation as a mode of articulation in particular when the underlying worldview is not implicitly shared by those who engage in public discussions. The ethical significance of the concern will simply get lost in public deliberation. The point is not that translation from one repertoire to another is impossible, or that world views are incommensurable, but simply that a more fundamental discussion about 'deep values' (Khushf 2006) may be necessary if a certain type of ethical concerns are to be successfully addressed.

\section{Combination}

A second mode of articulation is combination. Here, soft concerns are, in contrast to translation, explicitly expressed by ethical or aesthetic repertoires, but presented as part of a larger agenda on which also harder concerns feature. For those who aim to address concerns about 
taste and food culture this seems an appealing option, since the harder concerns may provide them with a more legitimate voice in public debate. This mode of articulation is often used by groups who have a broader, more encompassing view of food and food production.

A recent Dutch example of combination is the platform NieuwVers and its manifesto Building the Food Revolution, an initiative by Foodlog and Urgenda. Foodlog is an independent blog and online discussion platform about virtually all aspects of food. Urgenda is an environmental NGO that promotes sustainable innovation and entrepreneurship.

Their manifesto calls for a social movement of consumers, producers and retailers in favour of a more sustainable and socially responsible food supply. Among more legitimate concerns such as social responsibility, regional food cycles, respect for biodiversity, healthy eating, food security and fair trade, the softer concern states: 'Think EEEE. Our agriculture, food production and consumption must be in balance. Not only Economically (finance) and Ecologically (nature), but also Ethically (humans and animals) and Aesthetically (beauty).' By 2014, the manifesto was signed by 1400 persons and organizations.

Also, their website presents a menu of five guidelines. First is 'real food': food that is recognizable as such, containing no unnatural additives. 'It's simple and pure: what you see is what you get. No readymade dressings, but natural products that have kept their original nutritional value. Vegetables and fruit, bread, dairy, meat and fish (not too much) and products directly derived from them.' The other guidelines - about seasonal products, meat \& dairy consumption, responsible water use and waste management - promote the care for biodiversity, sustainability, health and animal welfare.

NieuwVers is a clear example of how concerns about good taste, freshness and naturalness can be made part of a 'package deal' together with more publicly recognized concerns around food, such as health and sustainability. As it directs our attention to a broader set of issues surrounding food and innovation, combination seems a promising strategy in getting soft concerns on the food innovation agenda. So far, NieuwVers has managed to build a diverse network of 
organizations that, taken together, promote a broad variety of food values, ranging from the support of local fine dining, adopt-a-cow and mapping regional farmers, to shortening the chain of fish supply and innovative chicken farming.

Comprehensive agendas like these can mobilize a variety of stakeholders from bottom-up, even where they may not share the full set of values and ideals promoted by such agenda. In the same time, this can be a backdrop to those soft concerns that eventually seek to inform technology actors, such as food engineers, R\&D officers, governmental organizations and industrial players. Combination agendas still allow for 'selective shopping' on their part.

A typical case of such selective shopping, for example, can be found in the 2007 report to the Ministry of Agriculture on food quality (Eten van Waarde), which can be read as a general inventory of the many values that the Dutch attach to food and consequent policy recommendations for the Ministry. While the report covers an extensive set of concerns raised by a variety of societal actors, the introduction already rules out a large portion of societal concerns generally considered as 'soft' without further explanation:

Society ascribes an increasing responsibility for food quality to the Ministry of Agriculture. In the same time, the Ministry aims for a less regulative role for the government and for a shift of responsibilities toward citizens and businesses. In several cases, the consumer takes care of himself. For instance, the government does not need to get involved with things like convenience, pleasure and taste. Other values, however, entail a more active approach. Safe food, healthy food, animal welfare, environment and fair trade require a stimulating, regulating or monitoring government. (WUR 2007:10)

Notably, this statement does not only waive responsibilities for soft concerns on part of the Ministry but also implicitly rejects the idea that the food industry may have to step in: 'the consumer takes care of himself'. More importantly, this report was partially based on the outcome of an internal strategic dialogue at the Ministry in 2005. The aim of this dialogue was to broaden the Ministry's perspective on food quality; but the organizers excluded the values of taste, convenience and pleasure from the start (LNV 2005). When a given distribution of 
responsibilities already sets the frame for such dialogue, organizations with comprehensive agendas have little opportunity to bring in 'softer' concerns - even when such dialogue is supposed to broaden the range of issues to be discussed.

In principle, initiatives like Nieuwvers do not challenge the traditional division of responsibilities in food innovation, unless they point out why, for example, food engineers who are concerned with healthy products should take an interest in the citizen-consumers' enjoyment of dining together.

\section{Entanglement}

A more fruitful way of getting soft concerns on the innovation agenda, therefore, is to point at the entanglement of specific soft and hard impacts: to show that they are intrinsically connected. This connection can be articulated in a weaker or stronger manner.

Several examples of the weaker mode of articulation can be found in Slow Food Nation (2007), the book in which Carlo Petrini elaborates on the ideological framework for the Slow Food movement which he founded in 1989. Slow Food, a grass roots organization that now claims to have over 100,000 members worldwide, was founded to counter a globalized fast food culture in which the values of pleasure, tradition and community are gradually disappearing. They define quality food as 'good, clean and fair'. Each of these notions reflects a larger set of a values and principles, varying between harder and softer concerns.

Food is 'good' whenever it tastes good, Petrini argues. He defines taste as an experience of appreciation constituted by both the sensory qualities of the food and the eater's understanding of it, thereby acknowledging it as both a physiological and a cultural good. One of his concerns is that current industrialized food production results in the homogenization of flavours, 'depriving us the joy of experiencing the natural diversity of taste, which is so rich, varied, and gratifying to the palate.' (2007: 64) Lack of such appreciation means a lack of pleasure a fundamental right that we need to foster and protect, according to Petrini. Another concern is that the length of the food production chain makes us ignorant and forgetful about what we eat and where it comes 
from: we become alienated from our food. Maintaining the connection between what we eat and its origins is part of what Petrini considers good food: 'A product can be linked with a certain naturalness which respects the product's original characteristics as much as possible.' (2007: 96).

'Clean' food is produced in an ecologically sustainable way: agricultural production, industrial processing and transportation of food should not pollute, waste or overuse natural resources. Petrini's concern is that the current mode of food production and consumption is a threat to soil, climate and biodiversity. 'Fair' food is socially and economically sustainable, meaning 'social justice, respect for workers and their know-how, rurality and the country life, pay adequate to work, gratification in producing well, and the definitive revaluation of the small farmer...' (2007: 135). This conception is based on the idea that producing communities are the corner stone of the food system and deserve protection, solidarity and respect for the work and knowledge they put into whatever ends up at the table.

The significance of Petrini's agenda is that it goes beyond a mere combination of softer and harder values; it highlights the ways in which they are interrelated. He invokes the concept of naturalness to this end:

Natural means not using too many elements that are extraneous and artificial with respect to the system / environment / mankind / raw material / processing: no additives and chemical preservatives, no artificial or supposedly 'natural' flavorings; no technologies that subvert the naturalness of the process of working, raising (...), growing, cooking, et cetera.

(2007: 102-3).

Here, naturalness is to bridge the values of animal welfare and sensory pleasure:

[A]nimals should lead a stress-free life. Great respect should be paid for their well-being. In other words they should lead as 'natural' as possible a life while they are being raised: adequate space if they are kept in stalls - but preferably they will be put out to pasture; very short journeys, made only when necessary and without them being crammed into trucks; no violence. It is not 
just a question of not being cruel to animals - all this is also to guarantee that the final product will be better: stress and trauma have a significant effect on the sensory qualities of meat. (2007:103).

In addition, Petrini contends that unpolluted, unstressed soil 'will yield products that have superior sensory characteristics.' In other words, environmentally sustainable and animal-friendly production is a vital condition for good, tasty food. In Petrini's line of reasoning, naturalness - itself known as a soft concern - is the general principle that highlights a connection between these hard and soft concerns.

In a similar fashion, Petrini argues in favour of local networks of food production and consumption, as locality binds the good, the clean and even the fair:

Local food has the advantage of freshness, of a greater preservation of flavour in its journey to the table (many 'export' varieties have been selected to meet criteria of preservation and resistance to travel, neglecting crucial gastronomic factors such as goodness and taste), and respect for certain criteria of sustainability. For example, with small local productions, the use of chemicals can be very limited, the produce does not travel and therefore does not pollute, and rural areas are kept alive with a native and variegated production (urban purchasing groups are an excellent way of connecting the city to the living countryside). (2007: 31)

A recurring theme in Petrini's argument is that culinary pleasure, biodiversity, animal welfare, communality and proximity are not to be appreciated and promoted in isolation: some of these values are intricately connected and interdependent. Insistence on the entanglement of softer and harder concerns is a promising strategy for getting soft impacts on the food innovation agenda, since it emphasizes that those with soft concerns have certain interests and goals in common with those who are concerned about (and feel responsible for) hard impacts.

Yet, this kind of entanglement is of the weaker sort, for two reasons. First, Petrini does not offer any substantiation of the claim that sustainably produced foods are more delicious than foods produced in 
a more conventional way, other than anecdotal evidence and his personal credibility as a gourmand. In fact, the claim is rather contested. Consumers are divided about it (Yiridoe et al. 2005), and the UK Advertisement Standards Authority reported to have found no supporting evidence for it, while a trained sensory panel concluded it may be true for orange juice, but not for milk (Fillion \& Arazi 2002). It's not the potential disagreement that makes this entanglement relatively weak (on the contrary), but the fact that Petrini fails to specify how or why taste and sustainability are entangled.

But there is a second reason why this sort of entanglement is rather weak. Petrini suggests that if we are concerned about taste and the pleasure of eating, we have good reason to promote a more sustainable food chain. This only makes the hard concern of sustainability more pressing, while it leaves the softness of concerns about aesthetics and the good life untouched. With respect to the public legitimacy of soft concerns, the reverse line of reasoning would make a stronger case: i.e. where it is argued that hard concerns cannot be adequately taken care of without taking seriously the softer ones. A few examples of this stronger kind of entanglement are discussed below.

\section{Stronger entanglement}

Food writer Michael Pollan, who strongly criticizes the prominence of processed food in the American diet, and the primarily scientific outlook on food in general, offers perhaps the best example of articulating the stronger kind of entanglement of soft and hard concerns. A close ally to the Slow Food movement, Pollan underscores that pleasure and mindful eating is an essential part of good food. His concern is that a food culture in which tradition, familiarity and taste are guiding principles for what to eat is gradually disappearing. These are soft concerns indeed.

In the same time, his manifesto In Defense of Food addresses the 'supposedly incredibly complicated and confusing question of what we humans should eat in order to be maximally healthy' (2008: 1). Pollan argues that healthy eating is not only a matter of what we eat, but also how. Referring to Rozin's study of French and American eating habits (2003), he explains what makes the French in better shape than the 
Americans: the French are served smaller portions and spend more time on it. Pollan's underlying message is that attentive and leisurely eating could be beneficial to one's health - at least under the presumption that 'the scientific case for eating a lot less than we presently do is compelling, whether or not you are overweight.' (2008: 184).

For a similar reason, Pollan suggests that there is a connection between healthy eating and time spent on cooking. He reports that convenience foods are responsible for the 300 extra calories per day that Americans have consumed since 1980.

They require very little, if any, time or effort to prepare, which is the reason we eat more of them. How often would you eat french fries if you had to peel, wash, cut and fry them yourself - and then clean up the mess? (2008: 186).

Also, he cites Cutler et al (2003) on the relation between the march of cheap convenience food, the introduction of the microwave, and the increasing weight of the average American, concluding that 'as technology reduces the time cost of food, we tend to eat more of it.' (2008: 187).

Pollan thus argues that healthy eating is partially dependent on the food culture that it is part of. This becomes also clear where he defends the value of sharing meals, not in the least for families:

At the dinner table parents can determine portion sizes, model eating and drinking behavior, and enforce norms about greed and gluttony and waste. Shared meals are about much more than fueling bodies; they are uniquely human institutions where our species developed language and this thing we call culture. (2008: 189).

Pollan's concern is that in the US, family members will no longer dine together and rarely enjoy the same dish, as microwave dinners and individualized diets enable each member to pick whatever meal is convenient at any place and any time of the day. The widespread availability of snacks testifies to the gradual disappearance of traditional meals as time markers for when to eat, and when not to. 
Hence, Pollan's advice is to 'eat meals' and 'try not to eat alone', because most of us tend to eat too much when alone, when we pay no attention to what and how we eat. If healthy eating depends on regulating our appetite, we better pay attention. For Pollan this means cultivating the senses, putting time and effort in what we eat, and allowing rituals and traditional norms - rather than industrial and techno-scientific morals - to shape our eating habits.

Many of these arguments rely on the assumptions that healthy food is a matter of eating not too much, and that highly processed foods and ready meals usually contain substances that, at best, we don't really need if we would change our eating habits. But whether these assumptions are valid, and whether the scientific evidence is strong enough for Pollan to draw his conclusions, is perhaps not that relevant in this context. What matters is that he appeals to scientific studies in the first place in order to highlight the entanglement of health issues on the one hand, and concerns about food culture on the other: one cannot adequately solve the one without taking into consideration the other. Whether or not this relation of dependency is sound from the perspective of public (and scientific) reason now becomes all the more urgent according to the current conditions for the public innovation agenda: after all, health as a hard, quantified and publicly recognized value is at stake.

If consumers and citizens seek to introduce soft concerns onto the food innovation agenda, strong entanglement as a mode of articulation seems the most promising strategy to follow. That Pollan, now internationally recognized as a leading spokesperson in matters of responsible food production and consumption, has been able to become an influential and renowned advocate of 'soft' concerns (featuring in the 2009 Newsweek top 10 'New Thought Leaders', and listed in the 2010 Time top 100 'The World's Most Influential people'), can be partially explained by the fact that he knows how to link experiential aspects of food and eating to more scientifically established and politically recognized issues like health and sustainability.

A similar kind of entanglement is articulated by the Dutch philosopher Annemarie Mol, who identifies the 'consumer-citizen' as a 
contemporary figure in which political, economic and physiological practices come together that cannot (and should not) be disentangled too easily. With regard to fair trade food, for example, she points out that the pejorative 'aftertaste' aptly describes what the eating body experiences when it is aware of unjust production and commerce: 'how can coffee be delicious, it is suggested, if you know that others, especially those who picked the coffee beans, suffered from it? Misery is something you can taste.' (Mol 2007: 26). Such common sense notions need our attention and deserve further investigation. The problem, Mol argues, is that current political philosophy and neoclassic economic theory lack the repertoire to explore and describe what good taste is, and to account for the bodily practices and social transactions that come together in this concept.

In the essay Tragiek van de kilocalorie (2011), Mol develops the building blocks for this repertoire. Her concern is that public health education about food, in its narrow focus on individual eating behaviour and science-based quantitative information, fails to address many relevant aspects of consumption. She proposes the study of 'eating in the wild'. This perspective requires anyone with an interest in healthy food intake to have an eye for the complex environment of social and material variables (such as shared meals, food habits, retailers' supplies and opening hours, social norms, affordability, TV commercials, family structure) that make up for everyday practices of eating. Indeed, the wide availability of processed foods is part of that. 'This environment does not cause their behaviour, as is sometimes suggested by schemes in which causal arrows show relations between quantities. Eaters act upon whatever their environment offers them. The question is how well they are equipped to do so.' (2011: 143). What eaters need in order to remain in good health, Mol suggests, is not necessarily science-based information about good amounts of calories, but the acquirement of food skills.

One of these skills is what Moll calls the cultivation of pleasure:

Suppose that bodies stop eating and drinking as soon as they are satisfied, when they have had sufficient satisfaction? Then a new question emerges: what satisfies eating bodies at all, what do people enjoy? And is this innate or something we (each in our own way) gradually acquire? If bodily pleasure is 
'to be learned', it really deserves more attention than is presently given to. (2011: 145).

What makes this mode of articulation stronger than Petrini's? It is not simply that she proposes and develops a new food vocabulary more hospitable to the intertwinement of soft and hard concerns. In fact, Petrini makes a similar move with reframing the consumer as a 'coproducer', and reinventing the art of gastronomy as an interdisciplinary body of knowledge. While making a case for the values of pleasure and good taste through the legitimate issue of health, Mol also challenges the very conditions of the food innovation agenda: she questions the narrow, quantitative approach to what to eat; she challenges the implicit assumption of liberal society that pleasure and good taste are strictly private affairs, while resisting the call for legal regulations (thus avoiding the trap of anticipatory liberalism); and she points out how causally indirect and unclear relations (in 'complex situations') can still be significant for tackling the problem of overeating.

What makes her approach rather promising, then, is that it works on two levels: on the one hand, it offers an adaptive, short term strategy for 'working around' the current three conditions for the food innovation agenda - since public health issues are already recognized as legitimate issues that deserve collective attention. On the other hand, it invites technology actors, societal actors and meta-level actors to rethink the conditions for public, scientific and political deliberation, and it opens up the possibility of a more inclusive food innovation agenda.

\section{Recommendations for societal actors}

So what should societal actors do if they want to raise any soft concerns about food technology and innovation? Since I present my explicit recommendations here, it seems only appropriate to address these recommendations directly to whom it may concern: that is what recommendations are for, after all.

Be careful not to translate your concern into the language of natural sciences too quickly. If your concern is seated in deep ethical or 
aesthetic convictions, these may not be recognized - let alone taken seriously - by those you address. If your concern draws upon a specific interpretation of the world, this meaning may get lost in translation. Your conception of nature may not be theirs; their approach to taste may not be yours. An appeal to 'purely scientific' arguments narrows down the possibility of discussing those differences. The point you want to raise will likely go unnoticed.

You may, however, need to mobilize social scientific research in order to indicate the likelihood, scope and meaning of technological impacts on the human world. Food studies, for example, comprise a range of political, sociological, psychological, anthropological and historical theories and insights that make sense of the practices and institutions involved in food production and consumption.

Likewise, be careful not to combine your concern with harder concerns too easily. Making your concern part of a more comprehensive food agenda may be appealing, but when a well-articulated connection between hard and soft concerns is missing, such agenda will not offer any special reasons why the addressees would indeed take into account your concern.

If your concern is to be aligned with current conditions of the food innovation agenda, make sure that you make explicit how your concern is entangled with harder, more publicly recognized problems. In fact, argue how and why such an established problem can (only) be tackled by taking into consideration your concern. Although this concern may rest on values of intrinsic worth, an instrumental interpretation of these values can provide reasons for bending, and even reconsidering the traditional division of responsibilities. It offers a perspective to common ground, and thus, common problem ownership.

\section{How technology actors can accommodate 'soft' concerns in a more charitable way}

The principle idea behind the first direction of solutions I propose, is to invite both technology actors and societal actors to meet each other 'half way' if they are interested in improving the quality of stakeholder dialogues about food technology and innovation. Societal actors who 
seek to address their 'softer' concerns to technology actors can do this by adapting to the current conditions of the innovation agenda, as was discussed above. Technology actors as addressees, on their part, can do this by suspending the application of those conditions, rather than relying on them as an a priori division of labour, i.e. even before a meaningful dialogue on 'soft' concerns can actually take off. To see what such suspension entails, we should go back to what the soft/hard distinction was supposed to be good for.

That is, there are several reasons why the soft/hard concern distinction should not govern the public discourse of food technology and innovation, as was discussed in Chapters 3 and 4, but it also has a certain function that technology actors may not want to get rid of. The function of this distinction is heuristic: it offers technology actors a few guidelines for sorting out which concerns do, and do not merit their attention, which is a scarce resource.

In other words: the distinction is supposed to prevent technology actors from thinking and talking about, and possibly acting upon, concerns that turn out be not really problems at all. According to the realist approach, real problems exist 'out there' even when we do not identify them as such. According to the constructivist approach, what counts as a real problem depends on whatever we define and decide as such (Hiltgartner and Bosk 1988). But either way, the soft/hard distinction specifically needs to help out in assessing and selecting those problems for which technology actors are and are not responsible. That is the point of making such distinction in the first place.

So if we are to give up the soft/hard distinction, we may need another heuristic principle. This heuristic principle should at least allow (i.e. not preclude) public concerns to 'pass' with the following characteristics:

- Concerns expressed in qualitative terms

- Concerns that appeal to unsettled values

- Concerns that point at mediated impacts

Consider these in contrast with the old distinction that strongly prioritizes: 
- Concerns expressed in quantitative terms

- Concerns that appeal to undisputed values

- Concerns that point at consequences with clear causes

Broadly speaking, this contrast reveals that both sets of concerns are possibly the extreme opposites on a scale from 'solidness' and 'fluidity'. They are gradually differing ways of making sense of experience:

- Mostly qualitative terms <--> mostly quantitative terms

- Extremely unsettled values <--> completely undisputed values

- Impenetrably mediated impacts <--> unmistakably clear causes

The alternative heuristic principle thus needs to account for the idea that concerns can become more 'solid' over time - but not by themselves. It needs to take into account that concerns which are expressed in qualitative terms, appeal to unsettled values, and/or point at mediated impacts, could turn out to be reasonable and relevant after giving them a fair hearing. This boils down to a principle that presupposes some degree of reasonableness in concerns even when not all of the facts, values and causal relations (and consequently, responsibilities) have been agreed upon.

The principle of charity exactly prescribes such assumption: a principle that technology actors need to adopt in order to be able to accommodate 'softer' concerns.

\section{The principle of charity}

The principle of charity originated and was developed in the fields of epistemology, linguistics and anthropology, in order to meet the challenge of radical interpretation: how can we be sure to adequately understand a language and world view ('conceptual scheme') completely different from our own? The answer of Donald Davidson, whose articulation of this principle is most well-known, is: in principle, we cannot be sure, but to suppose that such understanding is impossible in the first place would be meaningless. That would go against the idea that someone's utterance is a sign of language and thought; it would defy the idea of communication. Since we cannot be sure, we'll sometimes have to take a leap of faith and provisionally hold these 'alien' statements to be in line with reason. In other words, we 
must assume that different languages and worldviews are not completely different (i.e. incommensurable). It is a pragmatic principle.

The principle of charity requires that if you try to understand someone's utterances, you presuppose that his statements are (to some degree) rational, considering the possibility that a coherent and rational interpretation of his statements can be given. Davidson claims that applying this principle is not an option; it's simply what we do when trying to understand someone:

Charity is forced on us; - whether we like it or not, if we want to understand others, we must count them right in most matters. If we can produce a theory that reconciles charity and the formal conditions for a theory, we have done all that could be done to ensure communication. Nothing more is possible, and nothing more is needed. We make maximum sense of the words and thoughts of others when we interpret in a way that optimizes agreement (this includes room, as we said, for explicable error, i.e. differences of opinion). (Davidson 1973)

Thagard and Nisbett (1983) have pointed out that charitable interpretation does not necessarily require that one assumes that certain statements are true; only that they conform with certain standards of rationality. This makes sense, especially when conversation and disagreement, rather than accurate translation is the context in which the principle is to be applied. Although we may not need to count our conversation partners 'right in most matters', as Davidson has it, at least the principle forces us to presume that their utterances are cogent and reasonable: things we can possibly learn from.

The principle of charity is a heuristic device for the problem of translation and meaning, but is also advocated, albeit implicitly, in political, moral and cultural theory. Charles Taylor, for example, points out that members of a multicultural society ought to presume that 'all human cultures that have animated whole societies over some considerable stretch of time have something important to say to all human beings' (1994: 66). Here, the principle reflects the notion that presupposing some minimally shared form of rationality and morality between communities is the only option when non-violent cohabitation 
is their purpose. Archon Fung has proposed a similar principle to those who meet serious resistance in their effort to engage in fair and open practices of democratic deliberation: 'Though political waters in liberal democracies are filled with sharks, the principle of charity requires the deliberative activist to act as if his would-be interlocutors are willing to engage in good faith deliberation, until they prove themselves unwilling to comply with the norm of reciprocity' (Fung 2005).

Such applications suggest that the principle of charity does not necessarily reflect a neutral, apolitical attitude, solely concerned with the reconstruction of meaning. The need for charity emerges whenever we want to understand others - which implies that we have strong (moral or practical) reasons for trying to do so. It reflects the conviction that excluding others from being rational is highly undesirable, and if necessary, then a necessary evil. The principle of charity reminds us that the alternative to charitable interpretation is the end of conversation. It appeals to the assumption that other people matter, and that they have something interesting to tell.

\section{Application of the principle of charity}

How far must one go in being charitable? At what point is it justified to conclude: this particular concern fails to meet certain standards of rationality, and is therefore no longer of my concern?

Thagard and Nisbett (1983) distinguish several versions of the principle, according to degree of severity. Where the weakest version 'Do not assume a priori that people are irrational' - is too general and vague to be helpful, the strongest version - 'Never interpret people as being irrational' - is too strict, as it would not recognize that people sometimes do make serious mistakes in, for example, logical reasoning. A fruitful version of the charity principle, then, seem to be somewhere in the middle of the spectrum.

However, the modest version that Thagard and Nisbett advocate - 'Do not judge people to be irrational unless you have an empirically justified account of what they are doing when they violate normative standards [of rationality]' - seems to prioritize behavioural and cognitive explanations of human action (such as psychological or economic 
explanations) to the interpretation of beliefs. Arguably, this is justifiable where the principle of charity is applied as a methodological instrument for social scientific research, but when applied in dialogue, aimed at mutual understanding, this might not be satisfactory. It would mean that conversation partners could be rendered 'mute' as soon as one, confronted with 'soft' concerns, would explain away such concerns by drawing on a third-person perspective. The reduction of consumer concerns to e.g. a 'mere' expression of fear of new technology, or as 'only' a sign of romanticism, can hardly be considered a good reason for no longer trying to understand these concerns - even if such assessments can be backed by empirical social research.

Therefore, Thagard and Nisbett's proposal to locate the limitations of the principle of charity at this point where violations of rationality standards can be explained empirically, is not satisfying - at least, not when this principle is supposed to guide technology actors who are faced with 'soft' concerns. So where can we find such point, then?

The principle of charity in itself does not prescribe such point; but there are roughly three ways of approaching that question.

First, one can interpret this question from a moral point of view: a certain moral standard then prescribes at what point it is (morally) justified for the addressee to be no longer responsive to concerns raised by others. This point of view specifies what kind of rights and duties conversation partners have when they tend to disagree in e.g. ethical or political matters. This approach is more or less inspired by the Kantian idea that reason has its limits.

A second approach, in contrast, refutes the idea that a final and definite moral justification can be given for the point at which one is allowed to stop trying to understand the other and give up. It conceives of the values of responsibility as a moral imperative that asks of humans to do the impossible: the very idea of responsibility, if understood in all of its consequences, is that it is infinite and open-ended. In this respect, the philosopher's attempt to set the moral limits of charity by means of a rational justification is ridiculous, as it does not do justice to the gaps, inconsistencies and loopholes in human reason. Derrida's interpretation of concepts like hospitality, justice, democracy and 
responsibility is key to this approach.

Both are respectable philosophical approaches, and there is much to say in favour of each of them, but I consider none of them to be really fruitful for the purpose of my argument: to offer practical advice to technology (en)actors who are confronted with emerging soft concerns. The first approach seems too formal and artificial for the unruly business of engaging in dialogue, where the latter leaves us with deep insight but empty hands.

A third approach would be more pragmatic. If we consider the principle of charity an instrument that should promote understanding and meaningful (dis)agreement, we should recall the alternative to charitable interpretation: the end of conversation. Pragmatically speaking, therefore, the scope of charity ends where, in the long run, the benefit of ignoring 'soft' concerns outweighs the potential benefits of understanding. In other words, one should continue to apply the principle of charity as long as one reasonably expects that there is still the opportunity to learn about new perspectives and worldviews. Where charity ends, one may miss out on early warning signals and creative business opportunities.

This means two things. First, it means that the principle of charity, contrary to the soft/hard distinction, does not pretend to offer clear and stable criteria according to which technology actors can assess whether they should take any given concern seriously. Rather, it urges technology actors to consider (and recall) why it would be in their interest to get to an understanding, even partially, of what these 'soft' concerns may eventually be about. In this sense, the principle of charity does not offer a shortcut for deliberation, but it does offer a guideline for sorting out which concerns do, and do not merit their attention which was the heuristic function of the old hard/soft distinction.

Second, the principle of charity does not necessarily dismiss the three requirements (standards) that have governed the food innovation agenda thus far. It is a principle for public deliberation, not for action. The old soft/hard distinction rigidly holds on to the assumption that concerns should fully meet the three agenda conditions even before they can be meaningfully discussed. It tends to ignore the possibility 
that concerns may grow and develop into legitimate issues through collective exploration, deliberation and inquiry. In essence, the problem with the hard/soft distinction is not that it is too selective or excluding: the problem is that it is precluding. It dismisses a range of citizen and consumer concerns all too soon.

After all, taking concerns seriously can imply three very different things:

- Readiness to talk, listen, investigate, explore (responsiveness, curiosity)

- Readiness to decide, resolve, judge (determination, resolution)

- Readiness to act (realization)

Charity as a heuristic principle reminds us that concerns are not to be dismissed as irrelevant, incomprehensible, subjective or irrational before we have actually given thought to the reasons, causes and motives from which these concerns arise. Applying the principle means taking the first step in taking concerns seriously.

Contrary to the soft/hard dichotomy, the principle of charity does not rely on a given distribution of responsibilities for food concerns. The judgment whether or not technology actors should accept a responsibility to act upon 'soft' concerns, can still be subject to the requirements of quantifiability, publicity, and causality. What a charitable response implies, however, is that one is willing to suspend those requirements in dialogue, and, in principle, to reconsider assumed responsibilities as soon as a given 'soft' concern turns out to be a legitimate issue over time.

\section{Recommendations for technology actors}

When faced with soft concerns about food technology, be careful not to dismiss these concerns too soon for being subjective, irrational, or private. There are many reasons why consumers and citizens raise such concerns, and downright romanticism is perhaps only one of these. Try to find out what these other reasons might be.

Do not reject concerns for being emotional; they are an inevitable part of the food discourse. For every occasion of food fear among consumers, there is also a justified pride in engineers, a joyful promise 
given by marketers, and a sincere hope among policy makers. What matters, in the end, is whether these sentiments arise for good reasons.

If you are interested in understanding why consumer concerns are raised and what consumers are concerned about, rigid requirements for evidence may get in the way. Whereas the foreseen impacts of technology are not quantified, some of them could be made quantifiable. Whereas the concern would seem a strictly private affair, their advocates may suggest that it should become subject to public consideration, or at least a problem for which there are more fruitful solutions than the sole mechanism of free consumer choice. Whereas the suggested impact is not directly framed as a clear and unequivocal consequence of technology, concerns may indicate that technologies do play their parts as an enabling or constraining background against which individuals interact with food.

But to assess if and how that is really the case, at least requires further exploration through open dialogue. This means that you will need to ask for clarification, under the presupposition that certain concerns are perhaps not that irrational and subjective as they seem at face value. This requires, of course, patience.

Remember that innovations in food technology are inevitably valueladen; food safety is one of those values, just as good taste, convenience, naturalness and efficiency can be. If any of these values constitute 'good food', (re-)consider your responsibilities with regard to the effective realization of those values.

If you happen to consider food sustainability to be one of your responsibilities, remember that food sustainability hosts a diversity of meanings, values and practical implications. That it takes time and effort to define, identify and measure the causes and consequences of unsustainable food production and consumption. That remedial responsibilities can be shared, and pertain to a broad range of technological, economic, and political solutions. But that food sustainability is a legitimate issue despite these ambiguities and entanglements. This required patience, too. 


\section{Recommendations for facilitators}

Thus far, this chapter discussed what societal actors (those who raise concerns) and technology actors (those who are addressed with these concerns) can do in order to make sure that, when in dialogue, 'soft' concerns have a better chance at gaining access to the public innovation agenda. It is suggested that both parties will have to take a step towards each other so they can meet each other 'half way': societal actors by adjusting their modes of articulation to the three predominant agenda conditions, and technology actors by suspending their judgment of rationality when faced with concerns that, taken at face value, do not seem to meet these agenda conditions. The idea here is that the three agenda conditions (quantifiability, publicity, causality) are in themselves not unreasonable but need to be put to work in a way that allows for a more fruitful dialogue.

Nevertheless, the validity of these conditions in and of themselves can be questioned, as was demonstrated in Chapter 3 .

That is, the condition of quantifiability can be a powerful way of turning food concerns into manageable issues eventually, but still remains blind to those concerns for which it makes little sense to measure them, such as the concern that certain food technologies would have detrimental effects on good taste - a rich, cultural concept that entails much more than, e.g., the organoleptic properties of a food product. Also, what consumers value when they care for natural food may not be operationalized in quantitative terms without losing sight of what is essentially at stake for them. Concerns like these require interpretation, rather than calculation, if they are to be taken seriously.

Furthermore, the publicity requirement that concerns appeal to values that, in principle, can be shared and acknowledged by all, makes sense, from a liberal political point of view, when these concerns would eventually have to result in collectively (and possibly legally) binding decisions. The idea behind this requirement is that deep-seated ethical disagreement is to be avoided; food concerns that draw on a specific conception of the good life, as opposed to e.g. concerns that point at the health risks of food technologies, could never result in public agreement - not even in the long run, after careful and lengthy deliberation. Take the value of naturalness as a feature of food 
production: in the context of food production citizens do not only disagree on what natural is, but also on whether naturalness is something to value positively at any rate. Nevertheless, even if there is no prospect to consensus on the goodness of natural food production, this does not necessarily mean that some sort of meaningful agreement is impossible to reach.

For example, in their proposal for a pragmatist ethics in a technological culture, Keulartz et al. (2004) illustrate that for highly polarized issues, ethical consensus is not always necessary in order to attain peaceful cohabitation and cooperation - as long as a common ground can be found on practical terms. Even in the fierce ethical dispute on abortion, for example, pro-life and pro-choice advocates can agree on the necessity of preventing unwanted pregnancies. In a similar fashion, the ideal of authenticity in food production and consumption, a rather disputed value grounded in a specific set of ethical and aesthetic convictions, can still be meaningfully articulated in public dialogue, as Doorman (2012) suggests: those who frown upon 'authenticity' may still accept and agree to some of the practices that this ideal hints at, such as a respectful relation to animals, an environmentally friendly mode of food production, a transition to local and regional food systems, or the simplification (rather than extension) of food supply chains. In principle, one can still initiate a fruitful discussion of such issues without having to conceal the motive of authenticity - however paradoxical, inconsistent or romantic this concept may be. The point is that provisional, context-specific and practical agreements can be reached even where a fundamental ethical or aesthetic consensus is missing (for a more elaborate justification of this point, see Rawls's discussion of overlapping consensus; Rawls 1993).

Also, the requirement that concerns need to express an unequivocal, causal relation between a given technology and its negative societal impacts may be conducive in identifying who or what is responsible for resolving those impacts, but a sincere and definite demonstration of a specific relation can be impossible - even in the long run. This is a consequence of the idea that human action is often mediated by technologies deeply embedded in modern societies: technologies are able to suggest, modify, and compromise our plans and goals, in a way that is not always that visible, clear and easily subject to the 
individual's control. The notion of 'many hands problems', as the result of complex interactions between humans and technologies, points at the possibility that, in some cases, responsibility cannot simply be assigned to either humans or technologies. When food concerns articulate such many-hands problems, they imply that responsibilities for resolving such problem are likely to be shared: e.g. among consumers and food technologists - even where causal relations are not specified and demonstrated in an exact manner.

Given these considerations, it may not be entirely satisfying - at least not from a principled, theoretical point of view - to expect from societal actors to merely 'bend' their soft concerns to the current three agenda conditions (as with the entanglement strategy), nor to suggest to technology actors to simply 'suspend' their judgment of emerging concerns (as with the principle of charity). The theoretical arguments I've presented here, and more extensively in Chapter 3 , suggest that the three conditions should no longer govern (access to) the public discourse of food technology and innovation all together. The following recommendations indicate what facilitators can do in order to organize, structure and steer a stakeholder dialogue such that it challenges the three agenda conditions.

\section{Challenge positivism}

When you aim for a fruitful and meaningful assessment of food technology and innovation, mobilize a variety of stakeholders who are likely to draw on different sources of knowledge, values and experiences. Equally important, allow for interdisciplinary and transdisciplinary approaches to given concerns and potential issues. This means, for example, that arguments appealing to social sciences and humanities are treated with the same respect as those emerging from the standard 'scientific outlook'. It also means that you encourage the dialogue parties to take into consideration patterns of interaction between the natural, the technological, and the social dimensions of food. Invite participants to question if these interactions can and should be quantified, and if so, how much measurement it would take for them to acknowledge the seriousness of it.

Postpone and delay definition issues. When soft concerns are on the 
table, encourage participants to ask each other for tentative explanation and clarification of these concerns without forcing them to formulate clear-cut, decisive definitions. A conclusive and commonly shared idea of what naturalness means in the context of food additives, for example, can be the result of a fruitful stakeholder dialogue, but not the point of departure. A certain flexibility will enable stakeholders to discuss and negotiate the relevant facts, values and responsibilities implicated by soft concerns.

In sum, these recommendations point at a more fundamental ingredient for a fruitful stakeholder dialogue: a collective reflection and discussion of epistemic rights and responsibilities for making factual and normative claims. Deeply entrenched ideas of who has the right or responsibility to claim something about the truth and meaning of a given topic (i.e. 'the right to speak') can seriously obstruct a fruitful encounter of viewpoints. One way of organizing such reflection, the discursive action method (Lamerichs \& te Molder 2011), will be further discussed in the next chapter.

These recommendations will enable you to challenge the agenda condition informed by the positivist worldview.

\section{Challenge anticipatory liberalism}

Successful agenda building requires that most (if not all) stakeholder parties acknowledge that a specific concern deserves collective attention. Apart from epistemic considerations, discussed above, an exchange of normative viewpoints is part of that process. If you seek to promote such acknowledgement (which indeed presupposes that you already believe that certain soft concerns deserve collective attention), present a frame, image or narrative that allows most participants to identify, if only provisionally, a situation that is commonly recognized as problematic. In other words, offer the participants a possibly shared problem that emerges from the interaction of food innovations with the societal practices in which they are (to be) embedded.

Note that this does not require that all parties identify the problematic situation for the same reasons; they need not endorse the same norms, values and goals at stake for agreeing that the problem deserves 
attention. What matters here is that a common interest is envisioned in further exploring the concerns involved. This must have been the case, for example, in the issue of sustainable food production; the mere prospect of running out of natural resources for feeding humans makes possible such commonly shared interest, regardless whether that would be a commercial, social, political, spiritual or environmental concern.

Of course: a commonly shared, tentative identification of a problem does not guarantee any agreement on the nature of the problem, let alone on the potential solutions and the specific responsibilities with regard to those solutions. This is exactly demonstrated with the issue of food sustainability. But such guaranteed agreement is not your aim. Creating room for soft concerns means exactly this: opening up the possibility for such agreement by setting the conditions for meaningful disagreement. Taking soft concerns seriously is giving these concerns a fair opportunity in public dialogue.

Help the participants in avoiding the trap of anticipatory liberalism. Present the establishment of legally binding rules enforced by the state neither as the only resolution to (soft) concerns about technological innovation, nor as the sole purpose of the dialogue. Encourage participants to imagine more ways of organizing responsibilities for taking into account soft concerns. After all, the institution of laws requires a stronger justification than would be necessary for other resolutions, e.g. alternative ways of developing, processing, marketing or distributing food innovations.

But the recognition of a commonly shared problem may not be without consequences (i.e. non-committal). Therefore, on the other hand, do not allow participants to conclude too easily that the identified problem is a private matter, to be taken care of by individuals (e.g. as consumers). To participants, it may be tempting to consider soft concerns as private issues a priori, as they would emerge from conceptions of the good life, or good food for that matter, that cannot be shared across persons, families, or communities. But to consider a concern a private, not public matter already implies a specific distribution of responsibilities. That may well be the result of a fruitful stakeholder dialogue, but should not be the point of departure. Indeed, 
to assess whether something should be of public concern sometimes requires public deliberation. Invite participants to explore what values, if any, may create a common ground for overlapping consensus, and if necessary, how thick that common ground should be for them to take the concern seriously. In other words, use and explore the space in between state legislation on the one hand, and privatization on the other, as potential resolutions for moral conflict.

These recommendations will enable you to challenge the agenda condition informed by the liberal worldview.

\section{Challenge instrumentalism}

Invite participants to reflect on 'eating in the wild' (Mol 2011): what happens to, and what is enacted by, food innovations as soon as they leave the laboratory floor and run into the many hands of users and consumers? Encourage participants to imagine the unintended and unforeseen, yet plausible impacts of the innovation on what they consider to be important and relevant aspects of the experience of purchasing, preparing and enjoying food. This may require the investigation, perhaps negotiation, of what good food is about.

Allow participants to imagine and explicate the 'invitations' and 'inhibitions' that food technologies may offer to users, consumers and others who may be affected. A reduction of the object of concerns to clear and direct causalities between 'technology' and 'impact' carries the risk of concluding too quickly what factors are relevant and irrelevant to the problem at hand. While (morally) contested food practices may indeed be the result of deliberate and voluntary actions, encourage participants to broaden the scope of their observations and identify how these practices can or will be made possible or amplified by the innovations at issue. If, for instance, the decay of good taste is the object of concern, technological artefacts can be just as influential as supermarket assortments, culinary education, mealtime, and family traditions can be. A critical reflection of 'eating in the wild' requires that, in principle, none of these conditions are considered to be immune to moral assessment and all of them potentially relevant to the problematic situation. In sum, expand the vision of what could be causally (co-)responsible for problematic changes in food practices and 
institutions: allow participants to propose and contest a variety of causal storylines. If necessary, discuss with participants how far these causal explanations should reach.

Encourage participants to reconsider the current distribution of normative responsibilities. Causal storylines (Stone 1989) are never just descriptions of events that lead to a problem, but also imply a certain direction in which solutions (if any) are to be found. They may also imply a certain distribution of moral responsibilities: who or what causes the problem, and who is to solve it. For a constructive and fruitful dialogue on future innovations, avoid the question of guilt and liability (at least, as a free-standing topic). Ask participants to discuss forward-looking responsibilities: under the presumption that a given storyline is plausible, what to expect from whom? Suggest participants to consider responsibility as a matter of degree, and as potentially collective or shared, i.e. a problem of many hands.

These recommendations will enable you to challenge the agenda condition informed by the instrumentalist worldview.

In the next chapter, I will put these recommendations to the test, as a modest proof of principle, and as a way of specifying how these recommendations, specifically for facilitators, can be operationalized in the shape of a tool. This tool is an interdisciplinary tool that seeks to advance the inclusion of a wider range of ethical, cultural and political concerns in stakeholder dialogues on food technological innovation in order to promote the discussion of responsibilities regarding those concerns. 


\section{Appendix: recommendations for facilitators (summary)}

\section{Challenge positivism}

[1] Mobilize a variety of stakeholders who are likely to draw on different sources of knowledge, values and experiences.

[2] Encourage the dialogue parties to take into consideration patterns of interaction between the natural, the technological, and the social dimensions of food.

[3] Delay definition issues: encourage participants to ask each other for tentative explanation and clarification of these concerns without forcing them to formulate clear-cut, decisive definitions.

[4] Stimulate collective reflection and discussion of epistemic rights and responsibilities for making factual and normative claims.

\section{Challenge anticipatory liberalism}

[5] Present a frame, image or narrative that allows most participants to identify, if only provisionally, a situation that is commonly recognized as problematic.

[6] Present the establishment of legally binding rules enforced by the state neither as the only resolution to (soft) concerns about technological innovation, nor as the sole purpose of the dialogue.

[7] Do not allow participants to conclude too easily that the identified problem is a private matter.

\section{Challenge instrumentalism}

[8] Encourage participants to imagine the unintended and unforeseen, yet plausible impacts of the innovation.

[9] Stimulate the investigation, perhaps negotiation, of what good food is about.

[10] Allow participants to imagine and explicate the 'invitations' and 'inhibitions' that food technologies may offer to users, consumers and others who may be affected.

[11] Encourage participants to reconsider the current distribution of normative responsibilities. Avoid questions of blame and liability and focus on forward-looking responsibilities.

[12] Remind participants that responsibility can be a matter of degree; and potentially shared, in the case of many hands problems. 


\section{A concept so dear to people. Naturalness and the use of techno-ethical scenarios in stakeholder dialogues}

In the previous chapter I proposed a number of recommendations for those who seek to raise 'soft' concerns about food innovations and those who are addressed with this type of concerns. The chapter concluded with recommendations for facilitators; i.e. for those who are interested in organizing and facilitating a meaningful dialogue between groups of stakeholders on the impacts of food technology and innovation. Building further upon that conclusion, the present chapter introduces a specific tool - the techno-ethical scenario - that can be used by facilitators to this end. It is a tool that seeks to promote the inclusion of a wider range of ethical, cultural and political concerns.

The techno-ethical scenario can be considered a tool for technology assessment (TA) and as such subscribes to the philosophy of TA: '...to reduce the human costs of trial and error learning in society's handling of new technologies, and to do so by anticipating potential impacts and feeding these insights back into decision making, and into actors' strategies.' (Schot \& Rip 1996). It is a tool for constructive TA (cTA) in a modest sense: rather than having the direct aim of broadening the design of new technologies (and the redesign of present technologies), it aims to broaden the public innovation agenda, the items of which, in turn, may or may not feed into actual innovation processes. It is a tool for constructing discourse agendas, not for constructing technologies per se.

Apart from the TA goal of anticipation, techno-ethical scenarios may contribute to goals typical to CTA: societal learning and reflexivity. That is, they invite for an exploration of potentially relevant interactions between technology design, innovation processes, societal concerns and acceptability. Such exploration entails not only instrumental but also normative considerations, i.e. an explicit clarification of values which are promoted, undermined, or otherwise affected, by the design and application of technologies. In the context of responsible 
innovation in food technology, for example, this means that the question of good technology entails the question about good food. Also, techno-ethical scenarios invite stakeholders to conceive of the impacts of technological innovation as co-produced, rather than 'falling back in a naive contrast between technology and society and its attendant proponents-opponents dichotomies.' (Schot \& Rip 1996: 257).

The techno-ethical scenario, and its use in stakeholder dialogues, as described below, is a distinctive member of the cTA family in three ways.

First and most important of all, it seeks to broaden the innovation agenda to a larger extent than most ELSA (Ethical, Legal and Social Aspects) programs do, by addressing concerns generally considered as 'soft'. Surely, the involvement of ethical considerations in TA is nothing new (e.g. see ethical TA - Palm \& Hansson 2006). Also, the risk/ethics dichotomy often implicitly invoked in public discourses has already been identified, by a number of critical scholars, e.g. in the field of biotechnology (Levidow \& Carr 1997; Wynne 2001), public policy (Rayner 2003) and environmental issues (Sarewitz 2004). What these scholars have pointed out is that in public discussions about scientific and technological innovation, techno-scientific perspectives (such as the classic risk discourse) tend to dominate broader, normative questions. They argue that 'ethics' and 'politics' deserve a more legitimate standing in these discussions and that it makes little sense to isolate them from 'hard' risk issues.

The use of techno-ethical scenarios recognizes this need, but takes it to a more fundamental point: it aims to render dialogues more hospitable to any sort of concern that - at face value - seems to be subjective, private, irrational or irrelevant. Whether such concerns are labelled as ethical, cultural, political, aesthetic, cosmological or otherwise is not the point; what matters is that these concerns to a certain degree are expressed in mostly qualitative terms, appeal to publicly unsettled values and norms, and/or point at technologically-mediated impacts. Techno-ethical scenarios are thus designed to take into account a much larger set of concerns than, for example, the kind of moral assessment that focuses primarily on the ethics of rights, obligations, or consequences: they host 'public' as well as 'private' ethics. They are 
able to open up discussions of relatively unstable notions such as 'naturalness' - regardless whether it is a metaphysical, political, aesthetic or scientific notion.

A second distinguishing feature of the techno-ethical scenario follows from its orientation towards 'soft concerns': it is specifically suitable for the assessment of those technological innovations that are easily framed by most stakeholders as commodities of the market place. In food technology, users are typically defined as 'consumers' rather than e.g. 'clients', 'citizens', 'patients', 'co-producers' or simply 'eaters'. The implication of this perspective is that 'soft concerns' are easily set aside with an appeal to consumer choice (and, correspondingly, transparency): the equilibrium of supply and demand is supposed to be a more attractive and elegant mechanism for assessing the acceptability of food innovations than public deliberation. Responsibilities for 'soft' concerns, then, are implicitly attributed to the individual consumer (who is expected to act rationally as long as the market place is sufficiently transparent).

This privatization-by-default poses a serious obstacle to an open discussion and exploration of responsibilities with regard to food technology and innovation. Techno-ethical scenarios have a special eye for the risk of privatization exactly because they make soft concerns a matter of discussion and suggest that these may have public significance after all. This means that the use of techno-ethical scenarios enables a critical reflection of what should, or should not deserve public attention - and consequently, have the potential to open up rigid conceptions of responsibility implicit to the logic of markets. In the words of economist Albert 0. Hirschman (1970), it offers consumers a perspective to voice their concerns rather than vote with their feet and exit.

A third element of techno-ethical scenarios follows from the second, and pertains to their purpose and context in which they are used. Next to the goals of anticipation and exploration of technology impacts, techno-ethical scenarios are discussed with a strong focus on instructive, if not pedagogical purposes. If learning is part and parcel of TA exercises, then a bit of tutoring may have to be involved as well. Techno-ethical scenarios, as well as the way they are introduced during 
dialogue sessions, account for the way that stakeholder groups have been discussing similar technologies and relevant fields of application and the effects of such talk for the development of conversation.

More specifically, the techno-ethical approach aims to make dialogue parties aware of how actors implicitly claim or reject, ascribe or dismiss, epistemic rights and responsibilities for issues; i.e. who is assumed to have the right to speak about, or the obligation to account for the meaning and truth of certain concerns. (Lamerichs \& te Molder 2011; see also te Molder 2008; Veen et al 2011.) These conversational moves can pose serious obstacles to the discussion of 'soft' concerns (Swierstra \& te Molder 2012). To be sure, pedagogical instruction here does not imply that facilitators are to claim special authority on the substantial issues discussed by dialogue participants. It means that facilitators take a pro-active role in steering the discussion away from instances of privatization and irrationalization, and clarify to the participants why it is worthwhile to be sensitive to the way they, and their conversation partners, express their concerns and responses.

\section{Three stakeholder dialogues}

In the summer of 2012 and spring 2013, I have put this tool to the test in close collaboration with a research team of philosophers and science communication researchers from Maastricht University and Wageningen University. Taking the role of facilitators, we organized three stakeholder dialogues on food technology and innovation. This chapter thus reflects the experiences and insights that we have gained in setting up and facilitating these stakeholder dialogues (see Haen, Sneijder, te Molder \& Swierstra, forthcoming).

The following account does not pretend to cover all aspects of organizing and facilitating stakeholder dialogues (for a good overview, see Van Tulder et al. 2004). Instead, it highlights those aspects that are vital to the aims of broadening the food innovation agenda, and more specifically, of giving soft concerns a fair opportunity to enter the agenda. The numbered lines across the text correspond to the recommendations for facilitators as presented in the conclusion of Chapter 5. 


\section{Facilitator}

Stakeholder dialogues can be organized and facilitated by a variety of organizations, such as companies, governmental bodies, different kinds of NGO's or academic research teams. As a research team, we took the initiative to set up a series of three stakeholder dialogues in order to put our main findings about current public discussions on food technology and innovation to the test. The sessions served as proof of principle, to see if both our analysis and recommendations would be close enough to improve the scope and quality of dialogue - which, in the end, we consider a step towards a more responsive interaction between societal actors and technology actors. Here, we take responsiveness as the readiness to provisionally acknowledge the legitimacy of raised concerns, and the willingness to think and speak about them.

To be sure, as facilitators we were biased towards the inclusion of particular soft concerns on the public innovation agenda. This does not mean we accept the legitimacy and validity of these concerns a priori; it only means that we consider these concerns to be reasonable and cogent enough for further exploration by stakeholders themselves, regardless of the outcome of such exploration. Since we believe that a more hospitable, inclusive approach of soft concerns is, in the long run, in the interest of most, if not all stakeholders around food technology and innovation, we consider that such bias is justifiable. At any rate, in both the invitation to and the introduction of our sessions, we clearly stated this as our orientation.

In line with our research interests, we organized these dialogues with the following goals:

1. Stakeholders gain a shared insight in the present, implicit distribution of responsibilities with regard to soft concerns about food technology and innovation.

2. Stakeholders reflect on potential consequences of this distribution of responsibilities, for the (un)successful application and societal embedding of food technology and innovation.

3. Stakeholders collectively explore the meaning and validity of specific soft concerns, and what they imply in terms of expectations and responsibilities. 
4. Stakeholders share ideas on the preferred distribution of responsibilities with regard to soft concerns, and how that distribution may be brought about.

\section{Scenario}

The goals of these dialogues, covering the stimulation of awareness, insight and imagination, indicate that the aim is exploratory rather than in direct support of decision-making. We decided to present a future scenario as a point of departure for each of the sessions, in order to allow participants to share and discuss their perspectives and expectations of food technology and innovation, now and in the future, on the basis of a concrete, but multi-interpretable story.

We opted for techno-ethical scenarios as we acknowledge the shortcomings that Boenink, Swierstra and Stemerding (2010) have identified in ethical Technology Assessment (cf. Palm \& Hansson 2006) and conventional scenario methods (cf. Notten et al. 2003): both do not seem to take sufficiently into account the interaction between technology and morality. More precisely, they conceive of morality as a stable phenomenon. Soft concerns, however, tend to point at those impacts of technologies that touch upon contested and multiinterpretable values, norms and meanings - the interpretation and appreciation of which is likely to be subject to discussion as soon as new technologies emerge in the moral landscape. Techno-ethical scenarios, on the other hand, are specifically designed to highlight such impacts (see also Swierstra, Stemerding \& Boenink 2009).

For the scenarios we have used, see appendix 1. We have developed these scenarios according to the following criteria:

\section{Field-specific}

[2] Encourage the dialogue parties to take into consideration patterns of interaction between the natural, the technological, and the social dimensions of food.

[9] Stimulate the investigation, perhaps negotiation, of what good food is 
about.

In the scenarios, technologies play an important role in the storyline, in terms of their effects, as well as how they are discussed and evaluated by fictional characters. Yet, the narrative is not first and foremost about technologies in and of themselves. It highlights several values and meanings that stakeholders specifically attach to food production and consumption. The staged controversy in the storyline is essentially about the experience and evaluation of food. The narrative describes what happens to those aspects of food as soon as a particular technology is introduced. By focusing on the field of food, rather than the intervening technology, we tried to prevent the dialogue from reducing the range of potential public issues to matters of technological risk (cf. Levidow \& Carr 1997; Rayner 2003).

In one of our scenarios, therefore, we describe a possible future of food additives ('E-numbers') in terms of how they are jointly explained and justified by manufacturers, and how societal actors respond to that rather than solely in terms of specific technological innovations in the application of food additives. In another scenario, we describe the future of widespread availability of probiotic foods, where manufacturers market their products as natural food. Not the specific health claim attached to it, but the appeal to naturalness becomes a matter of contestation; the manufacturer's image of nature conflicts with what several other stakeholders conceive of natural food. They consider naturalness as the signature of unprocessed food. The innovation of probiotic foods, and how manufacturers frame it, thus seems to interrupt with strong but implicit convictions about good food.

\section{Concern-based}

[10] Allow participants to imagine and explicate the 'invitations' and 'inhibitions' that food technologies may offer to users, consumers and others who may be affected.

The storyline does not (exclusively) describe hard impacts of technology, such as beneficial or adverse health effects, but (rather) 
pictures those societal concerns which are generally considered as soft. We decided to introduce explicit concerns about naturalness as a featuring element, since they hardly seem to meet any of the three predominant agenda conditions and can thus be considered an exemplary type of soft concerns. Presumably, naturalness is hard to quantify and measure, and does not appeal to a publicly recognized and shared value. Also, unnatural food cannot easily be causally framed as a clear and direct result of technology. While the ideal of natural food is a key ingredient of the growing consumer trend towards more pure, wholesome and authentic foods (Rozin et al. 2004; Siegrist 2008; Kampffmeyer 2012; Fresco 2012; Dornblaser 2013), to many food experts and policy makers it seems a puzzling issue.

\section{Open to interpretation}

[3] Delay definition issues: encourage participants to ask each other for tentative explanation and clarification of these concerns without forcing them to formulate clear-cut, decisive definitions.

Where hard impacts are typically described from a third-person perspective, this does not seem to work so well for 'softer' impacts, since the latter are not (yet) expressed in an objectified, public vocabulary. In fact, this is an important reason why such aspects are considered 'soft' in the first place. Therefore, the storyline of the scenario describes more of 'talk' than 'action', through which characters express their concerns (hence, from a first-person perspective): unnatural food is not presented as a given fact, nor as a problem per se, but as a reported concern, the meaning of which is contested among characters, and left open for readers to discuss. In the staged controversy, the characters appeal to different understandings of 'natural'. Rather than forcing the participants to discover the true definition of natural food once and for all, the scenario invites them to reflect on the various values, motives and interests behind the concept, and to what extent the participants may find a common ground for further discussion of responsibilities. 


\section{Narrative}

[8] Encourage participants to imagine the unintended and unforeseen, yet plausible impacts of the innovation.

Rather than making an argument, the scenario tells a story. It has a narrative element, making the situation more concrete and thus easier to imagine; and offering a sequence of events, decisions and responses, so that the participants are invited to evaluate the course of action taken by the characters. Although the narrative is not intended to force the reader to arrive at one particular conclusion or resolution, it does make an effort in picturing a chain of events that result in a problematic situation. Also, it suggests that the course of events is contingent, influenced by human judgement and decision, and that there is a certain degree of freedom for actors to do things differently.

Furthermore, as Rasmussen (2005) points out, a compelling narrative should maintain a balance between the familiar and recognizable (identification) on the one hand, and the surprising (fascination) on the other. In our scenarios, we try to create this balance in two ways.

In terms of identification, we describe current technological developments the plausibility of which was based on a general analysis of the field of food technology, informed and checked by two food scientists associated to our project team. Also, the storyline reflects argumentative patterns that typically emerge from past and present food discourses, largely based on actual concerns, issues and responses that were raised in slightly different contexts, and in line with my analysis presented in Chapter 2. This analysis, in turn, was partially informed and checked by a valorisation panel.

In terms of fascination, we have given 'soft' concerns a more disruptive role than they seem to play in current food debates: however irrational, subjective or irrelevant they appear to many stakeholders, in the narrative they are imagined as forceful voices with 'hard' impacts on the further development of the discussed technologies. Consumer and citizen concerns may well present themselves as puzzles to technology developers: for instance, if E-numbers, by definition, live up to European food safety standards, then why do they remain the explicit 
object of public distrust? And if probiotics were essentially natural creatures, then why would their application in foods meet resistance from those who favour natural food? As long as these puzzles are not resolved, or at least properly understood, the narrative suggests, such food technologies in the long run will fail to do what they were supposed to do.

\section{Multi-layered}

[5] Present a frame, image or narrative that allows most participants to identify, if only provisionally, a situation that is commonly recognized as problematic.

In the scenarios, a problematic situation is suggested in two interrelated layers: (1) the technological application is reported to have certain effects that are unintended, or intended effects that are not realized; (2) and its launch gives rise to misunderstanding, frustration and distrust between several characters in the story. In other words, the key elements are to be found both in concerns about what technology does, and how the characters respond to and discuss those concerns: a problem of technology and a problem of communication.

We expected that not all participants would be willing to accept the validity of the reported 'soft' effects of technology (the first layer) - this was, after all, to be discussed. Therefore, what we tried to make clear with the scenarios in the first place, is what could happen as soon as none of the actors is willing to take responsibility for 'soft' concerns (second layer): the failure of a promising technology - due to a lack of public trust, misunderstanding and mutual frustrations. With that second layer, we tried to stimulate a commonly shared, 'second order' problem perception. In other words, even where participants would not initially recognize soft concerns as legitimate issues in themselves, at least they were given a reason to take these concerns seriously as a potential obstruction to successful, socially robust food innovations. 


\section{Stakeholders}

[1] Mobilize a variety of stakeholders who are likely to draw on different sources of knowledge, values and experiences.

In each of the dialogues, a variety of stakeholders participated from the food processing industry, private and public research institutes, governmental and semi-governmental policy advice, and consumerrelated NGO's (20 participants in total, see Figure 6.1 for an overview). We invited parties who are not necessarily already engaged in discussions about present or future food technologies, since we aimed for a field-specific, rather than a technology-centred dialogue. Thus, we attempted to bring together groups of participants who may have a strong sense of what good food is about, but may also draw on differing perspectives on that question.

Invitees were selected on the basis of an informal stakeholder analysis, partially informed by their engagement with current and past debates on broader food issues, partially by their expert and experiential knowledge of food additives or functional foods, and partially by their direct interests in food innovation in those fields. Since we aimed for an explorative dialogue with a broader range of concerns than we identified in recent public discussions (see Chapter 2), we considered parties with a direct (e.g. commercial or political) interest in these food technologies to be stakeholders, but also those parties of which we assumed that they have a 'stake' in what they regard as good food in general - not simply as consumers with personal preferences, but also as citizens who see a public interest in responsible food innovation.

\section{Dialogue}

[4] Stimulate collective reflection and discussion of epistemic rights and responsibilities for making factual and normative claims.

Dialogue facilitators may indeed recognize the importance of allowing room for soft concerns, but simply putting some of these concerns on the table may not be that effective when participants are reluctant to perceive these as legitimate concerns in the first place. As was 


\begin{tabular}{|c|c|}
\hline Stakeholder group & Organization \\
\hline \multirow[t]{3}{*}{ Industry } & Danone Netherlands \\
\hline & CSM Bakery Supplies Europe \\
\hline & Unilever R\&D Netherlands \\
\hline \multirow[t]{2}{*}{ Government } & Ministry of Health, Welfare and Sport \\
\hline & $\begin{array}{l}\text { Netherlands Institute for Public Health and the } \\
\text { Environment }\end{array}$ \\
\hline \multirow[t]{2}{*}{ Semi-government } & Netherlands Nutrition Centre \\
\hline & InnovationNetwork (Ministry of Economic Affairs) \\
\hline \multirow[t]{4}{*}{ NGO's } & Association of Natural Nutritionists \\
\hline & Food Guerrilla Network \\
\hline & Dutch Association for Housewives \\
\hline & Youth Food Movement Netherlands \\
\hline \multirow[t]{2}{*}{ Academia } & NIZO Food Research \\
\hline & Wageningen University, Food Chemistry department \\
\hline \multirow[t]{2}{*}{ Other } & Schuttelaar \& Partners consultancy \\
\hline & Vital Food Management consultancy \\
\hline
\end{tabular}

Figure 6.1: overview of participants

discussed in Chapter 5, the perceived epistemic status of certain topics - and of those who raise them - can provide an obstacle for fruitful dialogue. Where the naturalness of food products is discussed, for example, in a multi-stakeholder dialogue it is not evident what that means, if and how it can be understood in 'objective' terms, let alone who can or should claim a certain expertise and right to speak about it.

Once such softer concerns are raised, participants need to openly discuss rights and responsibilities for what they (claim to) know about such concerns before they can meaningfully express any expectations to each other for what to do about them. Without some agreed sense of knowledge distribution among participants (e.g. about who is justified in claiming to know what naturalness is about), certain concerns will fail to become a legitimate issue on the agenda, as some participants will not recognize those concerns as topics to be discussed in a cogent and rational way. People can hold each other accountable for actions, but also for ideas; if no agreement exists on who is to be held 
accountable for giving meaning and interpretation to the concern at hand, it becomes a dialogue of the deaf. A dialogue more hospitable to soft concerns, then, requires a discussion of epistemic rights and responsibilities.

Therefore, as an introduction to the dialogues, we made participants aware of recurring, often implicit interactional patterns that hinder open communication between stakeholders. We presented them with selected fragments of expert and citizen-consumer interactions. These fragments highlight the various epistemic claims made by discussants on food innovation. Epistemic claims describe the rights and responsibilities regarding what one can(not) know and vouch for, and such claims can be made implicitly or explicitly. We asked participants to spell out the unfruitful consequences of such implicated claims for the development of dialogue: e.g. how some discussants, unknowingly, disqualify others as not being able to make sound judgments on the topic, or how other discussants implicitly discharge themselves from having to account for whatever they claim. In such cases, little room is left, and little sense of urgency is created, for further discussion. We organized this introduction according to principles of the discursive action method (Lamerichs \& te Molder 2011).

[11] Encourage participants to reconsider the current distribution of normative responsibilities. Avoid questions of blame and liability and focus on forward-looking responsibilities.

In order to encourage participants to deliberate on present and future responsibilities for impacts of food technology and innovation in a constructive manner, the introductory part of the sessions also featured a short discussion of how to approach the notion of responsibility itself.

We thus presented the participants with a basic, conceptual distinction between backward-looking and forward-looking types of responsibility. Roughly put, whereas the first covers things like blame, accountability, and liability for past wrongs, the latter refers to efficacy, obligation and due care with regard to what remains to be done or taken care of in the future (Van de Poel et al. 2012). For the constructive kind of dialogue that we wanted to bring about, we asked 
the participants to focus primarily on the latter type of responsibility when raising concerns, responses and ideas.

[12] Remind participants that responsibility can be a matter of degree; and potentially shared, in the case of many hands problems.

Also, we pointed out to the participants that for some issues, it is hard if not impossible - to attribute responsibility to single actors. By means of an illustrative case, we argued that the failure of a food innovation can be the unintended and unexpected result from the mediated interaction between technologies and multiple actors (such as engineers, marketers and consumers), rather than specific designs and decisions in isolation. Resolving such failure, we suggested, may be a matter of shared, collective responsibility - since the alternative is that no one is expected to tackle the issue. This, of course, is typically the case with soft concerns.

[6] Present the establishment of legally binding rules enforced by the state neither as the only resolution to (soft) concerns about technological innovation, nor as the sole purpose of the dialogue.

[7] Do not allow participants to conclude too easily that the identified problem is a private matter.

Many, if not all soft concerns appear - at face value - to be private matters that are not suitable for public deliberation because if they would inform collectively binding laws and policies eventually, that would be in violation with liberal principles. This is the line of reasoning, in a nutshell, of anticipatory liberalism. Behind this idea lies a fear of moralism and paternalism. In food matters, soft concerns are therefore easily delegated to the realm of individual consumer preference (the market place), rather than the realm of public deliberation (the forum). Facilitators who seek to propose soft concerns as a topic for public reflection nevertheless, thus need to point out to participants that there is a space in between state legislation on the one hand, and privatization on the other, for potential resolutions for moral conflict. Because at both ends of the spectrum, there is little reason for participants to engage in dialogue. 
So how did we do this? First, by scenario design. We mentioned the option of state regulation in one of the scenarios; in the story, a concerned NGO asks for state regulation of naturalness claims in food products, which is instantly rejected by the minister of Public Health and Food. Thus, we let certain arguments pass why collectively binding regulation may be undesirable. Also, we suggested in the scenario that the concern for natural food - however subjective it seems - may still constitute a problem to stakeholders other than simply a minority of individual consumers. In other words, we suggested that the naturalness of food products may not be a strictly private affair as well (see my discussion above, under 'Design criteria').

Second, we decided to intervene, as facilitators, in the actual discussion as soon as participants would (implicitly) avoid a substantial discussion of soft concerns because of anticipatory liberalism; or whenever they would tend to 'stall' these concerns because these would be considered private, subjective, or individual anyway. We intervened, for example, by asking participants what problem - if any they identified in the presented scenario, and to what extent their problem perception was shared across the room. Also, we asked what alternative courses of action there could be, should national regulation not be a viable resolution for soft concerns. Furthermore, we asked the participants to recall that while there may not be an evident consensus about the meaning and value of naturalness, they may still have good reason to commonly explore the concept and see if there is any common ground to be found. In the end, we asked them to 'rewrite' the scenario, suggest a more desirable course of events and imagine a new distribution of responsibilities with regard to the soft concerns in the scenario.

\section{Insight into interactional effects}

With the introduction to the discussion of the scenario (see above), we tried to accomplish that participants gained a common understanding of the present, implicit distribution of responsibilities with regard to soft concerns about food technology and innovation. In selected fragments from focus group conversations, such distribution was reflected specifically in epistemic claims about naturalness. This understanding was supposed to feed into the discussion of the 
scenario: participants would have to be more attentive and critical about the possible effects of their own and each other's claims about soft impacts, for the progress of the dialogue.

From the observations that the participants made about these fragments, we conclude that they did gain a shared insight into the interactional effects of such implicit claims. They made clear statements, e.g. on how an industrial food expert forestalls the issue of naturalness by suggesting to know a definition of naturalness, superior to the consumers', while failing to make this definition explicit. Some described this talk as 'arrogant' and disqualifying with regard to consumers. Also, they identified a similar move in how consumers talk about naturalness in absolute, almost objective terms, thereby inviting silent confirmation rather than exploration of what the concept possibly entails. Talking this way, the participants agreed, obstructs rather than supports a fruitful dialogue on the desirability of food innovations.

Did this discursive insight into interactional effects of speech also become apparent in how participants proceeded with the discussion of the scenarios? This was, after all, what we hoped for. The truth is that we're not sure if this was a success. In several parts of the discussions (notably in the first session) participants were willing to acknowledge that natural food was somehow relevant to consumers, but seemed to avoid an explanation of what natural should refer to and why it would be relevant to themselves; let alone that they would present a justification (or criticism) of the meaning and value of naturalness. For example, one participant, working for a consumer NGO, said:

For many people the notion [of naturalness] is associated with 'processed a little as possible', I do prefer that people would simply eat fish rather than [food fortified with fish oil], and that they have a balanced food pattern consisting of food that is processed as little as possible. But if such [fortified food] products can actually make certain people healthier, then I won't tell them that they really should eat more traditional foods. That's what everyone should decide for himself.

This kind of reasoning occurred repeatedly in the course of the 
conversation: apparently, consumers care about natural food, but whether that is a valid preference is up to the individual consumer. Having discussed with the participants that this kind of (often) implicit reasoning provides a serious obstacle to a substantial discussion of the meaning and value of, and corresponding responsibilities for, natural food did not always prevent the participants from avoiding that discussion. We were surprised that even participants who represent consumer organizations were apparently reluctant to engage in such discussion.

On the other hand, we noticed that participants affiliated with industrial engineering and food science displayed a more responsive and open attitude with regard to the notion of naturalness than we observed in our earlier analysis of food controversies (see Chapter 2). Rather than dismissing the very notion as e.g. romantic in the first place, most of them declared that they were puzzled by the term and were interested to learn more about what it could mean. As one industrial engineer said:

If you're asking people, they'll ask for things like natural food. I'm quite positive this is the case. But the question is if they invite for innovation. What should we do then? To the industry it's unclear how to answer that question. Because there isn't such a clear idea of what [natural food] entails.

In posing this question, this participant did not appropriate any epistemic rights to the notion of naturalness - as was the case in the example discussed in the introduction of the session - but rather invites his fellow participants to help him find answers. Such contributions proved to be quite constructive in the dialogue process.

\section{Recognition of shared problem}

In each of the three dialogues, not all participants initially agreed on the nature of the problem as presented in the scenario. Some of them, in fact, did not see any issue at all. Especially in the first and second sessions, certain participants tended to delegate the responsibility for soft concerns - if they were to be perceived as problems at all - to the market place.

Initially, these participants displayed some degree of indifference as 
naturalness could simply appear as a meaningless but harmless marketing catch phrase. Others expressed their worries about the significance of the present dialogue if, after all, anyone is free to buy or not to buy the discussed food products. After all, applications of food technology are not only the fruits of science and technology, but also commodities on the market place. Implicitly, they appealed to the common distinction between citizens and consumers. As one industrial technologist happily commented on consumers who are concerned about unnatural products: 'the beautiful thing of the consumer is: then he won't buy it.' In other words: if unnaturalness is going to be a problem, the effective mechanism of the free market will eventually take care of it, and public dialogue will be unnecessary.

Occasionally, participants therefore seemed reluctant to further elaborate on the concept of naturalness. They privatized their views and preferences as just another individual and personal opinion. Interestingly, this mirrors the way that naturalness was discussed in the fragments presented in the introduction: such claims implicitly render the concept of naturalness immune to common exploration and further discussion.

As the dialogues proceeded, however, participants eventually arrived at an implicit agreement that the envisioned developments were problematic. They even seemed to agree on how to conceive the problem: the failure of technology (and dropping sales) due to poor communication. At first, poor communication was understood as a lack of transparency and information. Later on, it was framed as a serious lack of mutual understanding from both sides (technology enactors on the one hand, and consumer-citizens on the other). As one policy advisor commented:

One could say that [in the scenario] the food industry went too far and appropriated certain concepts that you can't appropriate just like that. The problem is that concepts so dear to people, as it were, were wrongly applied. And that's when people start protesting.

Since much of this misunderstanding was said to be about the meaning and value of naturalness, 'a concept so dear to people', participants eventually - however reluctant - started to explore this concept. 
Because we learned from the first two dialogue sessions that participants were willing to consider 'poor communication' as a problem, but only few would identify with the value of natural food itself, for the third session we decided to include food professionals who more explicitly claim to have a real 'stake' in natural food - so as to create a stronger sense of urgency with regard to naturalness as a substantial concern. The latter session proved to be more productive since these participants were willing and able to articulate specific ideas about natural food: what it means and why it is important to them. More than in the other sessions, all participants here were more eager to explore and negotiate the meaning of naturalness - a value, after all, no longer claimed to be apparently dear to consumers 'out there' but now defended by actual people in the room.

\section{Exploring and negotiating the meaning of naturalness}

As we expected, an obstacle that initially emerged in each of the discussions was the presumed subjective and idiosyncratic meaning of 'natural'. Scepticism about the possibility of ever reaching consensus on a clear and unequivocal definition of naturalness posed a serious obstacle to the discussion of consequent responsibilities. For instance, on the question if the food industry would be able to meet consumer demands, even when consumers ask for more natural food, an industrial engineer responded:

Yes. But it all depends on the definition that one attaches to naturalness. And the longer we'll talk about it, the more we'll agree that we actually have no definition at all.

We tried to soften this scepticism by pointing out that the participants nevertheless have an interest in attempting to arrive at some sort of mutual understanding on the concept, as well as reminding them that a common exploration of the meaning of naturalness may well be part of the discussion.

Also, some of the participants objected that naturalness is just another excuse for the consumer to argue with the food industry. They suggested that even if the concern of unnatural food would somehow be resolved (e.g. by avoiding the term all together), eventually, then 
consumers '...will come up with another concept within half a year... for which everyone has his own picture in mind.'

Comments like these make clear that in matters of food technology, not only certain products or producers are distrusted but also citizenconsumers can suffer from a bad image. As we noted before, some degree of mutual trust can be the result of public engagement exercises but is, at the same time, a precondition for meaningful dialogue. Regardless whether this rejection of naturalness as an exchangeable argument is justified, the fact that the integrity and veracity of such concerns were openly questioned, hindered actual discussion of the substance of naturalness.

Nevertheless, in all of the sessions, several different notions of 'natural' were brought to the table sooner or later, such as: a smaller distance between producers and consumers; a desire that expresses alienation typically experienced in urbanized societies; a balanced food system; everything that in theory can be prepared in a home kitchen; everything than can be found in a consumer's food cabinet; the use of unprocessed, raw materials offered by nature; familiar and recognizable food; the property of a process; the property of a product; part of a lifestyle; and, at any rate, a matter of degree.

Rather than taking a strong and confident stance, the participants tentatively explored the concept of naturalness by probing the concept and negotiating its limits of application. Here's an example of such exploration:

W: Natural is not always beneficial. It can also be poisonous.

$\mathrm{J}$ : But that's apart from the question whether it can be defined.

W: $\quad$ Naturalness can be defined.

J: Yes.

A: $\quad$ So what's natural? Products grown on the fields? That is natural? Or those products that were grown on the fields a hundred years ago?

K: I would say: of an origin in nature. But that's quite broad. And then one needs to define nature. Which brings us back in a circle.

D: Who knows what it means?

J: Substances that naturally occur in nature. On the farmlands or wherever. 
A: The wild strawberry used to be very small. By now it has become a large strawberry - and that one is natural as well, because it grows on the farmlands?

J: Yes.

W: Just like a chicken that is grown in 42 days?

J: And GM soy?

M: And that's what you consider natural?

A: No, well, so, how to define natural? A chicken that was grown faster is still a chicken that lived in nature, or at least, that could have lived in nature. That's what one could call natural.

D: Would you call it natural?

A: I'm not sure (laughs). I know it's a difficult and vague notion.

Then, one of the participants follows up on this conversation:

Here's what I tell my students: natural food is pure, so unprocessed and free of additives; fresh, so regional or local, but one can argue about the range; fair, to Earth, plants, animals and humans; and [certified as] organic. Those things taken together are natural food. I don't consider all organic to be natural, and natural is not necessarily organic. It's about several aspects. These four aspects taken together tell what choices have been made. These things make how natural something is.

The relevance of this latter contribution is that this participant was willing to 'take a shot' and proposed a definition while presenting herself as accountable to this particular conception. She leaves certain aspects of it open to discussion, while not giving in to the idea that any attempt to a common understanding would be circular or senseless. In fact, her comment opened up a further discussion of the constraints of organic certification; apparently, current regulations do not embody the values that they were supposed to. The concern of naturalness, here, is entangled with sustainability issues, but seems to capture a broader set of values and considerations. As one food engineer commented: 'We've had ten years of debate about the question: what is organic? This is also going to happen with naturalness. Probably, then, we'll end up with a list and a corresponding label.' 


\section{Distributing responsibilities}

In the last part of the discussion, we invited participants to reflect on future responsibilities with regard to the discussed issues: what can we reasonably expect from whom to take care of? The participants suggested a range of different options. Some proposed improvements in public communication, suggesting that the term naturalness is to be avoided from commercial expressions, that labelling will do the job of informing concerned consumers, or that food manufacturers will have to be more open and transparent about their production processes. Others proposed that the national government would give industrial and societal organizations an ultimatum: if they won't be able to come up with a joint, feasible approach towards natural food, the government will step in.

Some recommended an improvement of food technology and food processing itself, suggesting that innovations are to be developed in collaboration with consumers from an early stage in the process. About the distrust of E-numbers, a policy advisor said:

You could also see this given as an opportunity for the food industry to innovate and develop new products. Apparently, there's a group of consumers who are suspicious about E-numbers, so then you could develop products that are preserved in a different way. There are several techniques of preservation, like pascalization, using high pressure, so you won't need any chemical preservatives. Well, that's more expensive to produce, so then you'll also need to tell a story that is able to move consumers and get them to pay an extra 10 to $20 \%$.

Notably, most of these solutions are 'procedural' in the sense that they avoid the substantial question of what a plea for natural food implies: what kind of actions would be required to promote or protect the naturalness of food products and production. Rather, they hint at ways of organizing better communication and more inclusive innovation processes through which it may become clearer what naturalness stands for. This indicates that while specific responsibilities for specific tasks were not discussed at all, at least most participants seemed to agree that the concern about naturalness is worth of serious consideration, and that this concern requires a collective organization of responsibilities. 
We were glad to see that some of the participants were now at least able to draw explicit links between the epistemic and normative status of naturalness on the one hand, and taking forward-looking responsibilities for natural food on the other. That is, some of the participants, including engineers, marketers and policy advisors, suggested that the unstable and fluid ('soft') status of food concerns is not a sufficient reason for not engaging in a discussion on responsibilities for such concerns. Certainly, this is an important step toward responsiveness.

For example, a participant (A) working for the Netherlands Nutrition Centre was asked if she would see a responsibility for the Centre to organize or engage in a public dialogue on natural food. In discussion with a policy advisor (J), a marketer $(\mathrm{K})$ and a moderator $(\mathrm{T})$, she rejected the suggestion:

A: $\quad$ We're rather in the business of health and sustainability. I don't see any role for us with regard to the whole notion of naturalness with all of its meanings. I'd say this is rather something for NGO's that appeal to the sensation of naturalness.

J: $\quad$ But in the past, sustainability and animal welfare also used to be something for those NGOs and marginal groups. The Nutrition Centre used to be focused on scientifically established effects on health only. By now, you've included the issue of sustainability. So how did that happen?

A: $\quad$ The Ministry of Agriculture has made more means available for that; because of certain developments in society and consumer preferences. Apparently, that's how it works.

$\mathrm{J}: \quad$ But could you imagine that this will happen to naturalness as well?

K: $\quad$ Sustainability is about improving the world. And healthy food is healthy. But naturalness: we don't know what it is good for.

T: $\quad$ But could you imagine that there are people who can come up with a story about that?

K: $\quad$ Yes. I guess so. 


\section{Conclusion}

In this chapter I have described a way for facilitators to stimulate stakeholder participants to engage in a collective exploration of 'soft' concerns about food technology and innovations. The chapter can be read as a story about how to implement the twelve recommendations for facilitators (Chapter 5), which, in turn, serve as a set of guidelines for the transformative, more radical approach to the three dominant conditions of the public food innovation agenda. That is, if facilitators seek to challenge the way stakeholders usually think and talk about food technology and innovation and problematize the tacit assumption that concerns need to be expressed in mostly quantified terms; appeal to undisputed values; and point at consequences with clear causes; then the approach presented in this chapter may do the trick. It consists of a specific tool that we have developed to this end (the techno-ethical scenario), a specific setting in which it is used (an explorative, multi-stakeholder dialogue on forward-looking responsibilities) and a tutorial element by means of introduction (a discursive psychological analysis of the interactional effects of speech).

Certainly, the report of these dialogues does not provide a full-blown experimental proof of the validity of this approach, nor does it pretend to do so. Rather it provides a 'proof of concept'. As a practical suggestion for facilitators, it should provide an idea of how it can be done. The scenarios used by us are prototypes to be further developed, and should indicate where to start and what direction to take.

From the dialogue sessions, we have learned two things about giving soft concerns a fair opportunity to gain access to the public innovation agenda. First, that it can be done, and second, that it's not easy.

We managed to create a setting in which a diversity of stakeholders were willing and able to consider soft concerns about food technology and innovation as legitimate questions that deserve collective attention - if not responded to with answers and promises, then at least with a common exploration of what these concerns mean and imply. This becomes clear not only from our observations of the discussions but also from what several participants, particularly engineers, reported afterwards: the conversation made them aware that the discussed concerns were not as unreasonable and irrelevant as they assumed 
beforehand. What some of them at a first reading of the scenario did not acknowledge as a real problem, emerged from the following discussion as an issue worth reflecting on.

Also, in each of the discussions some of the conditions of the food innovation agenda were implicitly questioned. Several participants recalled that food sustainability, too used to be difficult to objectify and operationalize (imagining that natural food can be a new candidate for the food agenda); some discussed 'hard' values in an historical perspective, subject to change (implying that moral agreements can be built where they do not yet exist); and others suggested that food technologies have the ability to change elements of food culture (proposing that technology developers should accept their share in responsibilities for 'soft' food concerns). For us, as facilitators, these comments were bright signs of the kind of conversation that we hoped for.

I have described some of the obstacles we have encountered in making room for soft concerns during the dialogue sessions. Participants did not seem very eager to engage in a substantial discussion of the value and meaning of e.g. naturalness, alienation, good taste, authenticity and consumer autonomy, as soon as these terms did arise from the discussion: repeatedly, the free-market mechanism, rather than collective deliberation, was invoked as a one-size-fits-all solution for such soft concerns. Also, we were confronted with a deep and widely shared scepticism about the possibility of reaching consensus on an unequivocal definition of terms like natural, fresh and pure. However justified this scepticism may seem, it did pose a serious obstruction to the dialogue's aim of collectively exploring the meaning and validity of specific concerns, and probing each other's perspectives on good food. The challenge was to present these participants with sufficient reason to engage in such dialogue even though complete consensus was deemed out of reach.

Apart from these obstacles, it proved especially difficult to reach out for stakeholder parties in the food industry and retail and get them interested in attending the meetings. A great many explanations can be given for this - and surely few of them pertain any relevance to the challenge of making room for soft concerns on the public food 
innovation agenda. Nevertheless, it is safe to say from our own experience that it was difficult to convince several invitees in the industry and retail sector, and explain to them in advance why it could be in their interest to engage in the kind of dialogue they were invited for. Given my earlier analysis of the discourse of food technology and innovation, this did not come as a surprise, but it does point at another difficulty in the facilitator's attempt to give 'soft' concerns a fair opportunity to access on the innovation agenda. If the dialogue is meant to promote the discussion of those concerns that are typically unidentified, unexplored and ill-articulated, a facilitator has only limited means to convey the potential relevance of discussing these concerns in the first place, since a commonly perceived degree of relevance is the result of such dialogue, rather than a given.

To us, these difficulties taken together proved to be a source of disappointment but also, ironically, a sense of support. Surely, the setting of the dialogues was quite artificial and open-ended; there were no imminent, 'hard' risks lurking in the background, forcing the participants to come up with strong conclusions and decisions. This may explain some of the difficulties mentioned earlier: few of them felt a strong sense of urgency.

But these difficulties also provide with evidence (albeit somewhat circumstantial evidence) for my earlier analysis of the public discourse of food technology and innovation: citizen-consumers, policy advisors, industrial engineers, food scientists, marketers and other stakeholders share deeply held convictions about the relevance, cogency and public significance of certain types of food concerns; and about their consequent hierarchy. Apparently these persistent convictions, exemplified in the soft/hard dichotomy, are harder to tackle than one could hope for with a single, civilized dialogue session - not in the least because they are embedded in broader conceptions of science and knowledge, ethics and politics, technology and responsibility. Taking also into account the actual advances that we have made with our approach in challenging the soft/hard dichotomy, these are good reasons for further developing and testing this approach, and making it work in sustainable, on-going stakeholder dialogues and public debates on the question of good food. 


\section{Appendix: scenarios}

Scenario - Workshops $1 \& 2$

\section{2}

Finally, Yanola's food manufacturer gets approval from the European Food Safety Authority (EFSA) to make a specific health claim about Yanola yoghurt drink: according to EFSA, there is sufficient evidence for the claim that the added probiotics reduces the risk of colon cancer in healthy people. Making similar claims, two competitors introduce varieties of this yoghurt drink. Gradually, more and more health claims on probiotic foods are approved by EFSA. Some products are said to help reducing high blood pressure, and other products would be able to block the symptoms of certain food allergies. Soon, supermarket shelves are packed with products that present themselves as probiotic foods: yoghurt, cheese, fruit juice, cookies, ice cream and infant formula.

\section{4}

The Eurobarometer, a European citizens' poll, comes up with remarkable statistics: almost $40 \%$ of the respondents claims to have 'little to no confidence' in the food industry and its marketed products. When asked for the most preferred qualities of food, $65 \%$ reports 'health'. $34 \%$ mentions 'natural' as the most important quality.

The addition of probiotics in food, then, seems to be a golden opportunity for food manufacturers: the success of this food technology may well count on enthusiasm among food engineers, and in the same time, trust from the public at large. An ideal combination of healthy and natural food. And this is exactly how manufacturers market their products: 'all the best that nature has to offer'. Indeed, these are 'friendly' bacteria that become part of our food as living organisms. In other words, probiotics give a new impulse to 'natural' as a unique selling point.

\section{7}

This is going too far, according to the Association of Natural Nutritionists. Together with several other organisations, the 
association launches a campaign and demands for national regulation on naturalness claims. 'Natural' cannot and should not imply that food is highly processed technologically. That would be a clear case of deception. If there are strict regulations for 'organic' food, then why not for natural? An open letter to the Minister is published in a newspaper, and 14,000 citizens sign an online petition.

Minister Oudshoorn, of Public Health and Food, is not comfortable with this petition. He declares to the press that he doesn't wish to interfere in discussions about such a vague word - let alone that he would suggest any policy. 'Can we really draw a boundary between technology and nature?' Also, Oudshoorn argues, at least there are clear standards for organic certification warranted by the SKAL foundation. But we can't measure whether or not something is 'natural'. If there is a real demand for a naturalness label, then market players should mutually agree and take care of it.

\section{8}

A new wave of criticism comes from an unexpected source. The food technology group from KIVI-NIRIA, a national professional organisation of engineers, objects that Yanola would violate the Dutch Advertising Code. Allegedly, Yanola's campaign about probiotic fruit juices suggests that 'naturalness' is healthy and tasty by definition, thus unfairly discrediting food technology. The suggestion that processed food would entail less quality is a consumer deception. Quite the opposite is true, according to a spokesperson of KIVIA-NIRA: the application of probiotics is an exemplary case in point.

The Dutch Advertising Code Committee considers the complaint to be ungrounded: they point out that the average consumer likely does understand what 'natural' means in this context. Nevertheless, the committee advises Yanola to 'be careful with the possibly suggestive connotations of the term.'

\section{2}

A TV documentary - The Truth about Functional Foods - gives rise to another debate about probiotics in food. Can Yanola really live up to her promises suggested by the happy cows on a green pasture as depicted on their Yoghurt packaging? The documentary features an artist who designs diary packaging that shows cheerful 'free range' 
scientists, dressed in white coats, in a lab.

On top of it all, Yanola receives the Golden Windegg, an annual prize for misleading marketing in the food sector, awarded by consumer organization Foodwatch. The terms 'natural', but also 'genuine' and 'pure' are dismissed by the organization as suspicious.

\section{3}

Due to the persistent bad press, two major Dutch supermarket chains decide to avert a large variety of probiotic foods from the shelves. Not in the least because sales are gradually declining. In a interview in a Dutch newspaper, Hans Berends, former CEO at Yanola, looks back at the past ten years. His conclusion: 'the probiotics revolution has died all too soon. A great pity. Apparently, many consumers don't know what they want.' 
Scenario - workshop 3

\section{Strange E-numbers}

Because of the persistent public distrust of E-numbers, a number of food processing manufacturers decide to launch a big publicity campaign, in cooperation with Wageningen University, about the safety of E-numbers. They explain what the ' $E$ ' stands for, why specific additives are being used, and how safety of additives is tested.

Consumer organization 'Pure Nature' responds with a counter campaign. The organization claims that many E-numbers are not necessary at all, and do not belong in our food. There's not so much wrong with processed food as such, they argue, but the abundance of Enumbers makes us even more alienated from our food than we already are. Because of flavourings and colourings, for instance, today's children don't know what foods really taste and look like. And preservatives make people forget how several products can best be stored, resulting in indifferent consumer behaviour and enormous food waste. 'It's time for a more natural approach to food,' they propose in a petition. The organization demands that the food industry uses as few E-numbers as possible. The petition is signed by 80,000 people.

President of the Federation of Dutch Food Industries Michiel Boonstra responds in an interview: 'it all depends what one takes for "natural". That's a subjective matter. Eventually, the consumer is free to decide whether to purchase products with additives. But let one thing be clear: going back to the middle ages is not an option. Modern food technology is simply part and parcel of our food.'

A renowned research agency launches a consumer poll on E-numbers and finds that $60 \%$ has an issue with E-numbers for being 'unnatural'. This is also reflected in sales of processed foods with preservatives and flavourings, which are dropping rapidly. 


\section{Conclusion}

As the food supply chain has become longer, more complex and opaque over the past fifty years, the distance between those who make food and those who eat it has widened. This is not only a topographical distance, but also a symbolic one: both groups do not always seem to share the same values, meanings and perceptions of good food. Especially where technology is involved, public (dis)trust has become a growing issue.

My explanation for public distrust in food technology and innovation is that technology (en)actors fail to be responsive to a particular set of consumer-citizen concerns. Trust cannot be forced, but trustworthiness - a precondition for trust-can be enhanced. For the agro-food sector this means explicating the norms and values they act upon. After all, trust is a matter of normative expectations. More importantly, trustworthiness means to be responsive to public concerns and engage in a critical discussion about those norms and values. It implies the readiness to provisionally acknowledge the legitimacy of raised concerns, and the willingness to think and speak about them. Responsible innovation in food technology means that technology (en)actors are, at least, sufficiently responsive to a broad variety of societal concerns.

But out of so many food concerns that people raise, only a few make it to the public innovation agenda and become recognized issues. The central problem addressed in this dissertation is that a particular type of consumer-citizen concerns are structurally marginalized - by food engineers, policy makers, and even citizen-consumers themselves and kept away from the public food innovation agenda. This type can be roughly described as 'soft' concerns: Swierstra (2011) coined this term to indicate that such concerns are often considered by technology actors as vague, irrelevant, subjective. Eventually, the structural marginalization of soft concerns constitutes a problem of democratic legitimacy (i.e. a low degree of acceptability of innovations) but also a lack of efficacy of costly innovations (i.e. a low degree of acceptance). 
With this dissertation, I have offered an interpretation of the problem and a perspective on solutions. The interpretation consists of an analysis of the public discourse of food technology and innovation (of food additives in particular) in The Netherlands: I have identified three conditions of the innovation agenda (often implicitly relied on by stakeholders) that make up for a dichotomy between 'hard' issues and 'soft' concerns. My solution is two-fold. I have presented recommendations for several stakeholder groups for how to make sure that this dichotomy will no longer pose an obstacle to fruitful stakeholder dialogue on food technologies and innovations; and I have presented and tested a particular tool - the techno-ethical scenario for dialogue facilitators who aim to give 'soft concerns' a fair opportunity to gain access to the innovation agenda.

Both my analysis and my conclusion pertain to the terms in which people think and talk: it focuses mainly on discursive practices. Certainly, this approach has its limitations: the world is not shaped by words only. How agendas are built, how trust is established and how innovations come about, depends just as well on what people (and things) do. The politics of food covers a much broader range of societal responses to modern food technology that go beyond deliberation. By implication, my conclusions and recommendations have their limits as well. At best, they can be understood as partial guidelines. But my strong conviction is that the things we do, can be changed by the way we dispute, argue, criticize and justify. It matters on what grounds we do so, and whether these grounds are commonly shared. It should matter, at any rate, in relations of trust.

\section{Findings}

In my discussion of the paradox of E-numbers I have argued that the often-heard call for more transparency is not necessarily the solution for the problem of public distrust of food technologies. Distrust of food additives is persistent, and this cannot be adequately understood without taking into account the wider range of ethical, aesthetic and cultural concerns that citizen-consumers raise. Conversation partners tend to treat many of such concerns as irrational and private. This is a recurrent pattern in the public discourse of food technology. 
A typical example of such concerns is the complaint that technologically processed foods are unnatural. Another example is the 'social meal' argument, raised by consumers who are concerned that food additives enable fast dinners to be enjoyed in solitude. Also, there is the concern that convenience foods may induce laziness and indifference: they compete with the pleasure of cooking. And there is the broader concern about the decay of taste and food culture. These concerns point out that food is a bearer of culture, a source of good taste and pleasure, and an ingredient of the good life. Some consumercitizens are concerned that these positive aspects of food are gradually disappearing due to modern food technologies.

An essential point in my argument is that these concerns are not always as unreasonable and private as they seem at face value. They do not score very high on three criteria implicit to the way we think and talk about food issues - but these criteria are disputable. These criteria, identified and criticized by Swierstra (2002; Swierstra et al. 2009; Swierstra \& te Molder 2012), can be understood as agenda conditions: they prescribe what types of concerns qualify as legitimate topics on the public innovation agenda. Each of them is grounded in a broader conception of knowledge, politics and technology respectively (see Figure 7.1).

\begin{tabular}{|l|l|}
\hline Condition & Prescription \\
\hline Quantifiability & $\begin{array}{l}\text { A concern's substance is appropriate for measurement and can } \\
\text { be expressed in quantitative terms. }\end{array}$ \\
\hline Publicity & $\begin{array}{l}\text { A concern appeals to values commonly recognized by all of us; } \\
\text { and it proposes norms that, in principle we can all agree on. }\end{array}$ \\
\hline Causality & $\begin{array}{l}\text { A concern articulates a problem as the clear consequence of } \\
\text { either human action or technology. }\end{array}$ \\
\hline
\end{tabular}

Figure 7.1: Three conditions of the public innovation agenda

Taken together, they are supposed to indicate how well a given concern can be the object of responsibility: i.e. to what extent actors are willing and able to assume or accept responsibility for tackling the problem at hand. If a concern is not a 'real issue' at all, there is presumably no reason to take responsibility for dealing with it. They suggest under what conditions technology developers (or other actors who are addressed with these concerns) can reasonably be held accountable for 
food concerns. Concerns about food safety and health effects typically fulfil these conditions to a high degree; concerns about e.g. natural food, authenticity or the decline of food culture seem not to.

Critical insights in science and technology studies, political philosophy and philosophy of technology, however, make clear that the validity of these conditions is rather limited.

With regard to quantifiability: in theory, anything can be counted and measured - as soon as people have good reasons to do so. New concerns may exactly offer those reasons. Also, it is not always desirable to quantify the way people relate to food, nor is it always necessary in order to scrutinize the problem at hand.

The problem with the condition of publicity is the narrow way it is often interpreted in public debate. The condition may rightfully apply to collectively binding proposals, to be enforced by the state (such as formal legislation), but not to concerns per se. If concerns happen to appeal to rather contested values, norms and meanings, this is not a legitimate reason for keeping them from the public agenda - on the contrary. In the public sphere citizens should be able to critically investigate where to (re-)draw the line between public and private matters. New technologies may give rise to such considerations.

The condition of causality relies on the untenable idea that causal explanation precedes attribution of responsibility. Moreover, it presupposes that technologies are mere instruments, not agents; and that human actions can be clearly distinguished from material conditions and circumstances. But technologies are more than just instruments. Certain concerns about food technology cannot simply be reduced to the bare impact of technology itself, not to how it is put to use by individuals consumers.

There is a price to pay if societal and technology actors allow these conditions to govern the public food innovation agenda: vital aspects of our relation to food, and how they are affected through food technology and innovation, then remain below the public radar. Societal and technology actors thus miss the opportunity to engage in a meaningful dialogue on 'good food' and what that entails for food innovation. 
The three agenda conditions set high standards for concerns that aspire to become legitimate public issues. But the 'perfect' public issue is not one that is already resolved in the first place; it is one that has enough potential to grow, develop, and transform through collective inquiry. The by now recognized issue of food sustainability is a case in point: the work that these three conditions imply is not finished as soon as the issue has conquered access to the public innovation agenda. I have highlighted what kind of challenges food sustainability as a growing concern had (and still has) to face in order to gain its full recognition as a serious food issue - along the lines of the three agenda conditions. Thus, reality, in and of itself, does not offer a satisfactory explanation and justification for the fact that food sustainability has been able to rise as a legitimate issue over the past decades. One has to acknowledge the human efforts to allow concerns to grow.

If concerns generally considered as 'soft' are to be given a fair opportunity to gain access to the food innovation agenda, broadly two directions can be taken.

The first is more pragmatic and suitable for short-term improvements of public dialogue. It presupposes that the current three agenda conditions are in themselves reasonable but proposes dialogue parties to adopt, respectively, a strategy of adaptation (to the conditions) and a principle of charity. Here, technology (en)actors and societal actors will have to meet each other 'half way'.

My recommendation for societal actors is to align their 'softer' concerns with the present conditions of the food innovation agenda by making explicit how their concerns are entangled with more publicly recognized problems. To be more precise, they need to show how soft concerns are intrinsically connected with hard impacts, and why certain 'hard' concerns cannot be adequately taken care of without taking seriously the 'softer' ones. This is a promising strategy especially where it explicitly invites addressees to rethink the current, implicitly shared distribution of responsibilities for good food.

My recommendation for technology actors is that, when addressed with 'soft' concerns, they assume some degree of reasonableness in 
those concerns - even when not all of the facts, values and causal relations (and consequently, responsibilities) have been agreed upon. The principle of charity exactly prescribes such assumption. It reminds us that the only alternative is the end of conversation. It is hard to tell at what point one should stop being charitable, but I suggest a rule of thumb: the scope of charity ends where the benefit of ignoring 'soft' concerns outweighs the potential benefits of understanding them. Technology actors then are recommended to remain charitable as long as they reasonably expect that there is still the opportunity to learn about new perspectives and worldviews. These may result in creative business opportunities (how to innovate) and early warning signs (how not to innovate).

To be sure, whether or not technology actors should accept a responsibility to act upon 'soft' concerns can still be subject to the conditions of quantifiability, publicity and causality. But a charitable response implies that one is willing to suspend those requirements in dialogue, and reconsider assumed responsibilities as soon as a given 'soft' concern turns out to be a legitimate issue over time.

I have also presented a second, more critical direction of solutions. I recommend facilitators to challenge (rather than adapt to) the three agenda conditions by setting up dialogues in such a way that stakeholders are encouraged to deliberate on concerns about rather qualitative, morally contested, and technologically mediated impacts of food innovation. To this end, I have introduced a specific tool - the techno-ethical scenario - that is designed to broaden the public food innovation agenda.

The techno-ethical scenario, and how I suggest it is used in stakeholder dialogues, broadens the innovation agenda to a larger extent than most ELSA programs do, by opening up dialogue for any concern that - at face value - seems to be subjective, private, irrational or irrelevant. It is specifically suitable for the assessment of those technological innovations that are easily framed by most stakeholders as commodities of the market place. Also, it makes dialogue parties aware of how they implicitly claim or reject epistemic rights and responsibilities for issues; and the effects of such talk on the development of conversation. For the latter aim, the discursive action 
method (Lamerichs \& te Molder 2011) is particularly helpful in making participants aware of recurring, often implicit interactional patterns that hinder open communication between stakeholders.

In order to give rise to meaningful stakeholder dialogue on soft food concerns, the techno-ethical scenario needs to tell a story that is foodspecific, concern-based, open to interpretation, and multi-layered. As for the latter requirement, the scenario should problematize both what food technology does, and how the characters respond to and discuss concerns about technology impacts. Even where participants do not initially recognize soft concerns as legitimate issues in themselves, at least they are given a reason to take these concerns seriously as a potential obstruction to successful, socially robust food innovations.

In close collaboration with the project team I am part of, I have put this tool to the test in three multi-stakeholder dialogue sessions on natural food in the contexts of food additives and functional foods. Although, at first, participants seemed reluctant to elaborate on the concept of naturalness, at least they arrived at an agreement that the developments as envisioned in the scenario were problematic. In one of the sessions, participants were willing and able to articulate specific ideas about natural food: what it means and why it is important to them. Scepticism about the possibility of ever reaching consensus on a clear definition of naturalness posed a serious obstacle to the discussion of consequent responsibilities, but eventually, in all of the sessions, several different notions of 'natural' were brought to the table. Rather than taking a strong and confident stance, the participants tentatively explored the concept of naturalness by probing the concept and negotiating its limits of application.

While specific responsibilities were not discussed at all, most participants seemed to agree that the concern about naturalness is worth of serious consideration, and that this concern requires a collective organization of responsibilities. These are true improvements of the quality of stakeholder dialogue.

Nonetheless, stakeholders share deeply held convictions about the relevance, cogency and public significance of certain types of food concerns and their consequent hierarchy. These persistent convictions 
are hard to tackle, arguably because they are embedded in broader conceptions of science and knowledge, ethics and politics, technology and responsibility. Perhaps they are best epitomized by the adage 'in matters of taste, there can be no dispute'. By challenging these conceptions and pointing at the effects they have on the quality of dialogue on food innovation - explicitly with this dissertation and implicitly with the stakeholder dialogues we have organized - I have argued why such dispute can actually be fruitful if not necessary.

\section{The soft/hard distinction}

A key concept in my argument is the distinction between hard and soft concerns. The soft/hard distinction is a theoretical construct: it serves to make the implicit hierarchy of concerns more visible and subject to critical discussion. While actors themselves may not use the terms 'soft/hard' to justify this hierarchy, it does touch upon more conventional oppositions that many actors appeal to in discussion: public/private; objective/subjective; clear/vague; strong/weak; real/imaginary; and rational/emotional. I could have presented my argument without making use of the terms 'soft' and 'hard', but that would probably make this manuscript lengthier than necessary. Nevertheless my interpretation of this concept begs for further explanation, as it may give the false impression that I support the use of these terms in a context beyond the purposes of critical discourse analysis.

The soft/hard distinction can be interpreted in two ways. According to a realist understanding, concerns are 'hard' or 'soft' in and of themselves; their degree of 'hardness' is an intrinsic and essential property. In the constructivist interpretation that I uphold, in contrast, concerns are labelled 'hard' when they meet most of the three agenda conditions. They are labelled 'soft' when they barely meet any of these conditions. The essential difference between these interpretations is that the constructivist interpretation leaves room for the possibility that soft concerns may become harder through public deliberation. In the realist interpretation, the inherent 'softness' of certain concerns is sufficient reason to keep them away from the public innovation agenda.

Arguably, the soft/hard distinction might be a useful expression to 
roughly indicate the degree to which concerns are more or less articulated and scrutinized: i.e. to what extent these concerns have been substantiated by numbers, commonly shared values and causal stories. But it should not be used as a justification for denying soft concerns access to the public innovation agenda. That is the point I wanted to make.

A more appropriate term for 'soft' concerns, then, would be experiential concerns; since the common feature of these concerns is that they emerge from lived experience. How they are to be interpreted and evaluated, and what they imply in terms of responsibility, is relatively open. They are often expressed in qualitative terms. They appeal to values and norms that are not easily recognized by all of us. And they tend to point at mediated impacts of technology.

A more appropriate term for 'hard' concerns would be inquired concerns, in the sense that they have a history of intersubjective investigation. There is some sort of (tacit) agreement on how they are to be interpreted and evaluated, and what they imply in terms of responsibility. They are often expressed in quantitative terms. They appeal to values and norms that are less controversial. And they suggest a relatively clear-cut story about who or what causes the problem. As soon as hard concerns become part of the public agenda, we call them issues. To be sure, hard concerns can (and often do) give rise to public controversy and disagreement; but at least they are commonly considered as legitimate concerns.

What this alternative terminology clarifies in particular is that 'hard' concerns emerge from (or might become manifest in) experiential problems too; and that 'soft' concerns are claims to be inquired as soon as they are raised. In principle, all concerns are experiential; but only some of them will actually be inquired.

What does this imply for the three agenda conditions that constitute the soft/hard distinction in the constructivist sense? Ideally speaking and this is what especially dialogue facilitators should keep in mind the three agenda conditions should no longer govern the public innovation agenda. But as long as they do, that entanglement strategies and the use of a charity principle can be helpful to societal and 
technology actors in order to mitigate their influence.

Nonetheless, the three agenda conditions can still be productive as fair conditions for institutional innovation agendas.

Recall that the public innovation agenda is that part of the public agenda that tries to exert influence on various institutional agendas, and which in itself is shaped in and through informal public debate (see Chapter 3). It is a set of issues (regarding technological innovation) commonly recognized by public and institutional actors as deserving attention and deliberation. Institutional agendas of innovation, on the other hand, are formally tied to organizations and typically (but exclusively) inform decision-making processes. Institutional agendas in the field of food technology and innovation include R\&D agendas in the food industry, research agendas of private and public academic institutions, national and global policy agendas, parliamentary and legislative agendas, and so on.

As opposed to the public agenda, institutional agendas more directly implicate strategies, decisions, actions and consequential investments. Institutional agendas are not only discourse agendas ('which concerns deserve our attention?'); they are action agendas ('which issues call for action?'). If the three agenda conditions are supposed to permit inquired concerns only, then they better serve as gatekeepers for the institutional, rather than the public agenda. More than the public agenda, institutional agendas result in (collectively) binding decisions and programs - political or technological.

As for the public innovation agenda, on the other hand, current standards of rationality should be stretched, relaxed and suspended if we aim for a more fruitful public dialogue on food innovation. I contend that the public agenda should be governed by more general and open conditions, such as (1) assertibility, not quantifiability; (2) something like debatability, instead of publicity; and (3) relevance rather than causality. Assertibility may prescribe that concerns are based on assertions that in principle can be warranted by (further) qualitative and/or quantitative inquiry, and by reliable observations and interpretations about which intersubjective agreement is not impossible (cf. Dewey 1938: 9-10). Debatability would prescribe that 
concerns appeal to values about which it is not impossible to ever reach agreement through reason-giving and taking; if not about their meaning and relevance, then at least about the kind of norms and actions that they imply (cf. Pincoffs 1962: 2-4). Relevance could prescribe that concerns identify human and/or non-human factors that can become relevant to the problem as, upon further scrutiny, these factors can be commonly recognized as an extraordinary contribution to the problem, and, in principle, are not unavoidable - whereas judgments of what is 'extraordinary' and 'unavoidable' are open to discussion (cf. Meyer 2000).

These concepts are - at best - implicitly proposed in my criticism of the present agenda conditions (see Chapter 3) and merit further philosophical elaboration in the specific context of agenda building. That would go beyond the purpose of my argument. Nevertheless, these alternative concepts should at least hint at the possibility of a more hospitable and charitable conception of rationality, but also at the assurance that access to the public innovation agenda need not be unconditional. After all, not each and every single food concern may deserve collective attention.

\section{Responsible innovation}

My point is that the conditions of quantifiability, publicity and causality should transfer from the gateway of the public innovation agenda to those of institutional agendas. For institutional agendas, it is reasonable that conditions become stricter: assertible concerns will have to be quantifiable; debatable concerns will have to stand the condition of publicity; and relevant stories will have to turn into causal stories.

In order to clarify this point, let us consider what it means for the ideal of responsible innovation.

Von Schomberg (2011) offers a useful definition of the concept: 'Responsible Research and Innovation is a transparent, interactive process by which societal actors and innovators become mutually responsive to each other with a view to the (ethical) acceptability, sustainability and societal desirability of the innovation process and its marketable products (in order to allow a proper embedding of scientific and technological advances in our society).' 
One of the key features of this approach is mutual responsiveness. Stilgoe et al. (2013) point out that responsiveness refers to both reacting and responding; it involves 'responding to new knowledge as this emerges and to emerging perspectives, views and norms.' (2013:1572; cf. Pellizzoni 2004). One responds, in a modest sense, by answering to and taking into account emerging concerns: if not by concrete actions then at least by words. Responsiveness thus implies the readiness to provisionally acknowledge the legitimacy of raised concerns, and the willingness to think and speak about them. In this sense it somewhat overlaps with other dimensions of responsible innovation that Stilgoe et al. have identified, such as inclusive dialogue and reflexivity of technology actors (2013).

Although mere 'talk' may appear non-committal, it certainly helps as a start. In fact, it is hard to see how responsible innovations come about, when the societal hopes and fears that anticipate these innovations are not taken seriously. Dialogical engagement can be a strong sign of taking things seriously.

This kind of responsiveness suggests that various stakeholders explore and assess the opportunities and threads of a new or emerging technology through on-going dialogue, and discuss potential distributions of responsibilities. This is, at any rate, what Von Schomberg's conception of responsible innovation implies: responsibility presupposes dialogical responsiveness.

In essence, the conditions of quantifiability, publicity and causality - as gatekeepers of the public innovation agenda - obstruct the exercise of responsiveness.

To see why, it may be instructive to consider responsiveness as one of several types of responsibility. For example, Bovens (2007) warns not to confuse responsiveness with accountability in policy making:

Accountability (...) is in nature retrospective. Actors are to account to a forum after the fact. Responsiveness to the needs and preferences of a broad range of stakeholders and new forms of consultation and participation may be very important to enhance legitimacy (...), but they do not constitute accountability. 
They provide proactive inputs into the policy process and should be classified and studied separately for what they are: forms of consultation and participation. They lack the element of justification, judgment and consequences. (2007: 453).

Where accountability is backward-looking, responsiveness is rather a forward-looking type of responsibility.

Stivers (1994) draws a similar line between responsibility (as accountability) and responsiveness, and explains why administrators are reluctant to identify with the latter type: "The responsible bureaucrat is a proactive agent, one who causes things to happen, in charge of his or her own conduct, trustworthy, capable of moral judgment, reliable, and politically answerable to boot. The responsive bureaucrat, in contrast, is reactive, sympathetic, sensitive, and capable of feeling or suffering - worthy qualities, perhaps, but together hardly an image that would draw people to public service or strengthen their commitment to it.' (1994: 365).

Being responsive means to be receptive, attentive, and charitable to societal concerns. Where accountability invokes consequential judgment, responsiveness is mainly an exercise of understanding. As Schwandt (2001) has pointed out in the context of evaluation studies, 'responsiveness is not simply or even a particular methodology for evaluation. Responsiveness is also (and perhaps primarily) something like an epistemic and moral virtue-a particular kind of human excellence that we strive for in our efforts to understand others and the social world.'

In the light of responsiveness - as an open, interpretative and forwardlooking type of responsibility - the three agenda conditions (and the consequent hard/soft distinction) are not very helpful. But where other senses of responsibility are at stake, they can be quite productive; viz. where technology (en)actors are held politically or legally accountable, possibly liable or simply blamed for the negative impacts of technology. Institutional innovation agendas confront technology actors with momentous issues and forceful consequences. In such cases, quantifiability bears the promise of accuracy, stability, regularity, control, impartiality, consensus, and standardization. The condition of 
publicity seeks to avoid endless debate and aims to promote the justification of collectively binding decisions. And the condition of causality promotes the identification of unequivocal and distinct causes and consequences. Taken together, these conditions prioritize those problems that are manageable, already hint at possible remedies, and can be accounted for.

Responsible innovation starts with responsiveness, which depends on the degree in which emerging societal concerns are given the opportunity to grow, develop and transform into full-blown issues. This, in turn, is reflected in the quality of public discourse. When the conversation is about food (and) technology, societal and technology actors must allow themselves and each other to doubt and ask, to instruct and advise, to teach and learn, to support and appreciate, to provoke and experiment, to show and tell, to imagine and suggest, to identify and remember, to protest and negotiate. Lest we forget how to disagree. 


\section{References}

A

Académie des Sciences (2002) Genetically modified plants, Paris:

Institut de France.

Achterhuis, H. (1995) 'De moralisering van de apparaten', in: Socialisme en Democratie 52, 1:3-12.

Akrich, M. (1992) 'The de-scription of technical objects', in: Bijker, W. \&

J. Law (eds.), Shaping technology/building society (pp. 205-224),

Cambridge, MA: MIT Press.

Alliantie Verduurzaming Voedsel (2014) Duurzaamheidsakkoord 20072020, Alliantie Verduurzaming Voedsel, retrieved 1 August 2014 from:

http://www.duurzamereten.nl/bedrijven/afspraken/duurzaamhe idsakkoord-2007-2020.html

B

Barber, B. (1983) The logic and limits of trust, New Brunswick, N.J.:

Rutgers University Press.

Beck, U. (1992) Risk society: Towards a new modernity, London: Sage.

Becker, E., Jahn, T., and Stiess, I. (1999) 'Exploring Uncommon Ground:

Sustainability and the Social Sciences', in: Becker, E. \& T. Jahn

(eds.), Sustainability and the Social Sciences. A cross-disciplinary

approach to integrating environmental considerations into

theoretical reorientation, London: ZED Books.

Bentham, J. (1789/1984) An introduction to the principles of morals and legislation. London: Dover Publications.

Berlin, I. (1958) 'Two concepts of liberty', in: (1969) Four essays on

liberty, Oxford: Oxford University Press.

Bernstein, R.J. (1982) 'From hermeneutics to praxis', Review of

Metaphysics, 823-845.

Bijker, W. (1995) 'Democratisering van de technologische cultuur'

(Democratization of Technological Culture), inaugural speech,

Maastricht: University of Maastricht.

Boekel, T. van (2008) 'Verfrissende vragen over... E-nummers',

Vereniging Nederlandse Frisdranken Industrie.

Boenink, M., Swierstra, T., and Stemerding, D. (2010) 'Anticipating the 
interaction between technology and morality: a scenario study of experimenting with humans in bionanotechnology', in: Studies in Ethics, Law, and Technology, 4(2).

Borgmann, A. (1984) Technology and the character of contemporary

life: A philosophical inquiry, Chicago: University of Chicago Press.

Bovens, M. (1990) Verantwoordelijkheid en organisatie:

beschouwingen over aansprakelijkheid, institutioneel burgerschap en ambtelijke ongehoorzaamheid, Zwolle: Tjeenk Willink.

Bovens, M. (2007) 'Analysing and assessing accountability: a conceptual framework', in: European Law Journal, 13(4), 447-468.

Branen, A.L. and Haggerty, R.J. (2002) 'Introduction to food additives', in: Branen, A.L. \& P. M. Davidson (eds.), Food additives (2nd ed.), New York: Marcel Dekker, Inc.

Brom, F.W.A. (2000) 'Food, consumer concerns, and trust: Food ethics for a globalizing market', in: Journal of Agricultural and Environmental Ethics, 12(2), 127-139.

Brundtland, G.H. (1987) Report of the World Commission on environment and development: Our Common Future. United Nations.

Buiter, H. (2000) 'Koelen en vriezen', in: Schot, J.W. and H.W. Lintsen (eds.) Landbouw, voeding (Techniek in Nederland in de twintigste eeuw), Zutphen: Walburg Pers, pp. 338-351.

\section{C}

Carnap, R. (1966/1995) An introduction to the philosophy of science, Courier Dover Publications.

Carson, R. (1962) Silent Spring, Boston: Houghton Mifflin Company. CBL (2011) Zichtboek Duurzaamheid. Centraal Bureau voor de Levensmiddelenhandel / Platform Verduurzaming Voedsel. Clayton, A. and Radcliffe, N. (1996) Sustainability: A Systems Approach, London: Earthscan.

Cobb, R.W. and Elder, C.D. (1971) 'The Politics of Agenda-Building: An Alternative Perspective for Modern Democratic Theory', in: The Journal of Politics, 33:4, 892-915.

Collins, H.M. and Evans, R. (2002) 'The Third Wave of Science Studies: Studies of Expertise and Experience', in: Social Studies of Science 32(2): 235-96.

Consumentenbond (2010) 'E-nummers ontrafeld', in: Consumentengids (Dec), 46-49. 
Cramer, J. (1989) De groene golf: geschiedenis en toekomst van de

Nederlandse milieubeweging, Utrecht: Jan van Arkel.

Cutler, D., Glaeser, E., and Shapiro, J. (2003) Why have Americans

become more obese? (No. w9446). National Bureau of Economic

Research.

D

Datamonitor (2006) 'Authenticity in Food and Drinks: New Insights into Consumer Attitudes and Behaviors', retrieved July 052010 from

http://www.datamonitor.com/store/Download/Brochure/?produ ctId=DMCM4582

Davidson, D. (1973) 'On the very idea of a conceptual scheme', in:

Proceedings and addresses of the American Philosophical Association, 5-20.

Dewey, J. (1927) The Public and its Problems, Chicago: The Swallow Press.

Dewey, J. (1938) Logic: The Theory of Inquiry, Carbondale, IL: Southern Illinois University.

Dooremalen, A.J.P.W., de Regt, H., and Schouten, M. (2007) Exploring humans: An introduction to the philosophy of the social sciences, Amsterdam: Boom.

Doorman, M. (2012) Rousseau en ik. Over de erfzonde van de authenticiteit, Amsterdam: Bert Bakker.

Dornblaser, L. (2013) 'The changing face of natural foods', in: Food Technology 3(13), 34-39.

Douglas, M. (1992) Risk and Blame: essays in cultural theory, London: Routledge.

Dryzek, J.S. (2000) Deliberative Democracy and Beyond, Oxford: Oxford University Press.

Dutton, J.E. (1986) 'Understanding strategic agenda building and its implications for managing change', in: Scandinavian Journal of Management Studies 3(1), 3-24.

E

Emerton, V., and Choi, E. (2008) Essential guide to food additives, Leatherhead: Leatherhead Food International.

Estlund, D. (1997) 'Beyond fairness and deliberation: The epistemic dimension of democratic authority', in: Bohman and Rehg (eds.), 
Deliberative democracy: Essays on reason and politics, Cambridge, Mass.: MIT Press.

$\mathbf{F}$

Feingold, B.F. (1975) 'Hyperkinesis and learning disabilities linked to artificial food flavors and colors', in: American Journal of Nursing 75(5), 797-803.

Fillion, L. and Arazi, S. (2002) 'Does organic food taste better? A claim substantiation approach', in: Nutrition \& Food Science 32:4, 153157.

Fischer, F. (1999) 'Technological deliberation in a democratic society: the case for participatory Inquiry', in: Science and Public Policy 26:5, 294-302.

FNLI (2008) Visie op MVO en Duurzaamheid, policy paper, Federatie Nederlandse Levensmiddelenindustrie, retrieved 31 July 2014 from http://www.fnli.nl/werkgebieden/duurzaamheid.html.

FNLI (2010) De stille kracht. Route voorwaarts voor de Nederlandse levensmiddelenindustrie, Federatie Nederlandse Levensmiddelenindustrie, retrieved 31 July 2014 from http://www.fnli.nl/downloads.html\#downloads72.

Food Ethics Council (2013) Beyond Business as Usual. Towards a Sustainable Food System, Brighton: Food Ethics Council.

Food Standards Agency (2010) 'Nanofoods: At the Cutting Edge', in: Bite FSA Magazine (Summer), 14-21.

Foodwatch (2013) 'Verslag van het gesprek tussen Albert Heijn en foodwatch mbt het merk puur\&eerlijk', 27 August, retrieved 31 July 2014 from

https://www.foodwatch.org/fileadmin/foodwatch.nl/Onze campa gnes/Misleidende Marketing/Puur en eerlijk/Documents/Puuren eerlijk gezamenlijkverslagAlbertHeijnenfoodwatch nl.pdf.

Fraser, N. (1990) 'Rethinking the public sphere: A contribution to the critique of actually existing democracy', in: Social Text, 56-80.

Fresco, L.O. (2012) Hamburgers in het paradijs. Voedsel in tijden van schaarste en overvloed, Amsterdam: Bert Bakker.

Fung, A. (2005) 'Deliberation before the Revolution: Toward an Ethics of Deliberative Democracy in an Unjust World', in: Political Theory 33, 397-419.

G 
Gadamer, H.-G. (1960) Wahrheit und Methode, Tübingen: Mohr.

Genus, A. (2006) 'Rethinking constructive technology as democratic, reflective, discourse', in: Technological Forecasting \& Social Change 73,13-26.

Geuss, R. (2001) Public goods, private goods, Princeton: Princeton University Press.

Godfray, H.C.J., Beddington, J.R., Crute, I.R., Haddad, L., Lawrence, D., Muir, J.F., ... and Toulmin, C. (2010) 'Food security: the challenge of feeding 9 billion people', in: Science 327(5967), 812-818.

Goodland, R. (1995) 'The Concept of Environmental Sustainability', in: Annual Review of Ecology and Systematics, 26:1-24

Gouget, C. (2008) Wat zit er in uw eten? De gids die u alerter maakt op al die E-nummers, Jansen, W. (ed.), (translated by A. Bellion), Bilthoven: Bouillon.

GRI (2012) Sustainability Disclosure Database, accessed 31 July 2014 via http://database.globalreporting.org.

Gronow, J. (2004) 'Standards of taste and varieties of goodness: the (un)predictability of modern consumption', in: Harvey, M., A. McMeekin and A. Warde (eds.), Qualities of food, Manchester and New York: Manchester University Press.

The Guardian (2013) 'Synthetic meat: how the world's costliest burger made it on to the plate', 5 August, retrieved 1 August 2014 from http://www.theguardian.com/science/2013/aug/05/syntheticmeat-burger-stem-cells.

Gusfield, J.R. (1981) The Culture of Public Problems. Drinking-driving and the symbolic order, Chicago: University of Chicago Press.

Gutmann, A. and Thompson, D. (2004) Why deliberative democracy?

Princeton: Princeton University Press.

Gutmann, A. and Thompson, D. (1996) Democracy and Disagreement, Cambridge, Mass.: Harvard University Press.

Gutteling, J., Hanssen, L., van der Veer, N., \& Seydel, E. (2006) 'Trust in governance and the acceptance of genetically modified food in the Netherlands', in: Public Understanding of Science 15(1), 103-112.

$\mathbf{H}$

Habermas, J. (1995) 'Reconciliation Through the Public use of Reason: Remarks on John Rawls's Political Liberalism', in: Journal of Philosophy 92(3), 109-131.

Habermas, J. (1996) Between Facts and Norms. Contributions to 
discourse theory of law and democracy, Cambridge, Mass.: MIT Press.

Haen, D. (2014) 'The Paradox of E-Numbers: Ethical, Aesthetic, and Cultural Concerns in the Dutch Discourse on Food Additives', in: Journal of Agricultural and Environmental Ethics 27, 27-42 Haen, D., Sneijder, P., te Molder, H. and Swierstra, T. (forthcoming) 'Natural Food. Organizing responsiveness in responsible innovation of food technology', in: Van den Hoven, J., B.J. Koops, H. Romijn, T. Swierstra, and I. Oosterlaken (eds.), Responsible Innovation, Volume 2, Dordrecht: Springer.

Hannigan, J. (1995) Environmental Sociology, New York: Routledge. Hanssen, L., Gutteling, J.M., Lagerwerf, L., Bartels, J. and Roeterdink, W. (2001) In the margins of the public debate on 'Food and Genes', research under commission of the Committee Biotechnology and Food, Enschede: Twente University.

Hermans, M.A., Fox, T. and Van Asselt, M.B.A. (2012) 'Risk Governance', in: Roeser, S. (ed.), Handbook of risk theory, Dordrecht: Springer. Hertzberger, R. (2010) 'Er gaat niets boven een kant-en-klaarmaaltijd met additieven', in: NRC Handelsblad, December 4, Opinie \& Debat. Hilgartner, S. and Bosk, C.L. (1988) 'The Rise and Fall of Social Problems: A Public Arenas Model', in: American Journal of Sociology 94:1, 53-78.

Hirschman, A.O. (1970) Exit, Voice, and Loyalty: Responses to Decline in Firms, Organizations, and States, Cambridge, Mass.: Harvard University Press.

Hunt, R.G. and Franklin, W.E. (1996) 'LCA - How it Came About. Personal Reflections on the Origin and LCA in the USA', in: The International Journal of Life Cycle Assessment 1(1), 4-7.

\section{I}

iPhoneclub (2010) 'E-nummers: Weet wat je niet moet eten (review)', blog entry, iPhoneclub, retrieved 14 Augustus 2012 from http://www.iphoneclub.nl/73326/e-nummers-weet-wat-je-nietmoet-eten-review/.

J

Jasanoff, S. (2005) Designs on nature: Science and democracy in Europe and the United States, Princeton: Princeton University Press.

Jong, F.M. de (2008) Ons voedsel: Over wat er in zit en hoe het wordt 
gemaakt, 's Graveland: Fontaine Uitgevers.

Jong, S. de (2010) 'Ruzie in de keuken: Magnetronvoer of puur-natuurschotel?', blog entry NRC Opinieblog, retrieved 14 August 2012 from http://weblogs.nrc.nl/expertdiscussies/magnetronvoerkoken-keuken/.

$\mathbf{K}$

Kampffmeyer Food Innovation (2012) How to make clean label, Report 02, retrieved 28 January 2013 from

http://kfi.kampffmeyer.com/cleanlabelreport/en/index.html.

Kamsteeg, J. (2001) E = eetbaar? Alle E-nummers, kunstmatige zoetstoffen en andere geur- en smaakstoffen, Haarlem: Gottmer.

Keulartz, J., Schermer, M., Korthals, M., and Swierstra, T. (2004) 'Ethics in Technological Culture: A Programmatic Proposal for a Pragmatist Approach', in: Science, Technology \& Human Values 29(1), 3-29.

Khushf, G. (2006) 'Owning up to our agendas: On the role and limits of science in debates about embryos and brain death', in: The Journal of Law, Medicine \& Ethics 34(1), 58-76.

Kingdon, J.W., \& Thurber, J.A. (1984) Agendas, alternatives, and public policies, Boston: Little, Brown.

Korthals, M. (2004) Before Dinner, Dordrecht: Springer.

Korthals, M. (2008) 'Ethical rooms for maneuver and their prospects vis-a-vis the current ethical food policies in Europe', in: Journal of Agricultural and Environmental Ethics 21(3), 249-273.

L

Lamerichs, J. and te Molder, H. (2011) 'Reflecting on your own talk: the Discursive Action Method at work', in: Antaki, C. (ed.) Applied Conversation Analysis. Intervention and Change in Institutional Talk, Basingstoke: Palgrave Macmillan, 184-206.

Lassen, J. and Jamison, A. (2006) 'Genetic technologies meet the public the discourses of concern', in: Science, Technology and Human Values 31(1), 8-28.

Latour, B. (1999) Pandora's Hope. Essays on the Reality of Science Studies, Cambridge, Mass.: Harvard University Press.

Latour, B. (2005) 'From Realpolitik to Dingpolitik. Or how to make things public', in: Latour, B. and P. Weibel (eds.) Making things public. Atmospheres of democracy, Cambridge, Mass.: MIT Press, 
14-41.

Latour, B. (1994) 'On technical mediation. Philosophy, Sociology,

Genealogy', in: Common knowledge 3(2), 29-64.

Lawrence, R.G. (2004) 'Framing Obesity: The Evolution of News

Discourse on a Public Health Issue', in: Press/Politics 9(3): 56-75

Levidow, L. and Carr, S. (1997) 'How biotechnology regulation sets a

risk/ethics boundary', in: Agriculture and Human Values 14(1), 29-

43.

Lin, A. (2006) 'The Unifying Role of Harm in Environmental Law', in:

Wisconsin Law Review 3.

LNV (2005) Strategische Dialoog Voedselkwaliteit, powerpoint

presentation, Ministry of Agriculture, Nature and Food Quality, retrieved 31 July 2014 from

http://www.archief.verantwoordeveehouderij.nl/producten/Ver waarding/Dierenwelzijnsindex.pdf.

LNV (2009) Nota Duurzaam Voedsel. Naar een duurzame productie en consumptie van ons voedsel, The Hague: Ministry of Agriculture,

Nature and Food Quality.

LNV Consumentenplatform (2004) Natuurlijkheid, waarde voor beleid.

Consumentenonderzoek, The Hague: Ministry of Agriculture,

Nature and Food Quality.

Lupton, D. (1999) Risk, London: Routledge.

\section{M}

Marris, C., Wynne, B., Simmons, P. and Weldon, S. (2001) Public

Perceptions of Agricultural Biotechnologies in Europe. Final

Report of the PABE Research Project Funded by the Commission of European Communities, PABE research project, retrieved 14 August 2012 from

http://www.lancs.ac.uk/depts/ieppp/pabe/docs/pabe finalreport .pdf.

Martin, A. and Lynch, M. (2009) 'Counting Things and People: The

Practices and Politics of Counting', in: Social Problems, 56(2), 243266

Meadows, D.H., Meadows, D.L., Randers, J. and Behrens III, W.W. (1972)

Limits to Growth. A report to the Club of Rome, New York: New American Library.

Meijboom, L., Visak, T., and Brom, F. (2006) 'From trust to

trustworthiness: Why information is not enough in the food 
sector', in: Journal of Agricultural and Environmental Ethics 19(5), 427-442.

Meyer, P.G. (2000) 'The relevance of causality', in: Couper-Kuhlen, E.

and Kortmann, B. (eds.) Cause - Condition - Concession - Contrast:

Cognitive and Discourse Perspectives, Berlin: Mouton de Gruyter.

Mill, J.S. (1859/1974) On Liberty, Harmondsworth: Penguin.

Miller, D. (2001) 'Distributing Responsibilities', in: The Journal of

Political Philosophy 9:4, 453-471.

Mitcham, C. and Waelbers, K. (2009) 'Technology and Ethics:

Overview', in: Olsen, J.K.B., Pedersen, S.A., and Hendricks, V.F.

(eds.) A Companion to the Philosophy of Technology, Oxford:

Blackwell Publishing.

Mitchell, W. (1918) 'Bentham's Felicific Calculus', in: Political Science Quarterly 33:2, 161-183.

Mol, A. (2007) 'Goede smaak. De normativiteit van de consumentburger', in: Krisis 2007:3

Mol, A. (2011) 'Tragiek van de kilocalorie', in: Dijstelbloem, H. and Hagendijk, R. (eds.) Onzekerheid troef. Het betwiste gezag van de wetenschap, Amsterdam: Van Gennep.

te Molder, H., and Gutteling, J. (2003) 'The issue of food genomics: About uncaring citizens and united experts', in: Van Est, R., L. Hanssen, and 0. Crapel (eds.) Genes for your food - Food for your genes. Societal issues and dilemmas in food genomics, working document 92, The Hague: Rathenau Institute.

te Molder, H. (2008) 'Discursive psychology', in: Donsbach, W. (ed.) The international encyclopedia of communication, volume IV, Oxford: Wiley-Blackwell,1370-1372.

Mundry, J. (2009) Measured Meals. Nutrition in America, Albany: SUNY Press.

$\mathbf{N}$

Nationale DenkTank (2012) Verduurzaming van de Voedselketen. Final report, retrieved 31 July 2014 from http://www.nationaledenktank.nl/wat-doen-wij/denktank/resultaten/denktank-2012/

Natuurwetmoeders (2000) 'Enkele gedachten over genetische manipulatie' (Considerations on genetic manipulation), retrieved 31 July 2014 from http://www.natuurwetmoeders.nl. Natuurwetpartij (1994) Bewustzijn als Basis. Beginsel- en partijprogramma van de Natuurwetpartij, Lelystad: NWP 
Nederland.

Natuurwetpartij (1998) Gedachtengoed en programma, Lelystad:

Stichting Wetenschappelijk Bureau van de Natuurwetpartij.

Norwood, J.L. (1988) 'The Measurement of Unemployment', in: The American Economic Review 78(2), 284-288.

Notten, Ph., Rotmans, W.F.J., Van Asselt, M.B.A. and Rothman, D.S.

(2003) 'An updated scenario typology', in: Futures 35, 423-443.

Nuffield Council on Bioethics (1999) Genetically modified crops: The ethical and Social issues, Nuffield Council on Bioethics, retrieved 14 August 2012 from http://nuffieldbioethics.org/project/gm-crops/

$\mathbf{0}$

Otterloo, A.H. van (2012) 'Healthy, Safe and Sustainable: Consumers and the Public Debate on Food in Europe and the Netherlands Since 1945', in: Spaargaren, G., Oosterveer, P., \& Loeber, A. (eds.) Food practices in transition: changing food consumption, retail and production in the age of reflexive modernity, New York: Routledge.

\section{$\mathbf{P}$}

Palm, E. \& Hansson, S.O. (2006) 'The case for ethical technology assessment (eTA)', in: Technological Forecasting and Social Change 73, 543-558.

Parenti, C. (2012) 'The Limits to Growth: A Book That Launched a Movement', in: The Nation, December, 24-31.

Pellizzoni, L. (2004) 'Responsibility and environmental governance', in: Environmental Politics 13, 541-565.

Petrini, C., and Padavoni, G. (2007) Slow food nation, New York: Rizzoli Ex Libris.

Pincoffs, E.L. (1962) 'Debatability and Moral Assertion', in: The Philosophical Quarterly, 1-12.

Poel, I. van de, Fahlquist, J. N., Doorn, N., Zwart, S., \& Royakkers, L. (2012) 'The problem of many hands: Climate change as an example', in: Science and engineering ethics 18(1), 49-67.

Poel, I. van de, \& Van Gorp, A. C. (2006) 'The Need for ethical reflection in engineering design', in: Science, Technology and Human Values 31(3), 333-360.

Pollan, M. (2008) In Defense of Food. An eater's manifesto, New York: Penguin Press.

Popper, K.R. (1945) The open society and its enemies, London: 
Routledge \& Kegan Paul.

Porter, T.M. (1995) Trust in Numbers: The Pursuit of Objectivity in

Science and Public Life, Princeton: Princeton University Press.

\section{$\mathbf{R}$}

Rasmussen, L.B. (2005) 'The Narrative Aspect of Scenario Building -

How story telling may give people a memory of the future', in: AI \& Society 19, 229-249.

Rawls, J. (1993) Political Liberalism, New York: Columbia University Press.

Rayner, S. (2003) 'Democracy in the age of assessment: reflections on

the roles of expertise and democracy in public-sector decision

making', in: Science and Public Policy 30:3,163-170.

Reclame Code Commissie (2008) 'Uitspraak reclamecampagne Eerlijk

is Heerlijk', College van Beroep (verdict 1536/08.0121).

Redclift, M. (2005) 'Sustainable Development (1987-2005): An

Oxymoron Comes of Age', in: Sustainable Development 13: 212-

227.

Reijnders, L., Sijmons, R., et al. (1973) Voedsel in Nederland: gezondheid, bedrog en vergif. Amsterdam: Van Gennep.

Retailnews (2012) '"Liegebeest" Iglo hekelt Wakker Dier-campagne',

26 October, retrieved 1 August 2014 from

http://www.retailnews.nl/nieuws/H5QT4IT7EeOSgiIACiAWIg-

0/8216liegebeest8217-iglo-hekelt-wakker-dier-campagne.html.

Rhinehart, R. (2013) 'How I stopped eating food', blog entry, 13

February, retrieved 1 August 2014 from http://robrhinehart.com.

Richardson, D. (1997) 'The Politics of Sustainable Development', in:

Baker, S. et al. (eds.) The Politics of Sustainable Development.

Theory, policy and practice within the European Union, London:

Routledge.

Rickman, H.P. (1990) 'Science and hermeneutics', in: Philosophy of the

Social Sciences 20(3), 295-316.

Rose, N. (1991) 'Governing by numbers: figuring out democracy', in:

Accounting, organizations and society 16(7), 673-692.

Rozin, P., Kabnick, K., Pete, E., Fischler, C., \& Shields, C. (2003) 'The

Ecology of Eating Smaller Portion Sizes in France Than in the

United States Help Explain the French Paradox', in: Psychological science $14(5), 450-454$.

Rozin, P., Spranca, M., Krieger, Z., Neuhaus, R., Surillo, D., Swerdlin, A., 
and Wood, K. (2004) 'Preference for natural: instrumental and ideational/moral motivations, and the contrast between foods and medicines', in: Appetite 43: 147-154.

\section{S}

Sachs, W. (1999) 'Sustainable development and the crisis of nature: on the political anatomy of an oxymoron', in: Fisher, F. and Hajer, M. (eds.) Living with Nature. Environmental Politics as Cultural Discourse, New York: Oxford University Press.

Sagoff, M. (2001) 'Genetic Engineering and the Concept of the Natural', in: Eaglesham, A., Pueppke, S.G. \& Hardy, R.W.F. (eds.) Genetically Modified Food and the Consumer, NABC Report 13.

Sarewitz, D. (2004) 'How science makes environmental controversies worse', in: Environmental Science \& Policy 7:5, 385-403.

Schomberg, R. von (2011) 'Prospects for Technology Assessment in a framework of responsible research and innovation', in:

Dusseldorp, M. and Beecroft, R. (eds.) Technikfolgenabschätzen lehren: Bildungspotenziale transdisziplinärer Methoden, Wiesbaden: VsVerlag.

Schot, J. and Rip, A. (1996) 'The past and future of constructive technology assessment', in: Technological Forecasting and Social Change 54, 251-268.

Schwandt, T.A. (2001) 'Responsiveness and everyday life', in: New Directions for Evaluation 2001(92), 73-88.

Sheldon, R., Cleghorn, N., Penfold, C., Brown, A., \& Newmark, T. (2009) Exploring attitudes to gm food. Final report, London: National Centre for Social Research.

Shiskin, J. and Stein, R.L. (1975) 'Problems in measuring unemployment', in: Monthly Lab. Rev. 98,3.

Siegrist, M. (2008) 'Factors influencing public acceptance of innovative food technologies and products', in: Trends in Food Science \& Technology 19(11): $603-608$.

Skorupski, J. (2006) Why Read Mill Today? London: Routledge.

Stilgoe, J., Owen, R., \& Macnaghten, P. (2013) 'Developing a framework for responsible innovation', in: Research Policy 42(9), 1568-1580.

Stivers, C. (1994) 'The listening bureaucrat: Responsiveness in public administration', in: Public Administration Review, 364-369.

Stone, D. A. (1989) 'Causal stories and the formation of policy agendas', in: Political science quarterly, 281-300. 
Stone, D.A. (2002) Policy Paradox: The Art of Political Decision Making. Revised Edition, New York: Norton.

Strawson, P. (1963) 'Freedom and Resentment', in: Proceedings of the British Academy 48, 1-25.

Swierstra, T. (2002) 'Moral vocabularies and public debate: The cases of cloning and new productive technologies', in: Keulartz, J., M.

Korthals, M. Schermer, and T. Swierstra (eds.) Pragmatist ethics for a technological culture (pp. 223-240), Deventer: Kluwer Academic.

Swierstra, T. (2011) 'Heracliteïsche ethiek. Omgaan met de soft impacts van technologie', inaugural speech, 16 September, Maastricht: Maastricht University.

Swierstra, T. and te Molder, H. (2012) 'Risk and soft impacts', in: Roeser, S. (ed.) Handbook of risk theory, Dordrecht: Springer.

Swierstra, T. and Rip, A. (2007) 'Nano-ethics as NEST-ethics: patterns of moral argumentation about new and emerging science and technology', in: Nanoethics 1(1), 3-20.

Swierstra, T., Stemerding, D., and Boenink, M. (2009) 'Exploring techno-moral change. The case of the obesity pill', in: Sollie, P. and M. Duwell (eds.) Evaluating new technologies (pp. 119-138), Dordrecht: Springer.

Szerszynski, B. (1999) 'Risk and Trust: the performative dimension', in: Environmental Values 8(2), 239-252.

$\mathbf{T}$

Taylor, C. (1979) 'What's Wrong with Negative Liberty', in: Miller, D. (ed.) (1991) Liberty, Oxford University Press, 141-162.

Taylor, C. (1994) Multiculturalism: Examining the politics of recognition, Princeton: Princeton University Press

Teil, G. and Hennion, A. (2004) 'Discovering quality or performing taste? A sociology of the amateur', in: Harvey, M., A. McMeekin and A. Warde (eds.), Qualities of food, Manchester and New York: Manchester University Press.

Terlouw, J.C., Seydel, E.R., Dorrestein, R.M., Kok, F.J., Scheffer, H.C., and

Veraart, M. (2002) Eten \& Genen: Een publiek debat over

biotechnologie en voedel: Verslag van de Tijdelijke commissie

biotechnologie en voedsel, The Hague: Committee on Biotechnology and Food.

Thagard, P. and Nisbett, R.E. (1983) 'Rationality and charity', in:

Philosophy of Science, 250-267. 
Thompson, P.B. (2007) Food biotechnology in ethical perspective, Dordrecht: Springer.

TIFN (2009) Measuring Success: Annual Report 2008, Wageningen: Top Institute Food and Nutrition.

Topsector Agro\&Food (2011) Agro\&Food: De Nederlandse groeidiamant, The Hague.

Tulder, R. van, Kaptein, M., van Mil, E.M., and Schilpzand, R.A. (2004) De Strategische Stakeholdersdialoog. Opkomst, succesfactoren en toekomst, Rotterdam/Den Haag: Erasmus Universiteit Rotterdam/Schuttelaar \& Partners.

V

Veen, M., Gremmen, B., te Molder, H., \& Van Woerkum, C. (2011)

'Emergent technologies against the background of everyday life: Discursive psychology as a technology assessment tool', in: Public Understanding of Science 20(6), 810-825.

Verbeek, P. -P. (2005) What things do: Philosophical reflections on technology, agency, and design, University Park, PA: Penn State University Press.

Verbeek, P. -P. (2006) 'Materializing morality', in: Science, Technology and Human Values 31(3), 361-380.

Verbeek, P. -P. (2011) Moralizing technology: Understanding and designing the morality of things, Chicago: University of Chicago Press.

Vreugdenhil, J. (2010). 30 minuten koken is geen tijdverspilling. Blog entry at Foodlog, retrieved 14 August 2012 from http://www.foodlog.nl/artikel/30 minuten koken is geen tijdver spilling.

$\mathbf{W}$

Walzer, M. (1999) 'Deliberation, and what else?', in: (2007) Thinking politically: Essays in political theory, Miller, D. (ed.), New Haven, CT: Yale University Press.

Widdicombe, L. (2014) 'The End of Food', in: The New Yorker, May 12, retrieved 31 July 2014 from http://www.newyorker.com/magazine/2014/05/12/the-end-offood.

Winner, L. (1986) 'Do artifacts have politics?', in: The whale and the reactor: A search for limits in an age of high technology, Chicago: 
University of Chicago Press.

WUR (2007) Eten van Waarde. Voedselkwaliteit in Nederland, rapport voor Ministerie van Landbouw, Natuur en Voedselkwaliteit, Wageningen: Wageningen University \& Research Centre.

Wynne, B. (1991) 'Knowledges in context', in: Science, Technology and Human Values 16(1), 111-121.

Wynne, B. (1996) 'May the Sheep Safely Graze? A Reflexive View of the Expert-Lay Knowledge Divide', in: Lash, S., Szerszynski, B. and Wynne B. (eds.) Risk, Environment \& Modernity: Towards a New Ecology, London: Sage, 44-83.

Wynne, B. (2001) 'Creating public alienation: Expert cultures of risk and ethics on GMOs', in: Science as Culture 10(4), 445-481.

Wynne, B. (2002) 'Risk and Environment as Legitimatory Discourses of Technology: Reflexivity Inside Out?' in: Current Sociology 50(3): 459-477.

\section{$\mathbf{Y}$}

Yiridoe, E.K., Bonti-Ankomah, S., and Martin, R.C. (2005) 'Comparison of consumer perceptions and preference toward organic versus conventionally produced foods: a review and update of the literature', in: Renewable Agriculture and Food Systems 20(04), 193-205. 


\section{Summary}

\section{Chapter 1}

As the food supply chain has become longer, more complex and opaque over the past fifty years, the gap between those who make food and those who eat it has widened. Public (dis)trust has become a major food issue - in particular where technology is involved. One explanation for distrust in food technology and innovation is that technology (en)actors fail to be responsive to a particular set of consumer-citizen concerns. Trust cannot be forced, but trustworthiness - a precondition for trust-can be enhanced. For the agri-food sector this means acting reliably, but also explicating the norms and values they act upon. After all, trust is a matter of normative expectations. Also, trustworthiness means to be responsive to public concerns and engage in a critical discussion about those norms and values. Responsiveness implies the readiness to provisionally acknowledge the legitimacy of raised concerns, and the willingness to think and speak about them. Responsible innovation in food technology means that technology (en)actors are, at least, sufficiently responsive to a broad variety of societal concerns.

The main problem addressed in this dissertation is that a particular set of consumer-citizen concerns are structurally marginalized - by food engineers, policy makers, and even citizen-consumers - and kept away from the food innovation agenda. This is both a problem of democratic legitimacy (low acceptability) and of efficacy of costly innovations (low acceptance). With this dissertation, I offer an explanation of the problem and a perspective on solutions. The explanation consists of an analysis of the public discourse of food technology and innovation: I identify three conditions of the innovation agenda (often implicitly relied on by stakeholders) that make up for an artificial and untenable dichotomy between hard issues and soft concerns. My solution is twofold. I present recommendations for several stakeholder groups for how to make sure that this dichotomy will no longer pose an obstacle to fruitful stakeholder dialogue on food technologies and innovations; and I present a particular tool for dialogue facilitators who aim to give 'soft concerns' a fair opportunity to gain access to the innovation 
agenda.

\section{Chapter 2}

Food engineers and policy makers do recognize that public trust is a crucial ingredient for technological food innovations, and often consider this a reason to call for more transparency in the food chain and to provide objective, independent, consistent and unambiguous information to consumers (e.g. by labeling). But from the persistent distrust of food additives we learn that transparency and labeling do not necessarily dissolve the problem of distrust.

My claim is that the persistence of distrust (of food additives) cannot be adequately understood without taking into account the wider range of ethical, aesthetic and cultural concerns. The idea that public dialogue should be organized more inclusively is nothing new, but to do this successfully requires a more in-depth understanding of what keeps engineers, policy makers, manufacturers and consumers from doing so. In my analysis of controversies on E-numbers, I have identified two discursive mechanisms: irrationalization and privatization. Irrationalization occurs where consumers who raise concerns are instantly labeled by technology (en)actors as emotional, inconsistent and uninformed. A more charitable interpretation, however, demonstrates that some of these concerns are more reasonable than they seem at face value. The preference for natural food can be understood as a consumer strategy to deal with the individual's responsibility to choose safe and healthy food and the problem of how to identify them. It is not necessarily a rejection of modern technology, or a flight to the past, but a pragmatic retreat to the familiar and recognizable. This is a procedural concern closely related to the concern for safety and health.

There are also more substantial concerns that have little to do with health and safety. The social meal argument is raised when consumers are concerned that food additives enable fast dinners to be enjoyed in solitude. Also, there is the concern that convenience foods may induce laziness and indifference: they compete with the pleasure of cooking. And there is the concern about the decay of taste and food culture. These concerns point out that food is a bearer of culture, a source of taste and pleasure, and an ingredient of the good life. Consumer- 
citizens are concerned that this is gradually disappearing due to modern food technologies.

These concerns are not unreasonable once we realize that food additives do subscribe to ethical, cultural and aesthetic values and norms. In fact, this is how technology (en)actors themselves justify and promote the use of food additives. The mechanism of privatization occurs where concerns are excluded from the agenda for the reason that they do not deserve public attention - e.g. because they are considered to be informed by subjective and individual experiences; and thus cannot be expected to offer a common ground for meaningful (dis)agreement. This exclusion often relies on the logic of the free market: no one is actually forced to buy or eat anything, especially if consumers have a large range of options to choose from. Therefore, there would be no reason for discussing such concerns in the first place.

However, I suggest that we understand some of these consumer concerns as an attempt to re-imagine which impacts of food technology count as public matters. Several scholars in STS and philosophy of technology have made clear that technologies mediate: they invite, hinder, enable, transform, guide, and restrict human action. In qualifying technologies as matters of public concern, they question the pervasiveness and desirability of technology's impacts.

Thus, the ethical, cultural, and aesthetic concerns about food additives cannot be dismissed for the reason that the consumption of processed food is simply a matter of individual and free choice, because that is exactly the claim that is contested in the first place. Such concerns are not as private as they seem. The recurrent appeal to consumer autonomy fails to recognize the mediating character of food additives, or at least paralyzes any meaningful public dialogue about it.

\section{Chapter 3}

Upon a closer look, we see that these two mechanisms are the manifestation of three implicit requirements that prescribe what types of concerns qualify as legitimate topics on the public innovation agenda. These requirements are three conditions for meaningful discussion. Each of them is grounded in a broader view of knowledge, 
politics and technology respectively. With the notion of public innovation agenda I mean that part of the public agenda that seeks to inform various institutional agendas, and which in itself is shaped in and through informal public debate. The public innovation agenda is a set of issues (regarding technological innovation) commonly recognized by public and institutional actors as deserving attention and deliberation. This agenda is reflected in policy reports, consumer platforms, news media coverage, corporate mission statements, advertising, and so on. It is essentially a discourse agenda.

The three conditions discussed below prescribe what kind of concerns do and do not have access to the public innovation agenda.

(I) The condition of quantifiability prescribes that a concern's substance is appropriate for measurement and can be expressed in quantitative terms. This idea relies on a positivist conception of knowledge and science. There are good reasons for this demand: (1) numbers give an accurate and stable representation of the world; (2) regularities allow for prediction and control; (3) calculation suggests impartiality, enabling accountability and the settlement of conflict; and (4) quantification enables standardization and comparison. Nevertheless, even the simplest operation of counting is an act of interpretation. In highly disputed matters, the use of numbers does not necessarily result in normative or epistemic agreement. Numbers may conceal but cannot substitute normative judgments. Numbers don't speak for themselves. More importantly, anything can be counted and measured as soon as people decide to do so. People need good reasons to start quantifying qualitative concepts; and concerns may exactly offer those reasons. Also, by quantification we may get lost in translation: important experiences, meanings and values can be standardized, reduced, set aside and forgotten. Fortunately, apart from the repertoire of positivist science, scientific communities have many more resources to draw on in order to account for public problems, such as the hermeneutic arts and sciences.

(II) The condition of publicity prescribes that a concern appeals to values commonly recognized by all of us; and that it proposes norms that, in principle we can all agree on - no matter how different our experiences and world views may be. This idea is grounded in the 
liberal ideal of public reason, and is also expressed in the harm principle, according to which thick conceptions of the good life cannot justify coercion on behalf of the polity. The condition of publicity determines the boundary between public matters and private concerns. On a pragmatic account, the liberal conception of public reason can do three things for us. (1) It is a practical way of avoiding endless and useless debate on things citizens may never agree on; (2) it relies on a negative conception of liberty, and negative goals are easier to define and less controversial; (3) the public/private distinction shorthand for a great amount of ethical considerations - serves in everyday life as a convenient moral guideline. The problem with this condition is not liberalism as such, but the narrow way in which it is often applied in public debate. Most liberals distinguish between a sphere of legitimate power and a sphere of discussion. In the latter, the condition of publicity does not necessarily apply. The idea that in public debate, concerns should only appeal to uncontroversial values and meanings is based on the tacit assumption that all public propositions are candidates for state legislation (I call this anticipatory liberalism). This idea frustrates the quality of public discourse, in its richness and depth. Furthermore, what counts as harm is not as clearcut as it seems and sometimes requires public deliberation on substantial values. This is also true for the public/private distinction: citizens should have the opportunity to convince others that concerns now considered private, should actually be regarded as public matters. The incomplete but popular interpretation of the ideal of public reason, forestalls every public discussion on good food, good taste and the good life.

(III) The condition of causality prescribes that a concern articulates a problem as the clear consequence of either human action or technology. The idea behind this is that causal explanation should be prior to the attribution of moral responsibility (for tackling the problem). Satisfactory causal explanations - necessary for successful agenda setting - are restricted to relevant causes. Causes can be relevant in three senses: (1) causes are extraordinary events against the background of normal and trivial situations; (2) causes highlight the factor of human agency in the sense that these causes can be controlled or eliminated; and (3) causes are clear and distinct from other factors; they do not point at fuzzy interactions between humans 
and non-humans. If a causal explanation meets these three requirements, it becomes easier to ascribe or accept moral responsibility. However, causal explanation does not always precede attribution of responsibility. The act of reporting and selecting facts in presenting a causal story may already suggest - intended or not - some attribution of moral responsibility in the first place. Also, the condition of causality wrongfully presupposes that technologies are mere instruments, not agents; and that human actions can be clearly distinguished from material conditions and circumstances. Technologies are more than just instruments as they are able to suggest, modify, or compromise our goals and plans. Problems can be brought about by an association of humans and technological artefacts. Such are many-hands problems. It may be impossible to express this problem in terms of who is to blame, but if one, in contrast, is interested in the articulation of forward-looking responsibilities, this does not necessarily pose a problem. In sum, the three conditions of the public innovation agenda (quantifiability, publicity, causality) can be useful but there is a price to pay: vital aspects of our relation to food, and how they are affected through food technology and innovation, remain below the public radar. Societal actors then miss the opportunity to engage in a meaningful dialogue on 'good food' and what that entails for food innovation.

\section{Chapter 4}

The validity of these conditions is based on a too narrow view of knowledge, politics and technology. Taken together, these conditions can be held responsible for the implicit dichotomy of hard and soft concerns. This dichotomy obstructs a meaningful and fruitful dialogue on good food and good food technology. As such, it is a serious obstacle to trust between consumers and technology developers. I suggest that we conceive of 'hard' and 'soft' as rudimentary classifications that implicitly follow from the degree to which a concern is considered to meet these three conditions. Concerns are not hard in and of themselves, but implicitly labeled as such as they tend to meet most of the three conditions to a large extent. 'Soft' and 'hard' can best be understood as constructions rather than intrinsic and essential properties of these concerns. A constructivist perspective does not make an issue any less real or serious and it does not imply that all concerns are equally relevant. It only specifies what we mean when we 
consider concerns as 'hard' or 'soft'.

My discussion of the relatively new issue of food sustainability illustrates that 'soft' and 'hard' are labels that rely on a multidimensional, gradual judgment, and can be seen as both the result and the starting point of a public search for numbers, common values, and causal stories. It highlights what kind of challenges food sustainability as a growing concern had (and still has) to face in order to gain its full recognition as a serious food issue - along the lines of the three agenda conditions.

(I) Back in the 1960ies, environmental concerns failed to meet the condition of publicity. Now, their presence on the innovation agenda suggests a substantial moral agreement among stakeholders, but the issue still hosts a diversity of normative orientations that do not necessarily go hand in hand. There is only very thin common ground, where sustainability is framed as deeply entangled with global food security.

(II) Also, environmental concerns met the condition of quantifiability only to a minimal extent. The history of food sustainability as an issue indicates that quantification does not necessarily precede but rather goes along with the entrance of sustainability as an issue on the food innovation agenda. The growing recognition of problems can be a driving force behind further measurements. By developing methods, metrics and indicators, pioneers have made food sustainability quantifiable. Today, many relevant aspects of food production still are to be quantified.

(III) Concerns about unsustainable food barely met the condition of causality. Virtually any aspect of the food system and its environments can be identified in one way or another as a factor that contributes to unsustainable food production and consumption. Thus, actors concerned with turning our food system more sustainable have suggested a broad range of potential solutions. Most of them recognize that food sustainability is a many-hands problem. Only in a general sense, humans, not technologies (nor nature for that matter) were identified as the cause of unsustainability, but there is little agreement on specific responsibilities for tackling the issue of food sustainability. 
The case of food sustainability offers no exception to my claim that the three agenda conditions have to be met before concerns can become legitimate issues on the public food innovation agenda. But it also shows that the work that these three conditions imply is not finished as soon as the issue has been granted access to the public innovation agenda. The perfect public issue is not one that is already resolved in the first place; but one that has enough potential to grow, develop, and transform through collective inquiry.

\section{Chapter 5}

If concerns generally considered as 'soft' are to be given a fair opportunity to gain access to the food innovation agenda, broadly two directions can be taken. The first is more pragmatic and suitable for short-term improvements of public dialogue. It presupposes that the current three agenda conditions are in themselves reasonable but proposes dialogue parties to adopt, respectively, a strategy of adaptation and a principle of charity. Here, technology (en)actors and societal actors will have to meet each other 'half way'. The second direction is more critical of these conditions and proposes that facilitators challenge these conditions by setting up dialogues in such a way that stakeholders are encouraged to deliberate on concerns about rather qualitative, morally contested, and technologically mediated impacts of food innovation. I have specified this second approach in chapter 6.

(I) A strategy of adaptation is a way for societal actors to raise concerns generally regarded as soft, and present them as legitimate candidates for the public innovation agenda. I have identified three modes of articulation (strategies) for raising soft concerns - some of which are more promising than others: (1) translation, (2) combination and (3) entanglement. Translation of 'soft' concerns into 'hard' impacts relies on the idea that ethical, cultural or religious concerns can be completely reduced to issues of safety, health, risk or sustainability and expressed in the language of numbers and natural sciences. But if dialogue partners do not already share the worldview implicit to the concern, this is not a promising strategy. The ethical significance of the concern will get lost in public deliberation. Combination of 'soft' and 'hard' concerns occurs where ethical, aesthetic or cultural concerns are 
presented as part of a broader agenda that also includes concerns that are publicly well recognized. As it directs our attention to a broader set of issues surrounding food and innovation, combination seems a promising strategy in getting soft concerns on the food innovation agenda. Yet, it allows technology actors to be selective with regard to this broader set, as it does not really challenge the traditional division of responsibilities. Entanglement of specific 'soft' and 'hard' impacts is a way of showing that soft concerns are intrinsically connected with hard impacts. Strong versions of this mode of articulation demonstrate (by means of scientific evidence) why certain 'hard' concerns cannot be adequately taken care of without taking seriously the 'softer' ones. This is a promising strategy especially where it explicitly invites addressees to rethink the current, implicitly shared distribution of responsibilities for good food. My recommendation for societal actors, then, is to align their 'softer' concerns with the conditions of the food innovation agenda by making explicit how their concerns are entangled with more publicly recognized problems.

(II) Technology actors as addressees, on their part, can be more responsive by suspending the application of the three agenda conditions, rather than relying on them as an a priori division of responsibilities. They need to assume some degree of reasonableness in concerns - even when not all of the facts, values and causal relations (and consequently, responsibilities) have been agreed upon. The principle of charity exactly prescribes such assumption. The principle of charity requires that if you try to understand someone's utterances, you presuppose that his statements are (to some degree) rational, considering the possibility that a coherent and rational interpretation of his statements can be given. The principle reminds us that the alternative is the end of conversation. It appeals to the assumption that other people matter, and that they have something interesting to tell. To act upon this principle is often a leap of faith. Like any principle, it does not prescribe the limits of its own application. But keeping in mind that the end of conversation is the only alternative, the scope of charity ends where the benefit of ignoring 'soft' concerns outweights the potential benefits of understanding them. From a pragmatic point of view, one should remain charitable as long as one reasonably expects that there is still the opportunity to learn about new perspectives and worldviews. 
Contrary to the soft/hard dichotomy, the principle of charity does not offer clear and stable criteria according to which technology actors can assess whether they should take any given concern seriously. Rather, it urges them to consider why it is in their interest to get to an understanding of what these 'soft' concerns may be about. Whether or not technology actors should accept a responsibility to act upon 'soft' concerns can still be subject to the conditions of quantifiability, publicity and causality. But a charitable response implies that one is willing to suspend those requirements in dialogue, and reconsider assumed responsibilities as soon as a given 'soft' concern turns out to be a legitimate issue over time. My recommendation for technology actors is that, when addressed with 'soft' concerns, they are patient and ask for further clarification, under the presupposition that these are perhaps not that irrational and subjective as they seem at face value.

Thus far, my recommendations for societal and technology actors presuppose that the three agenda conditions are in themselves not unreasonable but need to be used and applied in a more constructive manner. (III) Facilitators, however, in and through their role as 'metalevel actors', have the special capacity to transform our ways of speaking and thinking about food concerns in a more fundamental way, by questioning the validity of the three agenda conditions in and of themselves. That is, certain concerns still require interpretation, rather than calculation, if they are to be taken seriously. Furthermore, provisional, context-specific and practical agreements can be reached even where a fundamental ethical or aesthetic consensus is missing. Also, when food concerns point at many hands problems, they imply that responsibilities for resolving such problems are likely to be shared - e.g. among consumers and food technologists - even where causal relations are not specified in an exact manner. These are good reasons for questioning the validity of the three agenda conditions as such. Given these considerations, and those I presented in chapter 3, my twelve recommendations for facilitators are the following.

(1) Mobilize a variety of stakeholders who are likely to draw on different sources of knowledge, values and experiences; (2) Encourage dialogue parties to take into consideration patterns of interaction between the natural, the technological, and the social dimensions of 
food; (3) Delay definition issues: encourage participants to ask each other for tentative explanation and clarification of these concerns without forcing them to formulate clear-cut, decisive definitions; (4) Stimulate collective reflection and discussion of epistemic rights and responsibilities for making factual and normative claims. (5) Present a frame, image or narrative that allows most participants to identify, if only provisionally, a situation that is commonly recognized as problematic; (6) Present the establishment of legally binding rules enforced by the state neither as the only resolution to (soft) concerns about technological innovation, nor as the sole purpose of the dialogue; (7) Do not allow participants to conclude too easily that the identified problem is a private matter. (8) Encourage participants to imagine the unintended and unforeseen, yet plausible impacts of the innovation; (9) Stimulate the investigation, perhaps negotiation, of what good food is about; (10) Allow participants to imagine and explicate the 'invitations' and 'inhibitions' that food technologies may offer to users, consumers and others who may be affected; (11) Encourage participants to reconsider the current distribution of normative responsibilities. Avoid questions of blame and liability and focus on forward-looking responsibilities; (12) Remind participants that responsibility can be a matter of degree; and potentially shared, in the case of many hands problems.

\section{Chapter 6}

As a specification of my recommendations for facilitators, I introduce a specific tool - the techno-ethical scenario - that can be used by facilitators to promote the inclusion of a wider range of ethical, cultural and political concerns. It is a tool for constructive technology assessment (cTA) in a modest sense: rather than having the direct aim of broadening the design of new technologies, it aims to broaden the public innovation agenda. Techno-ethical scenarios have the aim of supporting anticipation, societal learning and reflexivity. But the techno-ethical scenario, and its use in stakeholder dialogues, is distinctive in three ways. (1) It seeks to broaden the innovation agenda to a larger extent than most ELSA programs do, by opening up dialogue for any concern that - at face value - seems to be subjective, private, irrational or irrelevant. (2) Therefore, it is specifically suitable for the assessment of those technological innovations that are easily framed by most stakeholders as commodities of the market place. It has a 
special eye for the risk of privatization. (3) It has a strong focus on instructive purposes. Making use of DAM, it aims to make dialogue parties aware of how they implicitly claim or reject epistemic rights and responsibilities for issues; and the effects of such talk on the development of conversation.

In 2012-2013, I have put this tool to the test in close collaboration with a research team of philosophers and science communication researchers. As facilitators, we organized three stakeholder dialogues on food technology and innovation. The sessions serve as a proof of concept to see if both my analysis and recommendations are close enough to improve the scope and quality of dialogue - and thus result in a more responsive interaction between societal and technology actors.

For the dialogues, we drafted techno-ethical scenarios according to the following design criteria.

(1) Field specific: the staged controversy in the scenario is about the experience and evaluation of food and not technology-centred. (2) Concern-based: the storyline does not exclusively describe hard impacts of technology but rather pictures those societal concerns which are generally considered as soft. (3) Open to interpretation: the storyline describes more of 'talk' than 'action', through which characters express their concerns. These are not presented as a given fact, nor as a problem per se, but as a reported concern, the meaning of which is contested and left open for readers to discuss. (4) Narrative: the use of a story makes the depicted situation more concrete and thus easier to imagine. It offers a sequence of events, decisions and responses, so that the participants are invited to evaluate the course of action taken by the characters. (5) Multi-layered: problems are to be found in concerns about what technology does, and how the characters respond to and discuss those concerns: a problem of technology and a problem of communication. Even where participants do not initially recognize soft concerns as legitimate issues in themselves, at least they are given a reason to take these concerns seriously as a potential obstruction to successful, socially robust food innovations.

In each of the dialogues, a variety of stakeholders participated from the 
food processing industry, private and public research institutes, governmental and semi-governmental policy advice, and consumerrelated NGO's. We attempted to bring together participants who may have a strong sense of what good food is about, and have differing perspectives on that question. If no agreement exists on who is to be held accountable for giving meaning and interpretation to the concern at hand, it becomes a dialogue of the deaf. A dialogue more hospitable to soft concerns, then, requires a discussion of epistemic rights and responsibilities. Therefore, by means of the Discursive Action Method, we made participants aware of recurring, often implicit interactional patterns that hinder open communication between stakeholders.

In order to encourage participants to deliberate on present and future responsibilities for impacts of food technology and innovation in a constructive manner, the introductory part of the sessions also featured a short discussion of how to approach the notion of responsibility. In order to avoid discussions of blame and liability, we asked the participants to focus on forward-looking responsibilities. Also, we presented them with an illustrative case from which it became clear that responsibility is not necessarily attributed to single individuals but sometimes can be shared. Furthermore, we suggested to participants that there is a space in between state legislation on the one hand, and privatization on the other, for potential resolutions for moral conflict. We did this by both scenario design and moderation of the discussion.

In the sessions we observed that participants gained a shared insight into the interactional effects of implicit claims to epistemic authority for the progress of a conversation, but we are not sure if this understanding also fed into the subsequent discussion of the scenario. At least we noticed that participants affiliated with industrial engineering and food science displayed a more responsive and open attitude with regard to the notion of naturalness than we observed in our earlier analysis of food controversies. Occasionally, participants seemed reluctant to further elaborate on the concept of naturalness typically regarded as a 'soft' concern. As the dialogues proceeded, however, participants eventually arrived at an implicit agreement that the developments as envisioned in the scenario were problematic. Especially in the third session, participants were willing and able to 
articulate specific ideas about natural food: what it means and why it is important to them. More than in the other sessions, these participants were more eager to explore and negotiate the meaning of naturalness.

Scepticism about the possibility of ever reaching consensus on a clear definition of naturalness posed a serious obstacle to the discussion of consequent responsibilities, but eventually, in all of the sessions, several different notions of 'natural' were brought to the table. Rather than taking a strong and confident stance, the participants tentatively explored the concept of naturalness by probing the concept and negotiating its limits of application. While specific responsibilities were not discussed at all, most participants seemed to agree that the concern about naturalness is worth of serious consideration, and that this concern requires a collective organization of responsibilities. Some of the participants were able to draw explicit links between the epistemic and normative status of naturalness on the one hand, and taking forward-looking responsibilities for natural food on the other.

The report of these dialogues does not provide a full-blown experimental proof of the validity of this approach, nor does it pretend to do so. Rather it provides a 'proof of concept'. As a practical suggestion for facilitators, it should provide an idea of how it can be done. The scenarios used by us are prototypes to be further developed, and should indicate where to start and what direction to take. The difficulties we faced in organizing a stakeholder more hospitable to 'soft' concerns provide with additional evidence for my analysis of the public discourse of food technology and innovation: stakeholders share deeply held convictions about the relevance, cogency and public significance of certain types of food concerns and their consequent hierarchy. Apparently these persistent convictions are hard to tackle, arguably because they are embedded in broader conceptions of science and knowledge, ethics and politics, technology and responsibility. But taking into account the actual advances that we have made with our approach in challenging the soft/hard dichotomy, these are good reasons for further developing and testing this approach, and making it work in sustainable, on-going stakeholder dialogues and public debates on the question of good food. 


\section{Valorisation addendum}

\section{Relevance}

In this dissertation, I have presented an analysis of current public discussions on food technology and innovation in the Netherlands, as well as a number of recommendations to technology developers, citizen-consumers and dialogue facilitators for how to improve the quality of such discussions. The general thrust of my argument is that better discussions are those in which people are more responsive to concerns generally regarded as 'soft'; which, in turn, may help the (reJbuilding of trust between those who make our food, and those who eat it. A deeper understanding and recognition of whatever citizenconsumers hold dear is a vital step towards the ideal of responsible innovation, and consequently, the development of better food production, food processing and food products. As long as this understanding is lacking, technology actors and societal actors will be talking at cross-purposes.

My recommendations do not present a recipe for public trust. The importance of trust emerges where absolute certainties are missing. Relations of trust cannot be enforced but need to grow; and one can only cultivate a seedbed from which the growth of trust is at least not impossible. Nor do my recommendations offer a recipe for better food products. It takes a food engineer to know what creative and innovative possibilities are given within the limits of food technology. At least I have suggested why and how food engineers need to explore these possibilities, and what direction this exploration may take: towards the more 'experiental' aspects of food (i.e. generally regarded as soft) - those aspects that seem immeasurable, private and causally unrelated to technologies as such; and for which food engineers may not consider themselves responsible at face value.

\section{Stakeholders}

My research results are of interest, therefore, first and foremost, to 
technology (en)actors in the field of food innovation - and, given the kind of 'soft' concerns I have identified - those who are specifically involved with food processing. Although I have addressed food engineers in particular, my analysis should be instructive for many more actors in academic and industrial fields of food technology who are faced with public distrust; and from my critical analysis of the instrumentalist conception of technology it should become clear that responsibilities for 'soft' impacts may reach beyond the distinction between technology 'as such' vs. its application. Attention for 'soft' concerns, in other words, should not be left to marketing departments alone.

But if the quality of public dialogue is at stake, the imperative of responsiveness cannot apply to only one side of the table. I have presented several recommendations to societal actors who (try to) raise concerns that are generally regarded as soft. These include a broad variety of citizen-consumers who actively (and sometimes frequently) express their concerns on discussion forums, online and offline, some in the role of food professional, some speaking on behalf of NGO's, some as concerned parents, and some simply as sceptical consumers. Their interest is to be heard and adequately responded to. The key message for them is two-fold. If they have specifically ethical, cultural or aesthetic concerns, they better not conceal it; and they should articulate the ways in which their concerns are entangled with 'harder' food issues already recognized as legitimate by those they seek to address. Especially those who aspire to have a structural and substantial influence on the public food innovation agenda - the Slow Food movement, for example - thus need to master both technoscientific and ethical-esthetical repertoires. My analysis and recommendations show why and how to connect both.

A third group to whom my findings are of interest consists of those who are interested in facilitating public deliberation and dialogues on the innovation of food (and) technology, and bring the aforementioned stakeholder groups together (e.g. consultancy firms, communication advisors, governmental policy analysts, technology assessors and 'science cafe' organizers). The dialogue setting as well as the technoethical scenario design (criteria) suggested in this dissertation should provide them with guidance, if and when they have the ambition to set 
up a dialogue (series) that is more responsive than is currently the case with public discussions on food technology.

A fourth group, whom I did not explicitly address in my dissertation but to whom my analysis may well be instructive, are those who report public controversies and potential issues in food innovation and technology. Those include journalists and reporters on science, technology or food-related issues, and policy advisors who seek to draw a representative image of current positions, views and concerns in any of those fields. If they are interested in making a fair representation of current issues in food and technology, my dissertation urges them to take 'soft concerns' into serious consideration. Serious consideration here means to take them seriously on their own terms rather than instantly framing them as mere expressions of fear and romanticism.

\section{Activities}

I have shared the results of my research - and more importantly, the perspective I have developed in achieving those results - with some of these people in several ways.

I have participated in De Nationale DenkTank, a Dutch Think Tank of young academics. We conducted a field analysis of the sustainability of the food supply chain in The Netherlands, and presented our recommendations to key stakeholders - such as CBL (Dutch food retailers' trade organization) and FNLI (Federation of Dutch food industries). In the working group Consumers we have promoted the importance of food culture for developing a more sustainable food supply chain (Nationale DenkTank 2012).

In order to share our main findings and provoke further discussion, I have organized a stakeholder conference together with the research project team I am part of, and in collaboration with Schuttelaar \& Partners consultancy. We asked leading experts in the philosophy and sociology of food to moderate several discussion sessions, each addressing specific 'soft' concerns. The conference was attended by a number of food engineers, policy advisors, communication professionals and marketers. In preparation of this conference, we 
have launched a project website (Fasos-research 2013) and set up an open LinkedIn discussion group. Also, we published a YouTube animation video, produced by Daan Dirk de Jonge and Didier Jansen, in which our main findings are explained in lay terms (De Jonge 2013).

Furthermore, I appeared in a science radio show, in an episode dedicated to gluttony and food studies (Hoezo Radio 2013) and posted an article on Foodlog, a news blog on virtually all aspects of food production and consumption (Haen 2013). I have presented key findings of my analysis of the food additives controversy in Voeding $\mathrm{Nu}$, a magazine for professionals in the food sector (Haen 2014), and at VMT Food Event 2014, an annual conference for food professionals, the theme of which was food trust.

\section{Contribution}

Over the past five years, the issue of trust has become a growing priority on public as well as institutional food (technology) agendas in the Netherlands - although one could reasonably argue that food trust has been an issue of all times. In the public sphere, but also in the food sector in particular, this issue has given rise to an often-heard call for more transparency about food products, their origins, how they are processed and what health and safety warrants are in place. My main contribution to the discussion of food trust is distinctive in the sense that I challenge this call: more transparency will not do. In order to (reJestablish a mutual relation of trust with consumer-citizens, food innovators and other technology (en)actors in the food supply chain will have to engage in public dialogue and respond to substantial consumer concerns about good food - even if they do not consider themselves primarily responsible for those concerns. If they don't, they may miss out on early warning signals and creative business opportunities. The persistent controversy of E-numbers suggests that public trust in technologically produced and processed food is too fragile to leave it up to information campaigns and the mechanism of the free market. 


\section{References}

Jonge, D.D. de, [DaanDirk] (2013, October 17) Met elkaar in gesprek over voedseltechnologie. YouTube video at http://youtu.be/GqNSqlvl7xg

Fasos-research (2013) Maatschappelijk verantwoord innoveren in voedseltechnologie, project website, retrieved 26 August 2014 from http://fasos-research.nl/responsiblefoodtech/

Hoezo Radio (2013, August 15), Vraatzucht, NTR Science programme, retrieved 26 August 2014 from http://www.npowetenschap.nl/programmas/hoezoradio/Uitzendingen/2013/augustus/15-08-2013-vraatzucht.html

Haen, D. (2013) 'De tragiek van het E-nummer'. Blogpost on Foodlog, 3 September, retrieved 26 August 2014 from http://www.foodlog.nl/artikel/tragiek-van-het-e-nummer/

Haen, D. (2014) 'E-nummers: geen omkijken meer naar je eten', in: Voeding $\mathrm{Nu} 16$ (5/6), 27.

Nationale DenkTank (2012) Verduurzaming van de Voedselketen. Final report, retrieved 31 July 2014 from http://www.nationaledenktank.nl/wat-doen-wii/denktank/resultaten/denktank-2012/ 


\section{About the author}

Dirk Haen (Uden, 1981) studied philosophy at the University of Amsterdam, where he obtained his master's degree in 2008 with a thesis on the tension between democratic legitimacy and the need for scientific expertise in political decision making. As a visiting student, he attended the New School for Social Research, New York, in 2006, where he took several courses in political philosophy and investigative journalism. In 2008 and 2009 he taught at the Institute for Interdisciplinary Studies (UvA).

In 2009, Dirk started as a PhD student in Philosophy at Twente University, with a research project on responsible innovation in food technology in collaboration with Wageningen University. One year later, he transferred to the Faculty of Arts \& Social Sciences at Maastricht University, where he continued to work on the same project. He participated in the PhD programme of the Netherlands Graduate Research School of Science, Technology and Modern Culture (WTMC), where he graduated in 2012. He also participated in the Nationale DenkTank (Dutch think tank) - a group of young academics who, in 2012, conducted an analysis of food sustainability in the Dutch food supply chain. Currently, Dirk works at the Dutch Ministry of Education, Culture \& Science as a policy advisor. 
